\title{
V. DIE PRAXIS DES DIPLOMATISCHEN VERKEHRS
}

Der Austausch von Boten und Gesandten ist ein seit Beginn der historischen Zeit belegtes Phänomen. Das im antiken Griechenland und Rom geformte Zeremoniell wurde vor allem im byzantinischen Reich bewahrt. Im mittelalterlichen Westen waren es in erster Linie die Kurie und die italienischen Stadtstaaten, die das für die lateinische Christenheit gültige diplomatische Instrumentarium schufen, zuerst rezipiert von den französischen, englischen und spanischen Höfen'.

\section{Ad-hoc Gesandtschaften und ständige Vertretungen}

Zum Ende des 15. Jahrhunderts setzte die Herausbildung der permanenten Gesandtschaften ein, die der engeren Verflechtung der zwischenstaatlichen Beziehungen und damit dem Bedürfnis nach ständigem Informationsfluß zwischen den Höfen Rechnung trug. Um von einer ständigen Gesandtschaft sprechen zu können, muß nach Queller das Kriterium des officium erfüllt sein, also eines Amtes, das auch bei Vakanz und unabhängig von seinem jeweiligen Inhaber existiert ${ }^{2}$. Da die aus der neuzeitlichen Geschichte bekannten und fest definierten Begriffe wie »Amt« oder »Residentschaft« nicht unbesehen auf

1 Aus der Literatur zur Entwicklung des Gesandtschaftswesens siehe zur Kurie u.a.: Knut WALF, Die Entwicklung des päpstlichen Gesandtschaftswesens in dem Zeitabschnitt zwischen Dekretalrecht und Wiener Kongreß (1159-1815), München 1966; DERS., 》Gesandtschaftswesen, kirchliches«, in: LThK, 4, 1995, Sp. 545-547; Pierre BLET, Histoire de la représentation diplomatique du Saint Siège des origines à l'aube du XIX ${ }^{\mathfrak{c}}$ siècle, Rom 1982; Helmut WOLFF, Päpstliche Legaten auf Reichstagen des 15. Jahrhunderts, in: Erich MEUTHEN (Hg.), Reichstage und Kirche. Kolloquium der Historischen Kommission bei der Bayerischen Akademie der Wissenschaften (Göttingen 1991), S. 25-40. Zu den italienischen Stadtstaaten: P. MARGAROLI, »Gesandte, B. Mittel- und Westeuropa, IV. Italien«, in: LexMA, 4, 1989, Sp. 1372f.; immer noch wichtig für die Entwicklung in Venedig: Willy ANDREAS, Staatskunst und Diplomatie der Venezianer im Spiegel ihrer Gesandtenberichte, Leipzig 1943; Fritz ERNST, Über Gesandtschaftswesen und Diplomatie an der Wende vom Mittelalter zur Neuzeit, in: Archiv für Kulturgeschichte 33 (1951) S. 64-95. Zu den französischen und englischen Höfen Françoise AUTRAND, "Gesandte, B. Mittel- und Westeuropa, V. Frankreich«, in: LexMA, 4, 1989, Sp. 1373-1375; zur diplomatischen Praxis am englischen und kaiserlichen Hof REITEMEIER, Außenpolitik im Spätmittelalter; und KINTZINGER, Westbindungen.

${ }^{2}$ QUELLER, The Office of Ambassador, S. 76. 
spätmittelalterliche Verhältnisse übertragen werden können, sollte jedoch besser von »kontinuierlicher Diplomatie« gesprochen werden, aus der sich im Laufe der Zeit ein institutionalisiertes Amt entwickelte3. Der Ursprung der ständigen Vertretungen oder permanenten Gesandtschaften ist kontrovers. Es ist fuir die venezianische Vertretung an der Kurie seit 1431 plädiert worden ${ }^{4}$, aber auch für den Gesandtenaustausch im Rahmen des nach dem Frieden von Lodi 1454 entstandenen Systems von italienischen Territorialstaaten, das einer genauen gegenseitigen Abstimmung der politischen Entscheidungen bedurfte. Hierbei wird mehrheitlich Nicodemo Tranchedini, der bereits seit 1446 Francesco Sforza bei Cosimo de' Medici vertrat, als erster ständiger Gesandter genannt $^{5}$. In jedem Fall kann für Mailand in Anspruch genommen werden, zuerst eine ständige Vertretung nördlich der Alpen etabliert zu haben, nämlich am Hof Ludwigs XI. seit 1465 in Gestalt des Giovanni Pietro Panigarola ${ }^{6}$. Der Aufenthalt desselben Panigarola am Hof Karls des Kühnen nach Abschluß des Vertrages von Moncalieri schlo $\beta$ dann aber eine gleichartige Vertretung des Mailänders am französischen Hof aus. Die Anwesenheit des Gesandten war ein Zeichen der besonderen Freundschaft, ein officium war damit nicht etabliert, und das Fehlen einer ständigen Vertretung bedeutete im Umkehrschluß keinesfalls ein feindliches Verhältnis?.

Es war nördlich der Alpen nicht ungewöhnlich, die Entsendung eines ständigen Gesandten mit Mißtrauen zu betrachten, da man in ihm oft lediglich einen Spion und potentiellen Unruhestifter sah. Commynes verdächtigte Gesandte grundsätzlich der Spionage: Zwar sei der ehrenvolle Empfang fremder Gesandter, auch derjenigen eines Feindes, Pflicht jedes Herrschers, doch solle man verhindern, daß sie mit unzufriedenen Untertanen in Kontakt kämen und sie, sobald es die Etiquette erlaubten, zur Rückreise veranlassen ${ }^{8}$. Der mailän-

${ }^{3}$ MARGAROLI, »Gesandte, IV. Italien «, Sp. 1372f.

${ }^{4}$ QUELLER, The Office of Ambassador, S. 78; vgl. auch M. S. ANDERSON, The Rise of Modern Diplomacy (1450-1919), Harlow 1993, S. 1-40.

${ }^{5}$ Luis WECKMANN, Les origines des missions diplomatiques permanentes, in: Revue générale de droit international public 56 (1952) S. 161-188, hier S. 166; Vincent ILARDI, I Documenti Diplomatici del Secolo XV negli Archivi e Bibliotheche dell'Europa Occidentale (1450-1494), in: Rassegna degli Archivi di Stato, 28, Rom 1968, S. 349-402, hier S. 352; MARGAROLI, "Gesandte, IV. Italien «, Sp. 1372f.

6 Vincent ILARDI, France and Milan: The Uneasy Alliance 1452 - 1466, in: Gli Sforza a Milano e in Lombardia e i loro rapporti con gli stati italiani ed europei (1450-1530), Mailand 1982, S. 415-446, hier S. 416.

7 Pierre SAVY, Les ambassadeurs milanais à la cour de Charles le Téméraire, in: AB 68 (1996) S. 35-56, hier S. 51. Dagegen Gunther WOLF, Anfänge ständigen Gesandtschaftswesens schon zur Zeit Kaiser Friedrichs II.?, in: Archiv für Diplomatik 41 (1995) S. 147-153.

8 Commynes, Mémoires, hg. v. CalmetTe, 1, S. 219f. Vgl. dazu Werner PaRAvicini, Ein Spion in Malpaga. Zur Überlieferungsgeschichte der Urkunden des René d'Anjou und Karls des Kühnen für Bartolomeo Colleoni, in: Hagen KelLer, Werner PARAVICINI, Wolfgang SCHIEDER (Hg.), Italia et Germania. Liber Amicorum Arnold Esch, Tübingen 2001, S. 469 487. 
dische Gesandte am französischen Hof, Malleta, bestätigte dies 1464. Die Gewohnheiten in Frankreich entsprächen nicht denjenigen Italiens, "perchè in questa parte a tenere continuamente uno suo ambasatore pare una cosa de suspeto e non de tuto amore ${ }^{9}$. Generelle Verbreitung erlangte das Institut erst um die Wende zum 16. Jahrhundert. In der Tat bestand die Aufgabe eines ständigen Gesandten weniger im Führen wichtiger Verhandlungen, die meist noch immer ad-hoc Gesandtschaften mit speziellen Vollmachten anvertraut wurden, sondern in der Beobachtung der Verhältnisse seines Gastlandes und der Informationsübermittlung an seinen heimatlichen Hof. Entsprechend wurde er am fremden Hof mit weitaus weniger Zeremoniell behandelt als ein besonderer Gesandter und nur mittelmäßig bis schlecht bezahlt ${ }^{10}$.

Zwischen dem burgundischen Hof und den Reichsfürsten verkehrten ausschließlich ad-hoc Gesandtschaften. Nur italienische Fürsten ließen sich bei Karl durch über lange Zeiträume anwesende Vertreter repräsentieren, so Galeazzo Maria von Mailand durch Panigarola und König Ferrante von Neapel durch den Bischof von Capaccio. Die jeweils bei Bedarf ernannten und instruierten burgundischen Gesandten dienten dem Herzog als Räte, Kammerherren, Finanzverwalter, Heerführer oder Sekretäre und versahen diplomatische Aufgaben als Teil ihrer übrigen Pflichten. Allerdings ist vor allem bei Antoine de Montjeu und auch bei Guillaume de Rochefort die Tendenz zu fast ausschließlicher Beschäftigung mit diplomatischen Aufgaben erkennbar. Rochefort war zeitweilig beinahe eine Art ständiger Vertreter Karls am savoyischen Hof.

Über die von einem Gesandten gewünschten und in die im Idealfall erwarteten Eigenschaften und Fähigkeiten geben die zeitgenössischen Traktate Auskunft, die Aufgaben und Pflichten des Diplomaten beschreiben. Der ideale Gesandte war eine Verkörperung aller intellektuellen und moralischen Tugenden, von angenehmem Äußeren, mittleren Alters, eloquent, großzügig, unbestechlich, vorsichtig, fleißig und mit den Eigenarten des Gastlandes vertraut ${ }^{\prime \prime}$. Da diese Eigenschaften sich nur in den seltensten Fällen in einer Person vereinigten, wurde auf die Zusammensetzung einer repräsentativen Gesandtschaft aus Teilnehmern mit einander ergänzenden Eigenschaften und Fähigkeiten geachtet. In England war eine derartige ausgewogenen Besetzung am frühesten und häufigsten zu beobachten ${ }^{12}$ : Der hohe Adlige verlieh der Delegation Glanz durch sein persönliches Prestige, der Bischof zusätzlich durch die Würde seines Amtes, wobei er üblicherweise zusätzlich noch ein höheres $\mathrm{Maß}$ an Bil-

${ }^{9}$ Malleta an Francesco Sforza, 10.5.1464 Chartres, MANDROT, Dépêches des Ambassadeurs, 2, S. 125.

${ }^{10}$ GANSHOF, Le moyen âge, S. 272-274.

11 Betty BEHRENS, Treatises on the Ambassador written in the Fifteenth and early Sixteenth Centuries, in: English Historical Review 51 (1936) S. 616-627, hier S. 624-626; John FERGUSON, English Diplomacy 1422-1461, Oxford 1972, S. 156.

12 GANSHOF, Le moyen âge, S. 268. 
dung vorweisen konnte. Die sachkundige Verhandlungsführung garantierten Kanzleibeamte und andere Mitglieder der königlichen Verwaltung ${ }^{13}$. Auch im Hinblick auf den Adressaten der Mission war das soziale Prestige, das mit den Mitgliedem der Gesandtschaft verknüpft war, von nicht zu unterschätzender Bedeutung, da die Sendung bloßer Ritter oder niederer Geistlicher als Affront aufgefaßt werden konnte ${ }^{14}$. Wie in der dargelegten Hinsicht die Gesandtschaften Karls an die Angehörigen des Reichs zu bewerten sind, ist eine zentrale Frage dieses Kapitels.

Mehr als viele der übrigen Bereiche burgundischer Politik und Verwaltung unter Karl dem Kühnen waren die Außenbeziehungen durch das Fehlen von Institutionen charakterisiert ${ }^{15}$. Bei der Kanzlei angesiedelt und nur dem Herzog unmittelbar unterstellt, wurden die Außenbeziehungen weder in einem eigenen »Amt« organisiert, noch verfügte man über ein einschlägiges Archiv oder eigenes Personal. Besetzung und Auftrag einer Gesandtschaft waren ganz dem Herzog oder in Ausnahmefällen dem Rat anheimgestellt und spiegeiten vorherrschende politische Präferenzen.

\section{Die Gesandten Karls des Kühnen in das Reich}

Im folgenden werden die personellen und materiellen Voraussetzungen der am burgundischen Hof geübten diplomatischen Praxis im Verkehr mit dem Reich analysiert. Bildung und Stand der Gesandten, die Größe der Gesandtschaften und ihre materielle Ausstattung in Gestalt von Geschenken spiegeln deutlicher als der Inhalt mancher Verträge den zeremoniellen Stellenwert, den Karl dem Kaiser und den Reichsfürsten zumaß. Nicht zuletzt läßt die Untersuchung derjenigen Räte, die auf die Reichsbeziehungen des Herzogs Einfluß zu nehmen suchten, die Existenz zweier Parteien erkennen, die der burgundischen Reichspolitik entgegengesetzte Richtungen vorgeben wollten.

13 Eine eingängige, wenn auch auf den burgundischen Zusammenhang des ausgehenden 15. Jahrhunderts nicht mehr ganz zutreffende Zusammenfassung dieses Systems findet sich bei Thomas F. TouT, The English Civil Service in the Fourteenth Century, in: The Collected Papers of T.F. Tout, 3, Manchester 1934, S. 191-221, hier S. 203: "...the happy mixture of good breeding and capacity...by putting a great nobleman at the head of a foreign embassy, while associating with him a bishop...to help out his intelligence, and a chancery clerk...to supply the necessary hard work and technical knowledge«. Ebenso George P. CUTTINO, English Diplomatic Administration 1259-1339, Oxford ${ }^{2} 1971$, S. 140, »The former [die Adligen] represented the theatrical, the latter [Kleriker und Schreiber] the practical side of diplomacy, both were essential.«

14 QUELLER, Office of Ambassador, S. 155.

${ }^{15}$ COCKSHAW, Le personnel, S. 9 f. 
Die folgende Sammlung von Kurzbiographien vereint eine recht heterogene Anzahl von Männern auf der Grundlage, daß sie alle als Gesandte Karls im Reich tätig waren. Die Menge der zur Verfügung stehenden Informationen zu sozialem Hintergrund, Ausbildung und sonstigen Tätigkeiten differiert in Abhängigkeit von der Forschungslage und der Ergiebigkeit der Quellen. Um die personelle Grundlage des herzoglichen Gesandtschaftswesen insgesamt beurteilen zu können, wäre eine Prosopographie aller für ihn tätigen Gesandten erforderlich, die hier nicht geleistet werden kann, und die außerdem Hand in Hand gehen müßte mit einer entsprechenden Untersuchung zur gesamten burgundischen Verwaltung, wie sie bisher nur für einige Einzelgebiete existiert ${ }^{16}$. Durch Vergleiche mit der gesandtschaftlichen Praxis des Herzogs in seinen Beziehungen vor allem zu Frankreich und England können die gewonnenen Erkenntnisse für das Reich jedoch in einen größeren Kontext gestellt werden. Neben Beobachtungen zum diplomatischen Personal und damit dem burgundischen Gesandtschaftswesen insgesamt werden Einsichten über den Platz, den Karl dem Reich in seiner politischen Konzeption zuwies, gewonnen. Vergleiche zur Praxis der Vorgänger Karls können beim gegenwärtigen Stand der Forschung nur für die Verhältnisse unter Herzog Johann Ohnefurcht anhand der Untersuchung de Borchgraves angestellt werden, da eine Studie zur Praxis der Außenbeziehungen unter Philipp dem Guten fehlt ${ }^{17}$.

Die Untersuchung folgt der Definition von Petersohn, nach der es sich bei der Prosopographie um die »Sammlung und Verzeichnung aller Personen eines nach Raum und Zeit abgesteckten Lebenskreises « handelt. Auch sein Hinweis, daß die prosopographische Forschung des Spätmittelalters angesichts des im Vergleich zu früheren Epochen großen Quellenreichtums bereits im Vorfeld sichten und werten muß und sich so eine "Wechselwirkung zwischen Methode und sachlicher Thematik bei jeder Einzeluntersuchung « ergibt, trifft auf die vorliegende Studie $\mathrm{zu}^{18}$. Im folgenden wurden die Personen nach den

16 BARTIER, Légistes et gens de finances; COCKSHAW, Le personnel; DERS., Prosopographie des secrétaires.

${ }^{17}$ LACAZE, Philippe le Bon et l'Empire, befaßt sich nicht mit der gesandtschaftlichen Praxis Philipps.

18 Jürgen PETERSOHN, Personenforschung im Spätmittelalter. Zu Forschungsgeschichte und Methode, in: ZhF 2 (1975) S. 1-5, hier S. 1, 4f. Grundlegend zur prosopographischen Methode in der Mittelalterforschung Gerd TELlENBaCH, Zur Bedeutung der Personenforschung für die Erkenntnis des früheren Mittellaters, Freiburg 1957. Zu ihrer Anwendung in der Spätmittelalterforschung siehe Olivier MATTEONI, Une base de données informatisée pour l'étude prosopographique du personnel politique de la principauté bourbonnaise à la fin du moyen âge. Présentation et exploitation, in: Medieval Prosopography 19 (1998) S. 99-109. Vgl. in demselben Band, S. 230-233, auch den Überblick über die Tagungen zu Prosopographie des CNRS mit der Besprechung der letzten Tagungsakten, Jean-Philippe GENET, Gunther LOTTES (Hg.), L'Etat moderne et les élites XIII ${ }^{e}-\mathrm{XVIII}{ }^{\mathrm{e}}$ siècles. Apports et limites de la méthode prosopographique. Actes du colloque international CNRS - Paris I, 16-19 octobre 1991, Paris 1996. Forschungsüberblick bei Michael BORGOLTE, Personengeschichte 
Kriterien der sozialen und geographischen Abkunft, ihrer Ausbildung, ihrer Karriere am herzoglichen Hof und vor allem so vollständig wie möglich nach ihrer gesamten gesandtschaftlichen Tätigkeit erfaßt. An den beschreibenden Teil schließt sich die Analyse der Gesandten als Gruppe an. Die Erkenntnisse hinsichtlich ihres sozialen Rangs, ihrer Herkunft, Ausbildung und Stellung bei Hof gewinnen schließlich im Vergleich zu den entsprechenden Gesandtengruppen, die an die französischen und englischen Höfe reisten, noch größere Aussagekraft ${ }^{19}$.

\subsection{Adel: Räte und Kammerherren}

Adlige Räte und Kammerherren stellten auch unter Herzog Karl den größten Anteil der Gesandten, die mit Reichsangelegenheiten befaßt waren, und diese Beobachtung gilt ebenso für die Beziehungen zu Frankreich, England und Italien ${ }^{20}$. Mit Peter von Hagenbach, Rudolf von Baden-Hachberg und Johann von Nassau begegnet hier die höchste Anzahl an deutschsprachig oder zweisprachig aufgewachsenen Reichsuntertanen, die aufgrund der geographischen Nähe ihrer Heimat zu burgundischem Gebiet an den Hof des Herzogs gelangt und teilweise seine Lehnsmänner waren. Unter den elf untersuchten adligen $\mathrm{Ge}$ sandten in das Reich sind mit Gert von Assendelft, Guy de Brimeu und Johann von Halewin drei, die selbst keine bedeutenden Reisen zu Fürsten oder Städten des Reichs unternahmen. Bei einschlägigen Verhandlungen auf burgundischem Territorium aber waren sie zu einer oder mehreren Gelegenheiten an so prominenter Stelle vertreten, daß sie in der folgenden Aufstellung berücksichtigt werden.

Von diesen elf adligen Ratsherren hatten vier eine Universität besucht. Johann von Halewin und Woutre van der Noot führten den Titel maitre, was bei ihnen nur als Magister gedeutet werden kann. Bei Antoine de Montjeu und Guillaume de Rochefort, Doktoren beider Rechte und zwei der in Reichsdingen versiertesten Räte Karls, bestätigt sich die Beobachtung, daß der juristisch gebildete Adlige die idealen Voraussetzungen für diplomatisches Wirken mitbrachte, da er sowohl die nötigen fachlichen Kenntnisse wie auch das gewünschte soziale Prestige in sich vereinte ${ }^{21}$.

und Ereignis. Methodologisches zu Heribert Müllers Werk über Franzosen und französische Politik auf dem Basler Konzil, in: ZGO NF 101 (1992) S. 413-424. Zur prosopographischen Forschung in den Niederlanden, Belgien und Nordfrankreich bis 1992 Hilde de RIDDERSYMEONS, Prosopographical Research in the Low Countries concerning the Middle Ages and the Sixteenth Century, in: Medieval Prosopography 14,2 (1993) S. 27-120.

19 Die Kategorien zur Einteilung der Gesandten sind in Anlehnung an BORCHGRAVE, Diplomaten, erstellt worden.

${ }^{20}$ BORCHGRAVE, Diplomaten, S. $120 \mathrm{f}$.

21 PreVenier, Blockmans, Les Pays-Bas bourguignons, S. 133f. 


\section{Gert von Assendelft}

Geboren um 1420, erbte Gert 1443 die Herrschaft Assendelft von seinem Vater ${ }^{22}$. Ebenso wie sein Bruder Jan, der unter Karl als Rentmeister von NordHolland und Woerden amtierte ${ }^{23}$, war Gert als Mitglied des Rates von Holland ${ }^{24}$ vor allem mit den inneren Angelegenheiten der Provinz befaßt, so beispielsweise mit den Anleihen, deren Zahlung der Herzog von Bürgern und Geistlichkeit zur Finanzierung der Kriegführung erzwang25. Es waren ebenfalls holländische Belange, die 1473 seine Anwesenheit in Utrecht erforderten, wo er von Juli bis September zusammen mit Johann von Halewin die Verhandlungen mit den Vertretern der Hanse um ein Handelsabkommen führte. Der offizielle Leiter der herzoglichen Delegation, der Herr von Gruuthuse, folgte wegen anderer Verpflichtungen den Gesprächen ebensowenig wie der außerdem bevollmächtigte Guillaume de Clugny, so daß Assendelft auf burgundischer Seite den Verhandlungen vorsa $\beta^{26}$. Im November und Dezember desselben Jahres war es Assendelft allein, der die Verhandlungen auf burgundischer Seite leitete, da Halewin nicht abkömmlich war und durch Heinrich van der Mye vertreten wurde 27 .

\section{Rudolf von Baden-Hachberg}

Im oberrheinischen Grenzraum zwischen deutschsprachigem Reichsgebiet und dem Einflußbereich der französischen Krone war das Haus Baden-Hachberg ansässig, dem Rudolf von Hachberg, Markgraf von Rötteln, entstammte. Seiner Herkunft entsprechend war er deutsch- und französischsprachig erzogen worden ${ }^{28}$. Obwohl dem burgundischen Herzogshaus seit langem verbunden, vertrat die Familie Baden-Hachberg eigenständige Interessen sowohl auf Reichsgebiet wie auch auf burgundisch-französischem Territorium, wo sie jeweils begütert war. Rudolf brachte deshalb ideale Voraussetzungen mit, um als angesehener Vermittler zwischen dem expandierenden Burgund und den unmittelbar betroffenen Nachbarn, den Eidgenossen, dem Haus Österreich, dem Haus Baden oder dem Pfalzgrafen tätig zu werden. Allerdings erlaubte

22 W.M.C. REGT, «Assendelft, Gerrit van«, in: Nieuw Nederlandsch Biografisch Woordenboek, 7, 1927, Sp. 33f.; Mario DAMEN, Taxation for Prince and Officers. The Council of Holland and the aides in the Burgundian Period, in: STEIN (Hg.), Powerbrokers, S. 27-46, hier S. 34f., m. Abbildung des Grabes Assendelfts in St. Jakob, Den Haag; DERS., De staat van dienst, S. 443.

23 PARAVICINI, Brimeu, S. 413 Anm. 58a.

24 Adriaan Gerard JONGKEES, Staat en Kerk in Holland en Zeeland onder de Bourgondische Hertogen 1425-1477, Groningen 1942, S. 220.

25 JONGKEES, Staat en Kerk, S. $222 \mathrm{f}$.

${ }^{26} \mathrm{HR}, 7$, Nr. 24, S. 17.

${ }^{27} \mathrm{HR}, 7$, Nr. 77, S. 157.

${ }^{28}$ BAUER, Négotiations, S. 5. 
ihm dieser Hintergrund nicht, sich derart bedingungslos in den Dienst Karls zu stellen wie diejenigen, deren Besitz und Rang vollständig von der herzoglichen Gunst abhingen.

Bevor Rudolf 1458 als Rat und Kammerherr in die Dienste Philipps des Guten trat, begleitete er 1451 und 1452 Friedrich III. auf seiner Krönungsreise nach Rom. Dem Grafen von Charolais folgte Rudolf 1465 als Heerführer in den Krieg des Bien Public und auf den Feldzügen gegen Lüttich und Dinant ${ }^{29}$. Im April 1467 wurde er erstmals für Karl in seiner Heimatregion aktiv und traf am 3. April 1467 in Zürich mit Vertretern der Eidgenossen zu Bündnisverhandlungen zusammen. Der am 22. Mai geschlossene Vertrag wurde allerdings lediglich von Bern, Solothurn, Zürich und Freiburg i. Ue. unterzeichnet ${ }^{30}$. Von März 1468 bis August 1473 hatte Rudolf das Amt des Gouverneurs von Luxemburg inne. Die Freundschaft mit Guillaume de Rochefort, damals Präsident des Rates von Luxemburg, wird in dieser Zeit entstanden sein. Gleichzeitig engagierte er sich weiterhin in der Beilegung der Konflikte im Südwesten durch die Vorbereitung des Waldshuter Friedens und seine Anwesenheit im Mai 1469 in Saint-Omer im Gefolge Herzog Sigmunds. Bis zum Amtsantritt Hagenbachs im November 1469 verwaltete Hachberg die Pfandlande, er leitete die Kommission zur Inbesitznahme des Landes und vermittelte erfolgreich besonders in der Mülhausener Frage ${ }^{31}$. Im Frühjahr 1470 reiste er zusammen mit Guillaume de Rochefort und Charles Soillot zu Herzog Sigmund, mit dem sich eben in dieser Zeit intensive Verhandlungen um die burgundische Standeserhöhung entspannen ${ }^{32}$.

Auch bei den verfeindeten Linien des pfälzischen Hauses vertrat Rudolf die Interessen des Herzogs. Im Mai 1471 bahnten sich Verhandlungen Hachbergs mit Herzog Ludwig von Pfalz-Veldenz an, zu denen dieser dann aber wegen des Krieges mit Pfalzgraf Friedrich nicht erscheinen konnte ${ }^{33}$. Ende des Jahres nahm Hachberg die Gespräche gemeinsam mit Gérad Vurry wieder auf. Die angestrebte Vermittlung zwischen Friedrich dem Siegreichen und dem Veldenzer kam allerdings nicht zustande, und das von Ludwig von Veldenz angebotene Bündnis gegen den Pfalzgrafen wurde burgundischerseits abgelehnt ${ }^{34}$.

Schon im Januar 1471 hatte sich Rudolf brieflich an Herzog Sigmund mit der Aufforderung gewandt, weiterhin beim Kaiser für das römische Königtum Karls oder wenigstens ein Reichsvikariat zu wirken. Von der luxemburgischen Rechenkammer wurde die Abschrift der Urkunde über die Verleihung des

${ }^{29}$ BAUER, Négotiations, S. 9-11, 20-26.

${ }^{30}$ BAUER, Négotiations, S. 28-30.

31 BAUER, Négotiations, S. 35-39, $42 \mathrm{f}$.

32 Instruktion in Comines, ed. LENGLET, 3, Nr. 199, S. 238f. Lille ADN B 338/16 240; Brüssel AGR CC 1925 f.263v-264r, und GRÜNEISEN, Reichsstände, S. 55.

33 Hachberg an Karl, 25.5.1471 Luxemburg, Lille ADN B 1433/23 645, Briefwechsel Nr. 1865. BITTMANN, Ludwig XI., 2, 1, S. 388.

34 Lille ADN B 2088/66 600 . 
Reichsvikariats durch Karl IV. an Wenzel bezahlt, die Hachberg dem Schreiben beilegte und die den Habsburgern als Modell für eine vergleichbare Erhöhung des Herzogs dienen sollte ${ }^{35}$. Ob Rudolf diesen Schritt tatsächlich aus eigenem Antrieb tat, wie er eigens betonte, kann mit Fug bezweifelt werden. In dieser Frage hätte er sicher nicht ohne herzogliches Einverständnis oder wahrscheinlich sogar ausdrücklichen Befehl gehandelt. Im Januar 1474 begegnet Hachberg wieder im Elsaß im Gefolge Karls, als er gemeinsam mit Haneron und Hagenbach die Verhandlungen mit der Stadt Mülhausen und eidgenössischen Gesandten in Ensisheim zu einem vorläufigen Vergleich führte ${ }^{36}$. Im Mai desselben Jahres führte er die burgundische Gesandtschaft zum Reichstag in Augsburg an ${ }^{37}$.

Nach dem Ausbruch der Feindseligkeiten zwischen Karl, den Eidgenossen und Herzog Sigmund forderten alle Parteien von Hachberg die unbedingte Loyalität. Vor allem Bern gegenüber, dessen Bürgerrecht er besaß, war seine Lage mißlich. Karl verweigerte andererseits sowohl die Entlassung seines Sohnes Philipp aus dem burgundischen Dienst als auch die Zustimmung zu dessen Ehe mit Maria von Savoyen ${ }^{38}$. Es lag daher in Rudolfs eigenem Interesse, sich 1475 und 1476, teilweise zusammen mit Rochefort, um eine Vermittlung zwischen Karl und den Eidgenossen zu bemühen. Am 29. November 1475 wurde in Neuchâtel ein Waffenstillstand zwischen Burgund und der Niederen Vereinigung vereinbart, der burgundischerseits von Rochefort unterzeichnet, von Karl aber nicht ratifiziert wurde ${ }^{39}$. Die am 1. Januar 1476 zwischen Sigmund und Karl im Rahmen des Waffenstillstandes vereinbarten weiteren Friedensverhandlungen, die unter der Leitung Hachbergs in Neuchâtel stattfinden sollten ${ }^{40}$, wurden von den Ereignissen überholt.

Guy de Brimeu, Herr von Humbercourt

Leben und Karriere Guy de Brimeus sind von Paravicini abschließend erforscht worden. Für den hier betrachteten Zusammenhang ist von Bedeutung, daß Guy, zusammen mit dem Grafen von Charolais erzogen, sowohl Französisch wie auch Latein sprach und schrieb, an den üblicherweise in Latein geführten Verhandlungen mit deutschen Gesandten also mühelos teilnehmen konnte ${ }^{41}$. Seine Rolle in den burgundischen Beziehungen zum Reich wuchs gleichzeitig mit der persönlichen Hinwendung Karls zu den Reichsangelegenheiten durch die Eroberung Gelderns und den anschließenden Tag von Trier.

${ }^{35}$ CHMEL, Aktenstücke 1, 1, S. 28-30, vgl. S. $106 \mathrm{f}$.

${ }^{36}$ Cartulaire de Mulhouse, 4, Nr. 1728, S. 149-151.

${ }^{37}$ Außer Hachberg bestand sie aus "zwei Doktoren«, die bislang nicht identifiziert werden konnten, KRIEGER, Regesten der Markgrafen von Baden, 4, Nr. 10578, S. 346.

38 Philipp trat 1477 in französische Dienste, BAUER, Négotiations, S. 87f., 98-100.

${ }^{39}$ Gedruckt in: Anzeiger für Schweizerische Geschichte NF 10 (1906-1909) S. 448-450.

${ }^{40}$ Rudolf THOMMEN (Hg.), Urkundenbuch der Stadt Basel, 8, Basel 1901, S. 401 f.

41 PARAVICINI, Brimeu, S. 89f. 
Brimeu gehörte zum engsten Rat Karls während der Verhandlungen mit dem Kaiser im Herbst 1473. Friedrich III. zollte seinem Einfluß durch die Verleihung der Würde eines Hofpfalzgrafen im Sommer 1473 Tribut ${ }^{42}$. Im Zuge des Kölner Stiftskrieges leitete er die Gespräche mit der Stadt Köln, den vermittelnden Herzögen von Jülich, dem König von Dänemark und dem Legaten Luca de Tollentis. Der Waffenstillstand mit dem Kaiser vom 29. Mai 1475 wurde von ihm ausgehandelt und er bestimmte auch die sich anschließenden Verhandlungen mit den Kölner Parteien um die Beilegung des Stiftsstreits. Der mailändische Gesandte Panigarola sprach zu dieser Zeit davon, daß Humbercourt alle Fäden der burgundischen Beziehungen zum Kaiser und den deutschen Fürsten in den Händen halte ${ }^{43}$.

Zudem genoß er in einem solchen Maß das Vertrauen Karls, daß der Herzog auf seinen Rat auch in Abwesenheit nicht verzichten wollte und den in Geldern und den Niederlanden Verbliebenen von Burgund und Lothringen her durch reitende Boten über die Entwicklung der Beziehungen zum Kaiser auf dem laufenden hielt. Es kann also davon ausgegangen werden, daß Brimeu auch an dem Friedensvertrag mit dem Kaiser vom 17. November 1475 und dem Übereinkommen über die Eheschließung der Fürstenkinder wenigstens indirekt beteiligt war ${ }^{44}$. Das herzogliche Vertrauen ist umso bemerkenswerter, als er sich keinesfalls immer mit der von Karl verfolgten Politik einverstanden zeigte. Francesco Bertini meldete im Juni $1474^{45}$, daß Brimeu ihm seine Unzufriedenheit über die einjährige Verlängerung des Waffenstillstandes mit Ludwig XI., geschlossen in Compiègne und gültig ab dem 13. Juni 1474, anvertraut habe. Brimeu befürchtete französische Überfälle auf die Niederlande, während die burgundische Armee vor Neuss gebunden war. Seiner Meinung nach sollte zunächst der Konflikt mit Frankreich beendet werden, bevor eine weitere Expansion im Reich in Angriff genommen wurde. Der Herzog, dem diese Ansicht Brimeus nicht verborgen geblieben sein wird, zeigte hier eine für ihn nicht eben typische Toleranz gegenüber einer abweichenden Meinung. In seinen Entscheidungen ließ er sich allerdings auch von den Bedenken Brimeus nicht beeinflussen.

Peter von Hagenbach

Der Rat und Kammerherr Peter von Hagenbach, geboren 1423, enthauptet am 9. Mai 1474 in Breisach, entstammte einem oberelsässischen Adelsgeschlecht. Sowohl des Deutschen als auch des Französischen mächtig, diente er seit 1453 am burgundischen Hof, zunächst als Erzieher der württembergischen Prinzen

42 Paravicini, Brimeu, S. 428 m. Anm. 135.

43 Panigarola an Galeazzo, 31.5.-4.6.1475 Neuss, SeSTAN, Carteggi, 1, Nr. 304, S. 517.

44 Paravicini, Brimeu, S. 471-476 m. Anm. 82-90.

45 BITtManN, Ludwig XI., 2, 1, S. 233f., in Auszügen u. englischer Übersetzung bei VAUGHAN, Charles, S. 288-290. 
von Mömpelgard, dann als Kammerherr des Herzogs von Kleve ${ }^{46}$. Die Aufdeckung eines Mordkomplotts gegen den Grafen von Charolais 1461 trug ihm das unerschütterliche Vertrauen des Thronfolgers ein, der ihn zu seinem Hofmeister emannte ${ }^{4}$.

Die erste Verwendung Hagenbachs als Gesandter Karls ist Anfang des Jahres 1465 zu belegen, als er gemeinsam mit Ferry de Clugny in Heidelberg mit Pfalzgraf Friedrich einen Bündnisvertrag aushandelte, der am 15. Juni 1465 unterzeichnet wurde ${ }^{48}$. Seine persönliche Bekanntschaft mit dem Pfalzgrafen wird dazu beigetragen haben, daß Karl ihn diesem Fürsten im November 1466 nach Lothringen entgegensandte, um ihn von dort nach Brüssel zu geleiten ${ }^{49}$. Auch während der übrigen zehn Jahre seines Lebens empfahlen Hagenbach seine elsässische Herkunft und seine Kenntnis der deutschen Sprache dafür, die Belange Herzog Karls im südwestlichen Reichsgebiet, namentlich bei den Nachbarn der vorderösterreichischen Pfandlande, zu vertreten. Im November 1469 wurde er burgundischer Landvogt der Pfandlande. Das Amt des Landvogtes befaßte ihn sofort mit dem bereits lange schwelenden Konflikt zwischen der Reichsstadt Mülhausen und dem umwohnenden Adel, bei dem die Stadt erheblich verschuldet war. Als Enklave in den österreichischen Vorlanden unter der Vogtei des Pfalzgrafen als Reichslandvogt im Elsaß stehend, hatte sie sich den Eidgenossen zugewandt. Hagenbach, der sich auf die Seite des nun Burgund untertänigen Adels stellte, führte diese Verhandlungen mit mehr Härte als Geschick ${ }^{50}$. Neben der auch von Karl gedeckten Nichtachtung der Rechte von Städten wie Breisach oder Thann sollte sich vor allem die Geringschätzung der Eidgenossen, voran Berns, als fatal erweisen. Dagegen stand Hagenbach in regem Kontakt mit Herzog Sigmund, der nach der Verpfändung seiner Vorlande militärische Hilfe des Burgunders gegen die Eidgenossen verlangte und darin von Hagenbach unterstützt wurde. Der Landvogt konnte sich jedoch mit diesem Ansinnen am Hof nicht durchsetzen, obwohl er

${ }^{46}$ BRAUER-GRAMM, Peter von Hagenbach, S. 15f. spricht davon, daß Hagenbach auch dem Pfalzgrafen als Kammerherr gedient habe.

47 P.-J. SCHULER, »Hagenbach, Peter von«, in: LexMA, 4, 1989, Sp. 1838f. Zu Hagenbach siehe neben BRAUER-GRAMM, Hagenbach, S. 16f. (erste Zeit am burgundischen Hof) auch Hermann HEIMPEL, Peter von Hagenbach und die Herrschaft Burgunds am Oberrhein, in: Jahrbuch der Stadt Freiburg 5 (1942) S. 139-154; DERS., Das Verfahren gegen Peter von Hagenbach zu Breisach, in: ZGO NF 55 (1942) S. 331-357; demnächst Werner PARAVICINI, Hagenbachs Hochzeit (1474), in: Josef Fleckenstein zum 80. Geburtstag, Göttingen 2002 (im Druck), erweitert in den Akten des Kolloquiums: Der Oberrhein im 15. Jahrhundert. Politik, Wirtschaft und Kultur zwischen Habsburg und Burgund, Breisach, September 2000.

48 Comines, ed. LENGLET, 2, Nr. 54, S. 470-473, erw. bei BRAUER-GRAMM, Hagenbach, S. 21.

${ }^{49}$ Lille ADN B 2064 f.60v.

${ }^{50}$ BRAUER-GRAMM, Hagenbach, S. 207-217. 
selbst vor verfälschenden Darstellungen der Verhältnisse in den Pfandlanden nicht zurückschreckte, um den Herzog auf seine Seite zu ziehen ${ }^{51}$.

Auch in der Frage der möglichen Nachfolge auf dem Basler Bischofsstuhl entwickelte Hagenbach eigene, vom Herzog zunächst nicht sanktionierte Vorstellungen, indem er Antoine Haneron auf die Amtsmüdigkeit des Bischofs von Basel, Johann von Venningen, hinwies. Die Kontrolle über dieses lukrative Bistum wäre den politischen Interessen Burgunds am Oberrhein sehr entgegengekommen. Haneron, seinerseits einträglichen Pfründen nie abgeneigt, erreichte von Herzog Karl die Ausstellung von Vollmacht und Instruktion zu Verhandlungen mit Venningen über eine mögliche Resignation, die Hagenbach im Oktober 1470 erhielt. Zwar nahm der Bischof die Werbung wohlwollend auf, doch verhinderte der Krieg gegen Ludwig XI. weiteres burgundisches Handeln in dieser Angelegenheit bis zum Zug Karls in seine Stammlande Ende 1473. Zu diesem Zeitpunkt allerdings hatten Kapitel und Stadt Basel ihren Bischof bereits darauf verpflichtet, sein Amt ohne ihre Zustimmung nicht in fremde Hände zu legen. Eine diesbezügliche Mission des Abtes von Casanova, die wohl um den Jahreswechsel 1473/74 stattfand, blieb daher erfolglos ${ }^{52}$. Hagenbach suchte im weiteren Verlauf auch dieser Angelegenheit die Konfrontation, erhob Steuern auf den für Basel bestimmten Wein und beschlagnahmte Güter des Bischofs, was ihm der Herzog allerdings im Januar 1474 untersagte $^{53}$.

Trotz der offenkundigen mangelnden diplomatischen Begabung Hagenbachs in komplexeren Kontexten ${ }^{54}$ vertraute Karl ihm immer wieder Missionen von größter Bedeutung an. Im Sommer 1472 ließ Karl durch Hagenbach bei Sigmund vorfühlen, ob dieser bei Galeazzo Maria Sforza den Gedanken eines Bündnisses mit Burgund aufbringen könne, ohne aber Karl als Urheber des Planes zu nennen. Weiterhin führte Hagenbach einen großen Teil der Verhandlungen, die 1472 und 1473 das Treffen mit dem Kaiser in Trier vorberei-

51 Tag zu Bregenz mit Gesandten Sigmunds im Juli 1472: Beglaubigung Karls für Hagenbach, Ramstein und Potots vor 9.7.1472, Innsbruck TLA Urkunden I Nr. 8216, nach GRÜNEISEN RTA-Material, Briefwechsel Nr. 2108. BRAUER-GRAMM, Hagenbach, S. 199202. Zu den Parteiungen am Hof für und wider einen Schweizerkrieg siehe unten S. 265268.

52 Cartulaire de Mulhouse, 4, Nr. 1702, S. 128: eine Basler Gesandtschaft bat im November 1473 den Bischof, nicht zurückzutreten; BRAUER-GRAMM, Hagenbach, S. 218-221. OCHS, Geschichte Basels, 4, 1796, S. 227 teilt ohne Quellenangabe eine Kredenz Karls für Casanova an Johann von Venningen von vor dem 6.12.1473 mit, Briefwechsel Nr. 2436. Zu Bischof Johann siehe Pierre Louis Surchat, Johannes von Venningen, in: Erwin GaTZ (Hg.), Die Bischöfe des Heiligen Römischen Reiches, Berlin 1996, 2, S. 723; und zuletzt Volker HIRSCH, Zur Wirtschaftsführung im Territorium des Basler Bischofs Johannes von Venningen (1458-1478), in: Harm von SEGGERN, Gerhard FOUQUET (Hg.), Adel und Zahl, S. 99-119.

${ }^{53}$ Knebel, Basler Chroniken, 2, S. 64.

54 BRAUER-GramM, Hagenbach, S. 221-225. 
teten ${ }^{55}$. Karl bediente sich mit Hagenbach eines Vertreters gegenüber den südwestlichen Reichsfürsten, dem Kaiser und den Eidgenossen, der in hohem $\mathrm{Ma} B$ von persönlichen Abneigungen, Standesloyalitäten und einem nicht immer berechenbaren Temperament bestimmt wurde. Die Kombination dieser Eigenschaften unterschied ihn deutlich von den meisten übrigen burgundischen Gesandten. Doch wog das subjektive Vertrauen Karls in die unbedingte Loyalität seines Dieners allemal schwerer als fachliche Kompetenz oder die zahlreichen die Klagen derjenigen, die mit dem Landvogt in direkten Kontakt kamen.

\section{Johann von Halewin}

Johann, Herr von Zwevezeele ${ }^{56}$, immatrikulierte sich 1433 oder 1438 an der Universität von Löwen und führte die Titel des Magisters und des Doktors beider Rechte ${ }^{57}$. Zusammen mit Montjeu, Rochefort und Woutre van der Noot bildete er die kleine Gruppe der adligen Gesandten, die ein Studium vorzuweisen hatten. Halewin war herzoglicher Rat und seit 1473 General-Lieutenant von Flandern, Bailli von Lille und Präsident des Hofes von Holland ${ }^{58}$. Im Juni 1466 stieß er auf Befehl Herzog Philipps zu Simon de Lalaing und Jean Stoop, die sich bereits auf dem Weg zu den Herzögen von Kleve und Geldern befanden, um in deren Streit zu vermitteln ${ }^{59}$. In seiner Funktion als Präsident des holländischen Hofes wurde er 1474 gemeinsam mit Gert von Assendelft beauftragt, die dem holländischen Klerus auferlegte Sondersteuer einzutreiben ${ }^{60}$. Ebenfalls zusammen mit Assendelft und Lambert van der Ee führte er die Verhandlungen mit den Hansevertretern in Utrecht von Juli bis September 1473. Die Aufzeichnungen der hansischen Delegation geben insoweit einen Einblick in die Persönlichkeit Johanns, als sie an mehreren Stellen seine Neigung zu langatmigen Reden und ausführlicher Darstellung anmerken ${ }^{61}$. Die typischerweise Klerus und Legisten zugeschriebene Vorliebe für lange, wenn auch nicht notwendigerweise gelehrte Reden, findet sich hier bei einem - studierten - Adligen wieder.

55 BRAUER-GRAMM, Hagenbach, S. 193f. Trier: ebd., S. 192-199.

56 DAMEN, De staat van dienst, S. 464f.

${ }^{57}$ Matricule de l'Université de Louvain, 1, hg. v. E. REuSENS, Brüssel 1903, 90, 17; 104, 31; JONGKEES, Staat en Kerk, S. 237 Anm. 4; DAMEN, De staat van dienst, S. 464.

58 JONGKEES, Staat en Kerk, S. 220.

${ }^{59}$ Lille ADN B 2061 f.91r-v, f.121r.

60 JONGKEES, Staat en Kerk, S. 220.

${ }^{61} \mathrm{HR}, 7$, Nr. 24, S. 17 und ebd. Nr. 35, S. 72, $78 f$. 


\section{Pierre de Miraumont}

Der Rat und Kammerherr Pierre de Miraumont, Herr von la Boutillerie ${ }^{62}$, zählt zu den adligen Gesandten, die nur wenige Male mit den Angelegenheiten des Reiches direkt in Berührung kamen. Miraumont wurde im Mai 1473 von Valenciennes aus zu Herzog Johann von Kleve und von dort zu Bischof Heinrich von Münster gesandt, um mit letzterem ein Bündnis abzuschließen, das die Eroberung Gelderns von Norden und Osten her decken sollte ${ }^{63}$. Da Herzog Johann kein Interesse an einer solchen Allianz hatte, hielt er Miraumont in Kleve fest und sandte statt seiner eigene Boten an den Bischof von Münster, die wohl absichtlich keine Fortschritte erzielten ${ }^{64}$. Miraumont besaß als Erzieher des Jungherzogs von Kleve am burgundischen Hof besondere Verbindungen zum klevischen Herzogshaus und hatte sich aus diesem Grund für die Mission empfohlen ${ }^{65}$. Die taktischen Manöver Johanns von Kleve werden ihn allerdings recht unvorbereitet getroffen haben, auch, da er keinen erfahreneren Diplomaten zur Begleitung erhalten hatte.

\section{Antoine de Montjeu}

Antoine de Montjeu war der Sohn einer um und in Autun im Herzogtum Burgund alteingessenen Adelsfamilie, die den kapetingischen Herzögen in zivilen und militärischen Funktionen ebenso gedient hatte wie dann den neuen Herren aus dem Haus Valois ${ }^{66}$. Als zweiter Sohn des Jean I. de Montjeu und der Philiberte Pioche, Tochter des Jean Herm d'Aunay, wurde er nicht wie sein älterer Bruder Odile (II.) für die militärische Laufbahn bestimmt, sondern widmete sich dem Studium der Rechte an der Universität Ferrara. 1452 erwarb er den Magistertitel und wurde schließlich zum Doktor beider Rechte promoviert ${ }^{67}$. Zwar taucht sein Name nicht in den von zeitgenössischen Beobachtern verfaßten Aufzählungen der einflußreichsten Höflinge auf ${ }^{68}$, doch zeigt die Analyse seiner diplomatischen Aktivitäten während der gesamten Regierungszeit Karls seine zentrale Rolle in den Beziehungen zum Reich, zu Frankreich und zu Ita-

62 Am 17.2.1471 ordnete Ludwig XI. die Konfiskation der im Machtbereich der Krone Frankreichs befindlichen Besitzungen Miraumonts als Parteigänger Karls an, Paris BNF Ms fr 20458 f.276r.

${ }^{63} \mathrm{Karl}$ an Herzog Johann von Kleve, 4.5.1473 und 10.5.1473 Valenciennes, Briefwechsel Nr. 2273 und 2278.

64 Johann von Kleve an Karl, 6.6.1473, gedruckt in PARAVICINI, Kleve, Geldern und Burgund, S. 76, Nr. 2.

${ }_{65}$ Lille ADN B 2079 o. Fol.; Lille ADN B 2086/66 312.

${ }^{66}$ Zur Familie Montjeu siehe Abbé DORET, A. de MONARD, Montjeu et ses seigneurs, in: Mémoires de la Société éduenne, n. s. 9 (1880) S. 1-268, hier S. 3, 46-52. Siehe auch Paris BNF Coll. de Bourgogne 42 f.96v-99r, unter auffälliger Auslassung Antoines. Bis zu Beginn des 15. Jahrhunderts PLANCHER, Histoire, 2, 1741, S. 349 Note XXI.

67 DORET, MONARD, Montjeu et ses seigneurs, S. 73, und pièces justificatives Nr. 70, S. 251-253; vgl. auch Lille ADN B 2061 f.123v.

68 Siehe Vaughan, Charles, S. 4f., der Montjeu daher auch nicht zu diesem Kreis rechnet. 
lien. Die quantitative Betrachtung weist ihn neben Guillaume de Rochefort als den meistbeschäftigten Gesandten des Herzogs aus. Anfang 1470 hielt ihn die Stadt Köln für so einflußreich, daß sie ihn zusammen mit Rochefort und Fillastre während des Schoßprozesses um Fürsprache bat ${ }^{69}$. Karl ernannte ihn 1473 zu einem der vier Ritter des Parlaments von Mecheln ${ }^{70}$.

Als adliger Doktor beider Rechte brachte er ebenso wie Halewin und Rochefort die fachlichen und die sozialen Voraussetzungen für die Aufgaben des Gesandten mit. Im Auftrag Karls ist er zuerst im Dezember 1466 zusammen mit Simon de Lalaing und Johann von Luxemburg als Gesandter zu den Herzögen von Kleve und Geldern belegt ${ }^{71}$. Sofort im Anschluß erhielt er von Karl in Gorinchem die Vollmacht zu Verhandlungen mit Gesandten des Kaisers in Basel, wo er sich zusammen mit Léonard de Potots bis etwa Mitte März aufhielt ${ }^{72}$. Im Oktober desselben Jahres folgte eine Mission zu Herzog Johann von Lothringen ${ }^{73}$. Typisch für die Reichspolitik Karls war die burgundische Abordnung zum Regensburger Reichstag im Mai 1471, die unter der Leitung Montjeus lediglich aus zwei weiteren Doktoren und dem Gefolge bestand. Trotz dieser quantitativen Bescheidenheit machte die Delegation allerdings durch ihr als anmaßend empfundenes Insistieren auf Ehrenplätzen vor den Kurfürsten auf sich aufmerksam ${ }^{74}$.

Den Friedensverhandlungen mit Ludwig XI. wandte sich Montjeu in herzoglichem Auftrag im Januar 1473 gemeinsam mit Philippe de Croÿ-Chimay, Guy de Brimeu, Ferry de Clugny und Gérard Vurry zus. Im Juni dieses Jahres begab er sich zusammen mit Rochefort zum ersten Mal nach Venedig und zu dem venezianischen Söldnerführer Bartolomeo Colleoni, dessen Dienste Karl seit 1471 zu gewinnen suchte ${ }^{76}$. Im September kehrte er zu Karl nach Luxem-

${ }^{69}$ HUB, 9, Nr. 613, S. 513, 515.

70 PARAviCINI, Brimeu, S. 396 Anm. 611, und S. 425 Anm. 121.

71 Lille ADN B $2061 \mathrm{f} .123 \mathrm{v}$; Beglaubigungen Karls für Montjeu und Luxemburg vom 23.11.1466 und 15.12.1466 aus HStA Düsseldorf, Kleve-Mark, Beziehungen zu Geldern 76b und 3 II; ACO Dijon, Papiers Henri STEIN, Briefwechsel Nr. 467, 471.

72 Er kehrte am 31.3.1467 zu Karl zurück. Lille ADN B 2064 f.84v, 87v-88r. Zugleich reiste Jean Guillois, Diener Montjeus, mit Briefen des Herzogs zu Graf Gerhard von Sayn, ebd.

${ }^{73}$ Lille ADN B 2064 f.335r-v.

74 Ferry de Clugny an Präsident und Rat von Dijon, 18.3.1471 Brüssel, Comines, ed. DUPONT, 3, S. 275-277. Zu den Auseinandersetzungen um die Rangfolge siehe den Bericht des Kanzlers von Basel in: Deutsche Reichstagsakten unter Kaiser Friedrich III., 1471, bearb. v. H. WOLFF, Nr. 114h, S. 736: »der herzog von Burgunn hat einen doctorn und ander zwen edel in cleiner zal hie, die meinen, si söllen ob und vor allen churfursten und andern herrn gan und sitzen an der wirdigen stetten." Siehe auch ebd. Nr. 110a, S. 539 Anm. 1. Vgl. zum burgundischen Rangbewußtsein oben $\mathrm{S}$. $154 \mathrm{f}$.

75 PARAVICINI, Brimeu, S. 265 Anm. 66.

76 Instruktion vom 13.6.1473, PLANCHER, Histoire, 4, Nr. 248, S. 323-326. Zur Werbung um Colleoni, die Karl vornehmlich durch Montjeu vornehmen ließ, siehe allgemein (ohne Erwähnung Montjeus), PARAviCINI, Ein Spion in Malpaga; Dietrich ERBEN, Bartolomeo 
burg zur Berichterstattung zurück, reiste erneut nach Italien und war im Dezember wieder bei seinem Herzog, der ihn zusammen mit Johann von Luxemburg, Philippe de Croÿ-Chimay, Humbercourt und Ferry de Clugny zu weiteren Friedensverhandlungen mit französischen Gesandten bevollmächtigte ${ }^{77}$.

Das Jahr 1474 stand für Montjeu ganz im Zeichen der Verhandlungen mit Colleoni und Venedig, die er nun mit wechselnden Begleitern, Rochefort und Lupo da Garda, hauptverantwortlich führte. Hinsichtlich der Reichspolitik Burgunds ist vor allem der Plan Karls von Interesse, Colleoni und Venedig nach der Aufkündigung des Vertrages von Saint-Omer durch Sigmund zu einem Angriff von Süden auf österreichische und eidgenössische Lande zu bewegen. Colleoni allerdings scheint nie ernsthaft erwogen zu haben, auf die Werbungen Karls einzugehen ${ }^{78}$. Eng verbunden mit der Italienpolitik Karls waren die Beziehungen zu Herzogin Yolanthe von Savoyen, die Montjeu 1474 aufsuchte. Auch sie sollte in die burgundische Abwehr der Eidgenossen eingebunden werden. Außerdem hatte sie als enge Verbündete Karls um dessen Erlaubnis für die Hochzeit ihrer Tochter mit einem Grafen von Württemberg, wahrscheinlich Heinrich von Mömpelgard, gebeten. Montjeu erklärte ihr im Namen Karls, daß dies nur zugelassen werden könne, wenn sich die Württemberger nicht auf die Seite Sigmunds und gegen Burgund stellten ${ }^{79}$. Im Oktober 1474 wurde Montjeu in der Sache Colleonis erneut instruiert und verließ Herzog Karl im Dezember wieder in Richtung Venedig ${ }^{80}$. Noch im Februar 1475

Colleoni. Die künstlerische Repräsentation eines Condottiere im Quattrocento, Sigmaringen 1996, S. 26f.; B. Belort, La vita die Bartholomeo Colleoni, Bergamo 1923, S. 462 ff; und WALSH, Charles the Bold and Italy, S. 33f., 75.

77 Italienreisen: Quittung vom 21.12.1472, Lille ADN B 2093/66 890; ebd. 67 164; vgl. das Beglaubigungsschreiben Karls für Montjeu, Rochefort und Francesco d'Este vom 13.6.1473 Maastricht, Briefwechsel Nr. 2310; Francesco Bertini an Angelo di Andria, 12.9.1473 Luxemburg, Teresa ZAMBARBIERI, Milano e la Borgogna tra il 1474 e il 1477: le loro relazioni diplomatiche nel contesto dell'Europa mediana, in: Libri e documenti, 1, Mailand 1982, S. 50. Friedensverhandlungen mit Frankreich: PARAviCINI, Brimeu, S. 467 Anm. 71.

${ }^{78}$ Instruktion Karls für Montjeu, 3.1.1474 Ensisheim, Paris BNF Ms fr 5040 f.125r-129r. Geleit Galeazzo Marias für Montjeu nach Venedig, 18.3.1474 Pavia, SESTAN, Carteggi, 1, Nr. 210, S. 348f. Instruktion Karls für Montjeu und da Garda vom April oder Mai 1474 mit dem Plan eines Angriffs auf Sigmund von Süden, Paris BNF Ms fr 5040 f.55r-57v. Hinhaltende Antwort Colleonis in seiner Instruktion für Montjeu vom 9.9.1474 Malpaga, Paris BNF Ms fr 5040 f.67r-v.

79 Die Dokumente zur Gesandtschaft Montjeus nach Savoyen und Italien in Paris BNF Ms fr 18983 f.3r, 9r, 24r, 29r-v, 31r-32v. Beglaubigung Karls für Montjeu an Galeazzo Maria, 1.5.1474 Luxemburg, SESTAN, Carteggi, 1, Nr. 214, S. 358, Briefwechsel Nr. 2575. Instruktion Karls an Montjeu zum 2.5.1474 in PLANCHER, Histoire, S. 334. Vgl. GuICHENON, Histoire généalogique de la royale maison de Savoie, 4, 1, Turin 1780, S. 399f.; Karl an Yolanthe, 2.5.1474 Luxemburg mit Beglaubigung Montjeus, ebd., S. 399; Memorandum Yolanthes für Montjeu zur Vorlage bei Karl ebd., S. 400f. Instruktion Yolanthes für Montjeu zum Vortrag bei ihren Brüdern, Paris BNF Ms fr 18983 f.3 1 r-32v.

${ }^{80}$ Instruktion Karls für Montjeu, 1.10.1474 Lager bei Neuss, Paris BNF Ms fr 5040 f.69r. Zahlungsbefehl an die Chambre des Comptes in Dijon über 600 écus d'or für Montjeu, Dijon 
ist Montjeu aber auf dem Besitz Guillaume de Rocheforts bei Dôle nachzuweisen, wo er den mailändischen Gesandten Panigarola traf, der nach dem Abschluß des Vertrages von Moncalieri soeben auf dem Weg zu Herzog Karl war. Panigarola übermittelte Galeazzo Maria die Bitte Montjeus um Hilfe bei seiner Mission nach Venedig81.

Hier enden die Nachrichten über die Bewegungen Montjeus bis zum Tod Herzog Karls. Wir besitzen allerdings durch das Protokoll des Prozesses, den Ludwig XI. 1477 durch den Präsidenten des Parlaments von Toulouse gegen Montjeu führen ließ, aufschlußreiche Informationen über Montjeus weiteres Schicksal nach dem Tod Karls und über die Bedeutung, die ihm der französische König beimaß82. Die Anklage machte geltend, daß Montjeu, da aus dem französischen Königreich gebürtig, nie gegen den König von Frankreich hätte handeln dürfen. Trotzdem habe er als Gesandter Karls nach Deutschland, Italien, Venedig, Savoyen, Metz und an den Herzog von Kalabrien Allianzen gegen Ludwig vorbereitet, was man anhand der bei ihm gefundenen Schriftstükken beweisen könne. Montjeu berief sich dagegen auf die Generalamnestie Ludwigs, die dieser nach dem Loyalitätseid des Herzogtums Burgund verkündet hatte, und den auch er geschworen habe. Die Anklage hielt dies aber für unmöglich, obwohl der Schwur für Montjeu als "grant personnaige« des Herzogtums verpflichtend gewesen sei. Vielmehr habe er sich im Haus seiner Cousine in Saint-Geugoux (Mâconnais) versteckt.

Unter einem Vorwand, so führte die Anklage weiter aus, sei er dann nach Arras gereist, wobei er Dokumente mit sich geführt habe, die sich auf seine eigenen Gesandtschaften und auf die Korrespondenz Ludwigs mit den Gouverneuren Burgunds bezogen. In Arras habe er Ludwig XI. getroffen, von dem er die Bezahlung seiner Gesandtschaftsreisen im Auftrag Karls und »le paiement des biens delaissez de la succession dudit duc Charles son feu maistre" verlangte. Angesichts dieses einigermaßen kühnen Vorgehens nahm die Anklage an, daß er den König nur aufgesucht habe, um Geleit für die Weiterreise zu Herzogin Maria zu erhalten. Dies hatte er mit der Begründung verlangt, da $\$$ er während seiner letzten Italienreise, die beim Tod Karls noch nicht abgeschlossen war, vom Papst geweihte Kerzen und Ablaßbriefe für Maria erhalten habe. Wenn er diese nicht übergebe, werde ihn der Papst exkommunizieren. Die Anklage nahm hingegen an, daß er Maria über die Ergebnisse seiner letzten Verhandlungen mit Venedig über eine Allianz berichten wollte und bezeichnete denn auch den Vorwand als dumm - "simple « - besonders für einen Doktor beider Rechte. Abschließend wurde der Vorwurf formuliert, Montjeu

ACO B 11940, nach GRÜNEISEN RTA-Material. Karl kündigte die erneute Reise Montjeus am 4.12.1474 an, Briefwechsel Nr. 2815.

81 Panigarola an Galeazzo, 23.2.1475 Rochefort bei Dôle, SESTAN, Carteggi, 1, Nr. 250, S. $412 f$.

82 Paris BNF Ms fr 5040 f.59r-64r. 
habe zugegeben, in Arras Mitwisser des Komplotts gegen den König vor der Übergabe der Stadt am 6. Mai 1477 gewesen zu sein. Zudem habe er versucht, über einen Herold, den Maria an Ludwig senden sollte, Kontakt mit ihr aufzunehmen und ihr Dokumente zu schicken. Am 8. April 1478 wurde als Urteil gegen Montjeu die dauernde Verbannung aus Frankreich und die Konfiskation seiner Güter vorgeschlagen. Der Prozeß war noch 1479 nicht beendet und dauerte vielleicht bis zu seinem Tod um $1484 \mathrm{an}^{83}$.

Die Argumentation war aus Sicht der französischen Juristen stimmig: als Untertan der Krone Frankreichs hatte der Diplomat Montjeu Verrat begangen, indem er im Dienst seines Herzogs, eines Rebellen gegen den König, als Instrument zur Allianzenbildung gegen Frankreich gedient hatte. Daß andererseits die Karriere als Gesandter des burgundischen Herzogs nicht automatisch zu einer Verurteilung durch die königliche Justiz führen mußte, zeigte sich in den Fällen Rocheforts und der Brüder Clugny. Montjeu wurde die diplomatische Tätigkeit allein deshalb zur Last gelegt, weil er auch nach dem Tod seines Herrn nicht bereit war, sich den veränderten Machtverhältnissen anzupassen und in das Lager Ludwigs zu wechseln.

\section{Johann IV. Graf von Nassau}

Eine dem Markgrafen von Baden-Hachberg vergleichbare Stellung nahm Graf Johann IV, von Nassau (-Dillenburg-Breda-Vianden) am Hof Karls des Kühnen ein ${ }^{84}$. Geboren 1410 , wurde er 1436 Drost von Brabant und trat nach dem Tod seines Vaters 1443 den niederländischen Teil des Erbes an, zu dem nach dem Tod seines Bruders 1450 auch die deutschen Anteile hinzukamen. Als Karl 1465 die Regierungsgeschäfte übernahm, hatte sich Johann bereits als Diplomat und in zahlreichen militärischen Unternehmungen bewährt, namentlich gegen die aufständischen Genter und in der Soester Fehde. Wie BadenHachberg war er ebenso Reichsgraf wie burgundischer Höfling und diente zeitweise dem Erzbischof von Köln als Marschall in Westfalen.

Als Mitglied der Familie Nassau besaß Johann Verbindungen zu den führenden Familien des Reichs und zeichnete sich für Karl vor allem durch seine Verwandtschaft zu Erzbischof Adolf von Mainz aus. Unter der Leitung Johanns schloß eine burgundische Abordnung im Dezember 1469 ein Bündnis zwischen Erzbischof und Herzog85. Darüber hinaus war der Graf angewiesen

83 Todesdatum: DoRET, MORAND, Montjeu et ses seigneurs, S. 74f., die aus dem Aufenthalt Montjeus in Frankreich nach 1477 irrtïmlich schließen, Montjeu habe sich auf die Seite des Königs geschlagen; zum weiteren Verlauf des Prozesses Paris BNF Ms fr 5040 f.72r und ebd. f.156r-157r.

${ }^{84}$ P.J. BLOK, "Johan IV, graaf van Nassau-Dillenburg«, in: Nieuw Nederlandsch Biografisch Woordenboek, 1, Leiden 1911, Sp. 1218f.

85 Abschluß des Bündnisses am 26.11.1469, IADNB 1,1, S. 239. Das Mainzer Engagement in der Vermittlung zwischen Habsburg und Burgund hatte bereits Tradition, so ist der Main- 
worden, die Bereitschaft des Erzbischofs zur Unterstützung der burgundischen Ambitionen auf das römische Königtum oder das Reichsvikariat zu sondieren. Tatsächlich führten Johann und Erzbischof Adolf Gespräche mit Friedrich III., über die Johann dem Herzog im August 1470 Bericht erstattete ${ }^{86} .1473$ nahm Johann im Auftrag des Kaisers den Eid Guy de Brimeus für das Amt des Hofpfalzgrafen entgegen ${ }^{87}$. In der zweiten Oktoberhälfte 1473 sandte ihn Karl gemeinsam mit Pierre, Herr von Longueval nach England ${ }^{88}$, um die antifranzösische Allianz zwischen England, Bretagne und Burgund zu festigen.

Sein Einfluß auf den Herzog wurde so hoch eingeschätzt, daß man im Umkreis des Erzbischofs von Mainz während der Trierer Verhandlungen darüber nachdachte, ihm eine jährliche Pension von 1500 fl.rh. zukommen zu lassen ${ }^{89}$. Gleichzeitig besa $B$ er das Vertrauen des Kaisers in dem Maß, daß dieser ihn noch nach dem Beginn der Belagerung von Neuss mit der Abwicklung kaiserlicher Schulden bei der Stadt Köln beauftragte ${ }^{90}$. In dieser Mittelstellung zwischen Kaiser und Herzog wird der Grund zu suchen sein für den erstaunlich geringen Nutzen, den Karl aus den hervorragenden Kontakten Johanns im Reich zog. Während der Trierer Zusammenkunft nach England gesandt und auch an den Vorbereitungen des Treffens offenbar nicht beteiligt, kann sogar der Eindruck entstehen, daß der Herzog ihn, jedenfalls nach dem Scheitern der Initiative von 1469/1470, bewußt von diesen Gesprächen fernhielt. Die Parallele zu Rudolf von Baden-Hachberg untermauert die Vermutung, daß Karl als engste Berater nur solche Männer zulieB, die ihm aufgrund ihrer materiellen Abhängigkeit völlig ergeben waren.

\section{Woutre/ Gueldolf van der Noot}

Die Verwendung herzoglicher Diener über längere Zeit hinweg in einem eng begrenzten Bereich der Außenbeziehungen ist beispielhaft an Wou-

zer Domscholaster Volprecht von Dersch schon 1465 am burgundischen Hof als Vermittler in der Ehesache belegt, JANSSEN, Reichskorrespondenz, 2, Nr. 382, S. 245-247.

86 GRÜNEISEN, Reichsstände, S. 54f. Vertrag vom 6.12.1469 Brüssel, Lille ADN B 332/16 160. Reise Johanns: Brüssel AGR CC 1925 f.295v. Noch im Oktober 1470 ging in Frankfurt das Gerücht, der Mainzer Erzbischof habe in der Ehesache zwischen Karl und dem Kaiser vermittelt und wolle dem Burgunder einige Schlösser und Städte im Mainzer Stift öffnen, JANSSEN, Reichskorrespondenz, 2, Nr. 419, S. 258f.

87 HEINIG, Friedrich III., S. 1188f. Zur Linie Nassau-Dillenburg-Breda-Vianden siehe GENSICKE, Landesgeschichte des Westerwaldes, S. 289f.; zu Johann IV. auch WEBERN, Die Grafen von Nassau, S. 28.

${ }^{88}$ Quittung vom 6.10.1473, Lille ADN B 2097/67 295 von Pierre Herr von Longueval über $155 \mathrm{lb}$ als Vorschuß fur eine Reise nach England gemeinsam mit Johann IV. Daß die Gesandtschaft tatsächlich vonstatten ging, belegt die Anweisung Karls vom 30.4.1474 an die Domänenschatzmeister, Graf Johann die ihm während seiner von Trier aus angetretenen Reise nach England entstandenen Kosten schleunigst zu erstatten, Lille ADN B 17717, o.Fol.

${ }^{89}$ StA Würzburg, MOP I f.435v, nach GRÜNEISEN RTA-Material.

${ }^{90}$ Regesten Friedrich III., 7, bearb. v. Thomas R. KRAUS, 1990, Nr. 408-409, S. 222. 
tre/Woutrevan der Noot zu studieren. Van der Noot entstammte einer patrizischen Familie aus Brüssel, stieg zum Ritter, Rat und Kammerherrn auf und heiratete in den Hofadel ein ${ }^{91}$. Er ist als Student an der Universität Löwen nachweisbar und führte den Titel eines Lizentiaten oder Magisters. Unter Philipp dem Guten war er Mitglied des Rates von Brabant in Brüssel und wurde 1467 von Karl in dieser Funktion bestätigt ${ }^{92}$, der ihn außerdem 1474 zum Rat des Parlaments von Mecheln ernannte93.

Gemeinsam mit Lambert van der Ee und in der Begleitung des reitenden Boten Josse de Tutemberghe reiste Woutre im Auftrag Philipps des Guten von Juni bis August 1465 zu Herzog Ludwig dem Reichen von Bayern und zum Pfalzgrafen, um die Bündnisse auszuhandeln und abzuschließen, die im folgenden Dezember ratifiziert wurden. Parallel zur Mission Woutres verhandelten Hagenbach und Ferry de Clugny mit denselben Fürsten im Namen des Grafen von Charolais ${ }^{94}$. In den ersten beiden Oktoberwochen desselben Jahres trafen Woutre und van der Ee noch einmal mit dem Pfalzgrafen und Erzbischof Ruprecht in Köln zusammen, um neben den Allianzen auch die Anspriiche des Grafen von Katzenelnbogen zu regeln ${ }^{95}$. Im März und April 1466 konferierten sie wieder mit Abgesandten des Katzenelnbogeners in Maastricht und reisten im Juni und Oktober in derselben Sache nochmals zu Pfalzgraf Friedrich $^{96}$.

91 Paul de WIN, The Lesser Nobility of the Burgundian Netherlands, in: Michael JoNES (Hg.), Gentry and Lesser Nobility in Late Medieval Europe, Gloucester, New York 1986, S. 95-118, hier S. 106f. Lille ADN B 2061 f.99v. Die komplementäre Quellenlage zu den beiden Namensformen Gueldolf und Woutre legt nahe, daß es sich bei ihnen um ein und dieselbe Person handelt. "Woutre", dt. "Walther«, lautet in der französischen Übersetzung "Gaultier«, was wiederum in einer niederländischen Rückübersetzung zu "Gueldolf« wurde. (Frdl. Hinweis von Dr. Holger Kruse, Kiel.) In der Prokuration Herzog Philipps des Guten zu Verhandlungen mit dem Pfalzgrafen und Erzbischof Ruprecht vom 21.9.1465, Brüssel, wird die französische Form Gauthier verwendet. Lille ADN B 327/16 081. Im folgenden wird die Namensform Woutre gebraucht.

92 Matricule de I'Université de Louvain I, 44, 41. Magistertitel z.B. Lille ADN B 2058 f.169r. Rat von Brabant, BONENFANT, STENGERS, Le rôle de Charles le Téméraire, S. 125f. Anm. 1; Paravicin, Brimeu, S. 715; Philippe Godding, Le Conseil de Brabant sous Philippe le Bon. L'Institution et les hommes, in: STEN (Hg.), Powerbrokers, S. 101-114, hier S. 109. Am 24.10.1467 Tirlemont, ernannte Karl Woutre zu seinem Rat, und gleichzeitig Lambert van der Ee zu seinem Sekretär, Brüssel AGR Registre des chartes de la Chambre des Comptes de Brabant 134 f.60r; STEIN, Catalogue des Actes, Nr. 140.

${ }^{93}$ Brüssel, 27.6.1474, Brüssel AGR CC Brabant 134, f.154v, STEIN, Catalogue des Actes, Nr. 1897.

${ }^{94}$ Reise vom 13.6.-14.8.1465, Lille ADN B 2061 f.179v; Tutemberghe: Lille ADN B 2054 f.160r. Am 21.9.1465 wurden sie zum Abschluß von Bündnissen ermächtigt, Lille ADN B 327/16 081. Vgl. GrüNEISEN, Reichsstände, S. 41 und BONENFANT, STENGERS, Le rôle de Charles le Téméraire, S. 27.

95 Lille ADN B 2054 f.147r-v, f.174v. Siehe zu diesen Verhandlungen oben S. $102 f$.

96 Lille ADN B 2058 f.166v-167r. Lille ADN B 2061 f.132r-v. Botengänge Tutemberghes, Lille ADN B 2058, f.113v, 134v-135r, 142r, 146r, 151v, 157r. 
Woutre begegnet in Reichsangelegenheiten noch einmal im August 1475, als er und Lambert van der Ee Gérard Vurry nach Ungarn begleiten sollten, um der Hochzeit des Matthias Corvinus mit Beatrix von Aragon in Vertretung des Herzogs beizuwohnen. Nachdem Vurry im Dezember 1475 gestorben war, befahl Karl Woutre und Lambert, allein zu reisen. Ob sie bei der schließlich im Dezember 1476 gefeierten Hochzeit tatsächlich anwesend waren, ist nicht gesichert ${ }^{97}$.

\section{Guillaume de Rochefort}

Sohn einer in der Nähe von Dôle begüterten Adelsfamilie, studierte Guillaume de Rochefort an der Universität von Dôle und wurde zum Doktor beider Rechte promoviert. Zunächst im Dienst Philipps des Guten, wurde er 1466 Rat und maître des requêtes des Grafen von Charolais. 1474 berief ihn Karl als einen der Räte des Parlaments von Mecheln ${ }^{98}$. Unter Rudolf von Baden-Hachberg, mit dem er befreundet war, bekleidete Rochefort das Amt des Präsidenten des Rates von Luxemburg99. Gemeinsam bemühten sie sich um die Pflege der Beziehungen zu den Eidgenossen, die für Rochefort gleichbedeutend waren mit einer Einbindung Savoyens in den burgundischen Einflußbereich als Brückenkopf nach Italien. Er war ein Kenner italienischer Belange und unterhielt mehrere Informanten an den dortigen Höfen ${ }^{100}$. In Mailand erfreute sich Rochefort, besonders nach Abschluß des Vertrages von Moncalieri, eines hohen Ansehens, 1472 und 1476 sprachen Aliprando und Panigarola von ihm als einem der einflußreichsten und weisesten Räte Herzog Karls ${ }^{101}$. Der hauptsächliche Wirkungsbereich Rocheforts lag zunächst in den Beziehungen zu den Eidgenossen und zur Herzogin von Savoyen, seit Anfang 1475 dann auch in den Kontakten zu Mailand und Venedig. Letzteres zahlte ihm spätestens seit 1472 eine Pension ${ }^{102}$.

Noch als Diener des Grafen von Charolais handelte er in der ersten Hälfte des Jahres 1467 das Bündnis Karls mit Bern und weiteren eidgenössischen Kommunen aus ${ }^{103}$. Im November und Dezember desselben Jahres hielt er sich

97 Panigarola an Galeazzo Maria, 27.8.1475 Namur, Sestan Carteggi, 2, Nr. 342, S. 40. Lille ADN B 2105/67 594. Lille ADN B 17717, o. Fol.

98 J. MANGin, Guillaume de Rochefort, conseiller de Charles le Téméraire et chancelier de France, in: Position des thèses de l'École des Chartes 1936, S. 117-123.

${ }^{99}$ BAUER, Négotiations, S. $42 \mathrm{f}$.

100 Einen derartigen Gewährsmann besaß er beispielsweise in Padua, von wo er ein Schreiben datiert vom 27.6.1475 empfing, das ihn über die Reise Bastard Antons durch Italien unterrichtete. Rochefort hatte sich selbst schriftlich zuvor an seinen Informanten gewandt, Paris BNF Ms fr 5041 f. 72 r.

101 Aliprando an Galeazzo Maria, 25.11.1472 Gravelines, SESTAN Carteggi, 1, Nr. 181, S. 298. Panigarola an Galeazzo Maria, 31.12.1475-1.1.1476 Nancy, SESTAN Carteggi, 2, Nr. 389, S. $158 f$.

102 Pietro Aliprando an Galeazzo Maria, 31.12.1472, SeStan, Carteggi, 1, Nr. 183, S. 307.

${ }^{103}$ Lille ADN B 2064 f.162v, 192v, vgl. VAUGHAN, Charles, S. 4 m. Anm. 2. 
bei Herzogin Yolanthe von Savoyen auf ${ }^{104}$, die er wieder im Oktober $1468 \mathrm{zu}-$ sammen mit Emar Bouton aufsuchte, um sie über die Beziehungen Karls zu Ludwig XI. zu informieren ${ }^{105}$. Im Juni 1469 führte er zusammen mit Guillaume de la Baulme die Zahlung der $10000 \mathrm{fl.rh}$. an die Eidgenossen durch, die als Ablösung der von Sigmund aus dem Vertrag von Waldshut geschuldeten Summe liquidiert wurden. Zugleich war er zum ersten Mal instruiert worden, den Eidgenossen die Vermittlung Karls in ihrem Konflikt mit Sigmund anzubieten ${ }^{106}$; eine Politik, die in den folgenden Jahren immer wieder angewandt wurde, um die ungeduldigen Forderungen des Herzogs von Österreich nach bewaffnetem Vorgehen gegen die Schweizer zu besänftigen. Im Februar 1471 richtete Rochefort zwei Schreiben in diesem Sinne an die Eidgenossen und regte einen gütlichen Tag an, der unter seiner Beteiligung im März des Jahres in Basel stattfand. Hier wurde eine vorläufige Regelung des Streites zwischen Mülhausen und seinen Gläubigern und Hagenbach erreicht ${ }^{107}$. Im Frühjahr 1470 reiste Rochefort gemeinsam mit Markgraf Rudolf von BadenHachberg und Charles Soillot zu Herzog Sigmund, um die Pläne einer burgundischen Standeserhöhung zu verhandeln ${ }^{108}$.

Nur in Ausnahmefällen war Rochefort mit den Beziehungen zu den nördlichen Nachbarn Burgunds befaßt. Ebenso wie Montjeu und Fillastre baten ihn Anfang 1470 Vertreter der Stadt Köln, seinen Einfluß für die Sache der Stadt im Schoßprozeß geltend zu machen. Kurze Zeit später wurde er zum Berichterstatter des Prozesses bestellt, so daß es nicht zuletzt seiner Darstellung der Materie vor dem Großen Rat zu verdanken war, daß das Urteil zugunsten Kölns erging ${ }^{109} .1472$ begleitete er den Herrn von Gruuthuse nach England, der während der Gesandtschaft den Titel eines Grafen von Winchester empfing. Rochefort, der zu diesem Anlaß die feierliche Gesandtschaftsrede hielt, wurde von Aliprando für seine rhetorischen Fähigkeiten gepriesen 110 .

Die Laufbahn Rocheforts unter Herzog Karl war vor allem von dem Bemühen bestimmt, über ein enges Bündnis mit Savoyen den Weg nach Italien zu öffnen und den französischen Einfluß, vor allem auf Mailand, zurückzudrängen. Diese Zielsetzung konnte die Partei um Rochefort, Hugonet und Baden-

104 Lille ADN B 2064 f.398r.

105 Karl BitTManN, Der Kardinal Balue und die Zusammenkunft von Péronne, in: Die Welt als Geschichte 16 (1956) S. 98-123, hier S. 110 m. Anm. 5.

106 Eidgenössische Abschiede, 2, S. 398, Nr. 634; Lille ADN B 825/23 893.

${ }^{107}$ Emanuel von RoDT, Die Feldzüge Karls des Kühnen, 1, Schaffhausen 1843, S. 127. Die Beglaubigung Rocheforts durch Karl vom 14.1.1471 in Basel StA Eidgenossenschaft D3 f.3r-v, nach GRÜNEISEN RTA-Material. Zweites Schreiben Rocheforts vom 7.2.1471, Fribourg, Bibl. cant. Coll. Girard VII, S. 3, nach GRÜNEISEN RTA-Material. Abschied des Tages von Basel vom 21.3.1471, Cartulaire de Mulhouse, 4, Nr. 1585, S. 22-25.

108 Instruktion in Comines, ed. LENGLET, 3, Nr. 199, S. 238f. Lille ADN B 338/16 240; Brüssel AGR CC 1925 f.263v-264r und GRÜNEISEN, Reichsstände, S. 55.

${ }^{109}$ HUB, 9, Nr. 613, S. 510f., 513, 515.

110 Pietro Aliprando an Galeazzo Maria, 31.12.1472, SESTAN, Carteggi, 1, Nr. 183, S. 307. 
Hachberg bei Karl so weit durchsetzen, wie sie den Wünschen des Herzogs entsprach. Auch wenn Rochefort durch seinen seit Ende 1472 oder Anfang 1473 beinahe ununterbrochenen Aufenthalt in Savoyen und Italien nur noch selten in direkten gesandtschaftlichen Kontakt mit deutschen Reichsangehörigen trat, besa $B$ die von ihm vertretene Politik doch tiefgreifende Auswirkungen auf die Gestaltung des burgundischen Verhältnisses zum Reich. Die Hinwendung zu Savoyen und Mailand schloß einen Krieg gegen die Eidgenossen mit Bern an der Spitze aus, das selbst vitale Interessen in Savoyen besaß und den Durchzug italienischer Söldner nach Burgund hindern konnte. Dagegen trieb das unglückliche, von Karl aber gedeckte Vorgehen Hagenbachs Sigmund von Österreich geradezu in ein Bündnis mit den Eidgenossen, die ihrerseits eine burgundische Kontrolle der Alpenpässe um jeden Preis verhindern wollten. Das Scheitern der von Rochefort favorisierten Politik zeichnete sich daher seit dem Frühsommer 1474 ab und wurde in den folgen zwei Jahren zur Gewißheit.

Im September 1471 reiste Rochefort zum ersten Mal zusammen mit dem Abt von Casanova zu Bartolomeo Colleoni nach Venedig111. Die Werbung Karls um den Condottiere und um weitere italienische Truppen setzte er in den kommenden Jahren zumeist gemeinsam mit Antoine de Montjeu fort, während er gleichzeitig die Interessen Karls am savoyischen Hof vertrat ${ }^{112}$. Sein Wirken für den burgundisch-mailändischen Ausgleich trug im Mai 1474 erste Früchte, als ihm Galeazzo Maria zwar noch die Durchreise durch mailändisches Territorium versagte, er aber in Vercelli trotzdem dem Gesandten Antonio d'Appiano gegenüber das Interesse Karls an einem Bündnis mit dem Sforza darlegen konnte ${ }^{113}$. Bereits im darauffolgenden Dezember erhielt er von Karl die Vollmacht zu den Bündnisverhandlungen mit Mailand und Savoyen, die er in Moncalieri im Januar 1475 erfolgreich zum Abschluß brachte. Mehrere Male bezeugte ihm Galeazzo Maria in der folgenden Zeit seine Dankbarkeit für die geleisteten Dienste114. Auf seinem Besitz nahe Dôle traf er im Februar

111 Vollmacht Karls für Rochefort und Casanova, 15.9.1471 Saint-Omer, SESTAN, Carteggi, 1, Nr. 173, S. 279f.

112 Aliprando an Cicco Simonetta, 4.10.1472 Antwerpen, SESTAN, Carteggi, 1, Nr. 176, S. 283-285. Francesco Bertini an Angelo di Andria, 12.9.1473 Luxemburg, ZAMBARBIERI, 1, S. 50. Zu den Verhandlungen mit Colleoni siehe oben S. 230f. Zu Savoyen: BITTMANN, Ludwig XI., 1, 2, S. 599f. m. Anm. 119. Karl an Yolanthe, 2.8.1473 Lager am Rhein bei Griethausen, Briefwechsel Nr. 2375, übersetzt VaughaN, Charles, S. 302. Seit dem Abschluß des Vertrages von Moncalieri war Rochefort regelmäßig am savoyischen Hof, Frédéric de GINGINS-LA-SARRAZ, Dépêches des ambassadeurs milanais sur les campagnes de Charles-le-Hardi, duc de Bourgogne, de 1474 à 1477, 1, Paris 1858, S. 93-100.

113 SESTAN, Carteggi, 1, Nr. 216, S. 360f. Galeazzo Maria an Christoforo da Bollate, 30.6.1474 Pavia, ZAMBARBIERI, 1, S. 69 (nicht in SESTAN, Carteggi).

114 Comines, ed. LENGLET, 3, S. 360f. Am 16.1.1475 wurde Rochefort von Neuss aus eine weitere Instruktion zu den Bündnisverhandlungen nachgesandt, Lille ADN B 2102/67 514. $\mathrm{Zu}$ Moncalieri siehe das Schreiben Rocheforts an Galeazzo Maria, Moncalieri 31.1.1475, 
1475 mit Montjeu und Panigarola zusammen. Den Mailänder, der sich als ständiger Gesandter Galeazzo Marias auf dem Weg nach Neuss befand, unterrichtete Rochefort ausführlich über die Gepflogenheiten des burgundischen Hofes, was von Panigarola mit großer Dankbarkeit aufgenommen wurde ${ }^{115}$. Als Mitglied der großen Gesandtschaft des Bastard Anton nach Italien hielt Rochefort im selben Frühjahr in Mailand die öffentliche Gesandtschaftsrede und bat in privater Audienz Galeazzo Maria erneut um Truppen 116 .

Auch im letzten Regierungsjahr Karls arbeitete Rochefort an der Gestaltung des Verhältnisses zu Mailand. Die sich konsolidierenden Beziehungen Karls zu Friedrich III. führten auch Mailand näher an den Kaiser, und Rochefort wurde zusammen mit Georg Heßler mit der Festlegung der durch Galeazzo Maria für die kaiserliche Investitur zu zahlenden Summe beauftragt ${ }^{117}$. Karl sandte ihn im Juni 1476 auf Bitten des Herzogs von Mailand zu Friedrich III., um nach dem Verlust der Originale des Vertrages zwischen Karl und dem Kaiser in der Schlacht von Grandson den EinschluB Mailands in seine Bestimmungen bestätigen zu lassen. Auch die Frage der Investitur dürfte bei dieser Gelegenheit thematisiert worden $\operatorname{sein}^{118}$. Außerdem bemühte Rochefort sich um die Versöhnung zwischen Savoyen und Mailand und begrüßte im März 1476 während der öffentlichen Audienz in Orbe die Gesandten Galeazzo Marias ${ }^{19}$. Seine realistische Einschätzung des Verhältnisses zu Mailand bewies er durch den Vorschlag, Karl solle die gewünschte Sendung von Truppen durch eine Geldzahlung beschleunigen, auch wenn Galeazzo Maria eigentlich dieser Bündnisverpflichtung unentgeltlich hätte nachkommen sollen ${ }^{120}$. Offenbar als erster und einziger am burgundischen Hof sah er bereits im Mai 1476 Anzeichen für eine Wiederannäherung Mailands an Frankreich ${ }^{121}$. Gleichzeitig erkannte er die Gefangennahme Herzogin Yolanthes als einen Fehler und lenkte offenbar durch entsprechende Äußerungen das Mißtrauen Karls auf sich $^{122}$. Der Herzog seinerseits sah es schon im Mai mit Mißfallen, daß Rochefort in der Frage der mailändisch-habsburgischen Beziehungen für ihn unentbehrlich war, was ihm Panigarola bestätigte ${ }^{123}$.

SESTAN, Carteggi, 1, Nr. 240, S. 398; ZAMBARBIERI, 1, S. 36f. Anerkennung durch Galeazzo Maria, SESTAN, Carteggi, 1, Nr. 244, S. 403f.; ebd. Nr. 246, S. $405 f$.

115 Panigarola an Galeazzo, 23.2.1475 Rochefort bei Dôle, SESTAN, Carteggi, 1, Nr. 250, S. 412f. Panigarola an Galeazzo, 9.2.1475, SESTAN, Carteggi, 1, Nr. 246, S. 405f.

116 Panigarola an Galeazzo, 24.4.1475 Neuss, SESTAN, Carteggi, I, Nr. 283, S. 471.

117 Panigarola an Galeazzo, 6.5.1476 Lausanne, SESTAN, Carteggi, 2, Nr. 551, S. 458-461.

118 Karl an Galeazzo, 2.6.1476 Morrens, SESTAN, Carteggi, 2, Nr. 589, S. 543.

119 Die Gesandten an Galeazzo, 2.3.1476 Orbe, SESTAN, Carteggi, 2, Nr. 439, S. 246f.; Panigarola an Galeazzo, 18.4.1476 Lausanne, SESTAN, Carteggi, 2, Nr. 522, S. 403.

120 Panigarola an Galeazzo, 20.4.1476 Lausanne, SESTAN, Carteggi, 2, Nr. 525, S. 411.

121 Panigarola an Galeazzo, 20.5.1476 Lausanne, SESTAN, Carteggi, 2, Nr. 573, S. 511 f.

122 Panigarola an Galeazzo, 13.6.1476 Morat, Sestan, Carteggi, 2, Nr. 599, S. 563f; ders. an dens. 30.6.1476, ebd., Nr. 623, S. 610; ders. an dens., 3.7.1476 Salins, ebd., Nr. 626, S. 614. 123 Panigarola an Galeazzo, 23.5.1476 Lausanne, SESTAN, Carteggi, 2, Nr. 577, S. 524f. 
Am 27. Juli 1476 schließlich meldete der Gesandte nach Mailand, Rochefort habe den burgundischen Hof verlassen. Der Ausgang der Schlacht von Murten hatte in ihm die Überzeugung reifen lassen, daß der Politik Karls nicht mehr zu trauen sei. Wenig später zitierte der Herzog ihn mit einer achttägigen Frist zu sich, nach deren Ablauf Rochefort für vogelfrei erklärt wurde. Am 13. August sprach Karl die Bannung und die Konfiskation seiner Güter aus ${ }^{124}$. Von Herzogin Maria rehabilitiert, wurde er noch einmal als Gesandter für Burgund in den Verhandlungen über die Ehe Margaretes von Österreich mit dem Dauphin tätig. In ihrem Verlauf warb ihn Ludwig XI. für seine Dienste und ernannte ihn 1483 zum Kanzler von Frankreich.

\subsection{Der Kanzler: Guillaume Hugonet}

Obwohl Guillaume Hugonet, Kanzler Karls des Kühnen seit dem 22. Mai 1471, als Teilnehmer an Gesandtschaften in das Reich keine Rolle spielte, sondern seine praktischen diplomatischen Erfahrungen vor allem in Verhandlungen mit Frankreich gesammelt hatte, war sein Anteil an der Gestaltung der Reichspolitik erheblich. Sein Entscheidungsspielraum konnte sich allerdings nicht mit dem seiner Vorgänger unter Philipp dem Guten messen ${ }^{125}$. Greifbar wird sein Einfluß in Reichsangelegenheiten zunächst im Dank der Stadt Köln vom März 1472 für den günstigen Entscheid des Großen Rates im Streit Kölns mit dem Deutschen Kaufmann zu Brügge. In Trier leitete er die burgundische Delegation, die mit den kaiserlichen Räten über Königtum und Eheschließung verhandelte ${ }^{126}$. Wie die Ausführungen zu Rochefort gezeigt haben, zählte der

124 Panigarola an Galeazzo, 27.7.1476 La Rivière, SESTAN, Carteggi, 2, Nr. 643, S. 657. Ultimatum Karls, ebd., Nr. 647, S. 670; Bannung, Paris BNF Coll. de Bourgogne 107 f.289v. BAUER, Négotiations, S. 88, hat falsch den 8.6.1476. Vgl. die Notiz über die Achterklärung in Paris BNF Coll. de Bourgogne 65 f.176r-v. Rochefort hatte möglicherweise schon im Juli 1476 Kontakt mit Ludwig XI. aufgenommen, um den Wechsel auf die französische Seite vorzubereiten, siehe Lille ADN B 2111/67978.

${ }^{125}$ Hugonet stammte aus Mâcon und war Herr von Saillant, Espoisses und Liz, wahrscheinlich Lizentiat der Rechte. Rat Philipps des Guten, Richter des Beaujolais, 1467 Bailli des Charolais, Maître des requêtes de l'hôtel, Leiter des Großen Rates, CoCKSHAW, Le personnel, S. 17f., 20, 52; Wim P. BLOCKMANS, "Hugonet, Guillaume", in: LexMA, 5, 1991, Sp. 180f.; Werner ParaviCINI, Zur Biographie von Guillaume Hugonet, Kanzler Herzog Karls des Kühnen, in: Feschrift für Hermann Heimpel, 2, Göttingen 1972, S. 443-481; Anke und Werner PARAVICINI, L'arsenal intellectuel d'un homme de pouvoir au $\mathrm{XV}^{\mathbf{e}}$ siècle: les livres de Guillaume Hugonet, chancelier de Bourgogne, in: Dominique BOUTET, Jacques VERGER (Hg.), Penser le pouvoir au Moyen Âge (VIII ${ }^{e}-\mathrm{XV}^{e}$ siècle). Etudes d'histoire et de littérature offertes à Françoise Autrand, Paris 2000, S. 261-325. Zur großen Bedeutung der burgundischen Kanzler für die Außenbeziehungen ihres Herrn unter Johann Ohnefurcht siehe BORCHGRAVE, Diplomaten, S. 113-117. Zur Machtfülle des Kanzlers unter Philipp dem Guten und der Einschränkung durch Karl, CoCKSHAW, Le personnel, S. 1-6, 10.

${ }^{126}$ HR, 6, Nr. 510, S. 473f. Zu Trier siehe S. 169. 
Kanzler zu den Befürwortern einer schweizerfreundlichen Politik und lehnte die Kriegspläne Hagenbachs ab. Als Leiter des Regentschaftsrates schließlich blieb er während der Feldzüge Karls 1475 und 1476 in den Niederlanden zurück und führte die Friedensverhandlungen mit dem französischen König ${ }^{127}$. Für eine Beteiligung an den weiteren Verhandlungen mit dem Kaiser um einen Friedensschluß und die Ehe Marias und Maximilians gibt es keine Belege. Ganz auszuschließen ist sie jedoch nicht, wie die Beteiligung des ebenfalls in den Niederlanden verbliebenen Guy de Brimeu an diesen Gesprächen bezeugt.

\subsection{Geistliche ${ }^{128}$}

Ebenso wie unter Johann Ohnefurcht bildete auch am Hof Karls des Kühnen der hohe Klerus einen festen und unbedingt loyalen Bestandteil der burgundischen Führungsschicht, da er seine Ämter fast ausschlieBlich herzoglicher $\mathrm{Pa}$ tronage verdankte. Diese Geistlichen waren in aller Regel Juristen und immer auch Räte des Herzogs. In Verbindung mit dem Ansehen des geistlichen Standes verlieh ihnen ihre Ausbildung die idealen Voraussetzungen für die Tätigkeit als Gesandte ${ }^{129}$.

In den Beziehungen zu den Reichsständen allerdings ging Karl mit dem Einsatz geistlicher Gesandter aus seinem unmittelbaren Beraterkreis vergleichsweise sparsam um. Die Brüder Clugny waren vor allem mit den Kontakten zu England und Frankreich befaßt, und nur Antoine Haneron engagierte sich stark in den Beziehungen zu den östlichen Nachbarn. Der Adel dominierte quantitativ die Verbindungen zum Reich und verband damit teilweise den Vorteil der Zweisprachigkeit und der besseren Kenntnis der dortigen Verhältnisse. Andererseits ist zu beobachten, daß Karl gerade für die wichtigen Verhandlungen mit dem Kaiser nach 1474 zwei Geistliche verwandte, die nicht zu seiner unmittelbaren Umgebung zu rechnen waren: Der Piemontese Agostino da Lignana, Abt von Casanova war Untertan der Herzogin von Savoyen, Francesco Bertini, Bischof von Capaccio, Gesandter König Ferrantes von Neapel.

${ }^{127}$ PARAVICINI, Brimeu, S. 478f.

128 Martin Steenbergh und Charles Soillot, die zwar die niederen Weihen empfangen hatten, deren kirchliche Karrieren aber unbedeutend blieben, werden hier nicht zu den Geistlichen gezählt, sondern in ihrer Funktion als herzogliche Sekretäre besprochen.

129 BorChgrave, Diplomaten, S. 130f. ; PrEVEniER, BlockMANS, Les Pays-Bas bourguignons, S. 141. 
Ferry und Guillaume de Clugny ${ }^{130}$

Ferry de Clugny wurde um 1420/25 in Autun geboren und studierte in Padua, Ferrara und Bologna bis zum Erwerb des Doktorgrades beider Rechte. Philipp der Gute ernannte ihn zum Rat und maître des requêtes und sandte ihn mehrfach nach Rom und zu Ludwig XI. Auch Karl bediente sich seiner in erster Linie für die Verhandlungen um Waffenstillstände und Frieden mit dem französischen Königi131. Ferry diente dem Herzog zunächst als Präsident des GroBen Rates in Abwesenheit des Kanzlers und folgte 1473 Guillaume Fillastre als Bischof von Tournai und Kanzler des Ordens vom Goldenen Vlies nach. Im selben Jahr ernannte ihn Karl außerdem zum Präsidenten des neugeschaffenen Parlaments von Mecheln ${ }^{132}$. Zu Beginn des Jahres 1476 bezeichnete Panigarola ihn als den angesehensten Geistlichen und einen der einflußreichsten Männer am burgundischen Hof, »dignissimo prelato $\mathrm{e}$ lo più reputato di questa corte, capo di consiglio ${ }^{133}$. Er starb 1483 in Rom, nachdem er 1480 noch in den Kardinalsrang aufgestigen war.

Die aktive Teilnahme Ferrys an den diplomatischen Kontakten zum Reich beschränkte sich auf die gemeinsame Mission mit Peter von Hagenbach im Frühjahr $1465 \mathrm{zu}$ Bündnisverhandlungen mit dem Pfalzgrafen und Herzog Ludwig dem Reichen von Bayern im Auftrag des Grafen von Charolais. Sie agierten hier parallel zu den von Herzog Philipp bevollmächtigten van der Noot und van der $\mathrm{Ee}^{134}$. Vor allem aber wird sein Einfluß auf die Entscheidungen in Reichsfragen sichtbar in seiner Teilnahme an den Verhandlungen von Trier, die durch seine Unterschrift unter den Vertrag vom 4. November 1473 belegt ist ${ }^{135}$.

Sein Bruder Guillaume de Clugny, päpstlicher Protonotar und seit 1474 Dekan von Tournai und Administrator von Thérouanne ${ }^{136}$, wurde 1473 zum Vermittler im Streit zwischen der Hanse und den holländischen und seeländischen Städten bestellt, nahm an den Verhandlungen aber wahrscheinlich nicht teil ${ }^{137}$. Seine Anwesenheit bei den Geheimverhandlungen in Trier ist ebenfalls

130 Literatur zur Familie Clugny bei PaRAVicINI, Brimeu, S. 281 Anm. 108; u. A. de SCHRYVER, M. DYKMANS, J. RUYSSCHAERT, Le pontifical de Ferry de Clugny, cardinal et évèque de Tournai, Vatikanstadt 1989 (Collezione Paleografica Vaticana, 3), S. 81-118.

131 Siehe z.B. PaRAVICINI, Brimeu, S. 467 Anm. 71.

132 M. DYKMANS, »Clugny, Ferry de«, in: LexMA, 2, 1983, Sp. 2171. PARAVICINI, Brimeu, S. 278 Anm. 97, S. 350 Anm. 434.

133 Panigarola an Galeazzo Maria, 31.12.1475-1.1.1476 Nancy, SESTAN, Carteggi, 2, Nr. 390, S. $158 f$.

134 Pfalzgraf: Comines, ed. LENGLET, 2, Nr. 54, S. 470-473. Herzog Ludwig: HStA München Bundesbriefe fasz. 13, nach GRÜNEISEN RTA-Material, vgl. GRÜNEISEN, Reichsstände, S. 41.

135 STEIN, Haneron, S. 341.

136 M. DYKMans, "Clugny, Guillaume de«, in: LexMA, 2, 1983, Sp. 2171f.; PARAVICINI, Brimeu, S. 281 Anm. 108-112.

${ }^{137}$ HUB X, Nr. 248, S. 166. 
nicht zweifelsfrei nachzuweisen, auch wenn sein Name unter den Begleitern des Herzogs bei seinem Einzug Anfang Oktober genannt wird.

\section{Guillaume Fillastre}

Ähnlich wie Ferry de Clugny war auch sein Vorgänger auf dem Bischofsstuhl von Tournai, Guillaume Fillastre, unter Karl dem Kühnen nur innerhalb des burgundischen Machtbereiches als Unterhändler tätig. Der überwiegende Anteil seiner gesandtschaftlichen Tätigkeit fältt in die Regierungszeit Philipps des Guten, dem der Doktor des Kirchenrechts als Rat und Kanzler des Ordens an einflußreicher Stelle diente. 1454 begleitete er seinen Herrn nach Regensburg, um das von ihm besonders geförderte Ziel des Ordens, den Kreuzzug, der Verwirklichung näher zu bringen ${ }^{138}$. Unter Karl dem Kühnen begegnet Fillastre im Juni und Juli 1469 in Brügge als Vermittler im Streit zwischen England und der Hanse. Mit den Belangen der Hanse blieb er weiter befaßt und war 1472 an der Entscheidung zugunsten Kölns im Schoßstreit beteiligt, wofür ihm die Stadt ihren Dank aussprach ${ }^{139}$.

\section{Johann Espach}

Johann Espach war der einzige nicht-adlige Deutsche in der Gruppe der Gesandten, die Karl mit Aufträgen in das Reich versah. Der aus Frankfurt am Main stammende Kleriker immatrikulierte sich 1450 an der Universität Heidelberg, wo er 1454 das Lizenziat in kanonischem Recht erwarb und in den Dienst des Erzbischofs von Mainz trat. Der genaue Zeitpunkt seiner Übersiedlung an den burgundischen Hof ist unbekannt, doch liegt die Vermutung nahe, $\mathrm{daß}$ er durch Johann von Nassau im Zuge der Bündnisverhandlungen mit dem Erzbischof Ende 1469 dazu veranlaßt wurde ${ }^{140} .1471$ ist er zuerst in Diensten Herzog Karls belegt, als er zusammen mit Guy de Brimeu und dem Rat und maître des requêtes Johann von Ostende bevollmächtigt wurde, in Köln mit den Kurfürsten über die Rheinzölle zu verhandeln. 1473 führte er den Titel eines maître des requêtes ${ }^{141}$. Karl ernannte ihn am 17. Dezember 1474 zum Rat an der Ratkammer in Maastricht mit einer dienstabhängigen Jahresgage von $200 \mathrm{lb}$. Hier wird er zum ersten Mal mit dem Titel eines Doktors des Kirchen-

138 Malte PRIETZEL, Guillaume Fillastre der Jüngere (1400/07-1473). Kirchenfürst und gelehrter Rat, Stuttgart 2001 (Beihefte der Francia, 51). Evenico BELTRAN, Malte PRIETZEL, Le second chancellier de l'ordre: Guillaume Fillastre II, in: Pierre COCKSHAW, Christiane VAN DEN BERgen-Pantens (Hg.), L'ordre de la Toison d'or de Philippe le Bon à Philippe le Beau (1430-1505): idéal ou reflet d'une société?, Brüssel 1996, S. 118-127, hier S. 118f.; Evenico BeLTRAN, Guillaume Fillastre (ca. 1400-1473). Eveque de Verdun, de Toul et de Tournai, in: Monique ORNATO, Nicole PONS (Hg.), Pratiques de la culture écrite en France au XVe siècle, Louvain-La-Neuve 1995, S. 31-54.

139 HR, 6, Nr. 221, S. 191; Nr. 510, S. 473f.

140 GRÜNEISEN, Reichsstände, S. $54 \mathrm{f}$.

141 PrIEBATSCH, Politische Correspondenz, 1, S. 543, Nr. 646. 
rechts belegt ${ }^{142}, 1476$ mit dem eines päpstlichen Protonotars. Er erwarb außerdem Kanonikate an Sankt Lambert zu Lüttich und Sankt Servatius zu Maastricht, sowie das Archidiakonat des Hennegau. Noch unter Maximilian diente Espach als Rat und Diplomat ${ }^{143}$.

Am häufigsten trat Espach als Gesandter im Sommer 1473 in Erscheinung, als er gemeinsam mit Hagenbach zwischen Herzog Karl und dem Kaiser hin und her pendelte. Im Juni suchten die Gesandten Friedrich III. in Ulm auf, Anfang Juli trafen sie ihn in Baden. Dort erhielt Espach die kaiserlichen Urkunden, die Guy de Brimeu zum Hofpfalzgrafen ernannten. Noch einmal sandte Karl Hagenbach und Espach dem Kaiser entgegen, den sie in der ersten Augusthälfte wiederum in Baden erreichten ${ }^{144}$. Anhand der überlieferten Instruktionen kann nicht sicher davon ausgegangen werden, daß Espach an den inhaltlichen Verhandlungen mit dem Kaiser beteiligt war. Hagenbach war zuletzt im Februar 1473 bevollmächtigt worden, über Königtum und EheschlieBung zu sprechen, doch sind weitere einschlägige Anweisungen des Herzogs nicht auszuschließen. Offenbar gelang es Espach, während der Aufenthalte am kaiserlichen Hof, das Wohlwollen Friedrichs III. zu gewinnen. Im Oktober gewährte der Kaiser in Trier die Erneuerung des Lehnsbriefes für Guy de Brimeu auf Bitten Espachs gebührenfrei, »dominus dedit gratis magistro Johanne Espach, qui eandem rem sollicitavit «145. Am selben Tag übertrug er Espach, ebenfalls gratis, die Vollmacht, die Rechtmäßigkeit der Notare in den Ländern des Herzogs von Burgund zu überprüfen und diejenigen abzusetzen, die sich das Amt widerrechtlich anmaßten ${ }^{146}$.

Im August 1475 beauftragte Karl ihn mit einer Gesandtschaft an Herzog Galeazzo Maria von Mailand. Es ist zu vermuten, daß er dort die Bitte Karls um Truppen zu wiederholen hatte, wahrscheinlich auch veranlaßt durch die etwas kühle Aufnahme, die Bastard Anton in Mailand kurz zuvor zuteil geworden war ${ }^{147}$. Zum letzten Mal wurde er für Karl im November 1476 als Gesandter

142 PARAVICINI, Brimeu, S. 370 Anm. 497.

143 PARAVICINI, Brimeu, S. 376 m. Anm. 533.

144 Gesandtschaft nach Ulm: Lille ADN B 2097/67 292. Baden Anfang Juli: PRIEBATSCH, Politische Correspondenz, 1, S. 543, Nr. 646. Überbringen der Hofpfalzgrafenurkunde: ParaviCINI, Brimeu, S. 428 Anm. 135. Baden Anfang August: Instruktion vom 30.7.1473 in CHMEL, Aktenstücke 1, 1, S. 37-39, vgl. BRAUER-GRAMM, Hagenbach, S. 238 m. Anm. 1114.

145 Wien HHStA Hs weiß 1059 f.257v, nach Grüneisen RTA-Material; vgl. HEINIG, Friedrich III., S. $1188 \mathrm{f}$.

146 Wien HHStA Hs weiß 1059 f.258r, nach Grüneisen RTA-Material.

147 Karl an Galeazzo Maria, (28.)8.1475 Namur, Briefwechsel Nr. 3221; Karl an Galeazzo Maria, (27. oder 28.8.1475, Namur), Briefwechsel Nr. 3219; Karl an Salvatore de Clarici, (28.8.1475 oder kurz davor), Briefwechsel Nr.3220. Vgl. SESTAN, Carteggi, 2, Nr. 344, S. 42; ebd., Nr. 345, S. 45-48; und VaUGHAN, Charles, S. $236 f$. 
tätig, als er für einen Vorschuß für eine demnächst bevorstehende Reise in geheimen Angelegenheiten nach Köln und Koblenz quittierte ${ }^{148}$.

\section{Antoine Haneron}

Der wohl älteste Vertraute Herzog Karls, sein Lehrer Antoine Haneron, diente ihm noch in der Herzogszeit als Finanzfachmann und Diplomat. Haneron, gebürtig aus dem Artois in den ersten Jahren des Jahrhunderts, erwarb zunächst den Magister Artium, dann den Titel eines Baccalaureus des Rechts an der Universität von Löwen. Von 1430 bis 1438 war er Regent der dortigen Artistenfakultät. 1439 begann seine Karriere als Rat im Herzogsdienst, die er unter anderem auch für den Erwerb zahlreicher Pfründen zu nutzen wußte ${ }^{149}$.

Nachdem ihn 1449 seine erste Gesandtschaft an den Hof von Frankreich geführt hatte ${ }^{150}$, brachte ihn das nächste Jahr in Kontakt mit Reichsangelegenheiten, als er im Juni und Juli Verhandlungen mit der Herzogin von Kleve bezuiglich der Besetzung des Bistums Münster aufnahm ${ }^{151}$. In den folgenden Jahren wurde er von Herzog Philipp vor allem mit den Beziehungen zu Papst und Kaiser befaßt, wobei einerseits die Vorbereitung des Kreuzzuges, andererseits die Klärung der Lehnsbeziehungen des Herzogs zum Reich und ein zu schaffendes burgundisches Königreich im Mittelpunkt der Verhandlungen standen. 1459 nahm Haneron im Gefolge des Herzogs von Kleve am Konzil von Mantua teil und brachte unmittelbar darauf bei Papst und Kaiser die Anliegen seines Herrn vor ${ }^{152}$. 1466 erschien er wiederum am Kaiserhof und hob dort einen Sohn des Kaiserpaares aus der Taufe ${ }^{153}$.

Nach dem Regierungsantritt seines Schülers erlangte Haneron 1468 die Würde des Propstes von Sankt Donatian in Brügge und wurde zum Domänenund Finanzkommissar bestellt, seit 1473 fungierte er auch als Domänenschatzmeister ${ }^{154}$. Wie hoch sein Einfluß auf den Herzog eingeschätzt wurde, zeigte sich in den Pensionen und Geschenken, die er von verschiedenen Ständen und Städten erhielt, um seine Patronage zu gewinnen ${ }^{155}$. Aliprando rechnete ihn im November 1472 zu den wichtigsten Räten des Herzogs ${ }^{156}$.

148 Quittungen vom 20.11.1476, Lille ADN B 2111/67987 und 26.11.1476, Lille ADN B 2111/67 988 .

$149 \mathrm{Zu}$ seinen Pfründen JONGKEES, Staat en Kerk, S. 142 Anm. 3, S. 290 Anm. 2, S. 312; und PARAVICINI, Brimeu, S. 221f. Anm. 497.

150 STEIN, Haneron, S. 287.

${ }^{151}$ STEIN, Haneron, S. $288 \mathrm{f}$.

152 STEIN, Haneron, S. 291f. Siehe die Instruktion in CARTELLIERI, Über eine burgundische Gesandtschaft, S. $448-464$.

153 Brüssel AGR CC 1924 f.369v-370r.

154 JONGKEES, Staat en Kerk, S. 226f.; STEIN, Haneron, S. $295 f$.

155 PARAvicINI, Brimeu, S. 350 Anm. 434 und ebd., S. 407 Anm. 42.

156 Aliprando an Galeazzo Maria, 25.11.1472 Gravelines, SESTAN, Carteggi, 1, Nr. 181, S. 298. 
Auch Haneron vermittelte im Streit zwischen England und der Hanse im Juni und Juli 1469 in Brügge. Hier wird zuerst seine Verbindung zu Hagenbach erkennbar, mit dem ihm in den folgenden Jahren die Abneigung gegen Eidgenossen und Städte und der Wunsch verbanden, den Herzog zum Krieg am Oberrhein zu bewegen ${ }^{157}$. Versagt blieb ihm hingegen der Erfolg in seinem energisch betriebenen Projekt, Nachfolger des an Rücktritt denkenden Bischofs von Basel, Johann von Venningen, zu werden. Es war Hagenbach gewesen, der Haneron auf diese Aufstiegsmöglichkeit mit einem Brief vom Juli 1470 hingewiesen hatte. $\mathrm{Da}$ auch dem Herzog an der Besetzung des Bischofstuhles mit einem ihm ergebenen Mann sehr gelegen war, erhielt Hagenbach durch Haneron Anfang Oktober 1470 herzogliche Vollmacht und Instruktion, bei Bischof Johann im Namen Karls Erkundigungen über die Abdankungsabsichten und den Wert des Bistums einzuziehen ${ }^{158}$. Dem Bischof wurde eine großzügige Abfindung in Aussicht gestellt. Wie aus seinem Begleitschreiben an Hagenbach hervorgeht, handelte Haneron im Einverständnis mit dem Herzog, der ihm seine Protektion für diesen letzten Karrieresprung zugesagt hatte ${ }^{159}$. Trotzdem scheiterte der Plan am Widerstand von Stadt und Kapitel von Basel, die ihrem Bischof das Versprechen abnötigten, nicht ohne ihre Zustimmung das Amt aufzugeben und daran, daß für Karl Ende 1470 diese Angelegenheiten hinter den Konflikt mit Ludwig XI. zurücktraten.

Intensiv war Haneron, teilweise gemeinsam mit Hagenbach, in die Beziehungen zu Reich und Kaiser während der Vorbereitung des Trierer Tages eingebunden. Ab Juli 1473 reiste er ununterbrochen zwischen Karl und Friedrich III. hin und her, von Nijmegen nach Straßburg, zurück nach Bastogne, von dort nach Basel und schließlich zusammen mit dem Kaiser nach Trier ${ }^{160}$. Über die Verhandlungen, die Haneron mit dem Kaiser fuhrte, ist so wenig bekannt wie über diejenigen Hagenbachs und Espachs in dieser Zeit. Der Einsatz dieser Gesandten aus der engsten herzoglichen Umgebung aber spricht dafür, $\mathrm{da} ß$ es um mehr als nur die Terminabsprachen für das Trierer Treffen ging. In Trier zählte Haneron zum inneren Rat des Herzogs. Ihm ist die Überlieferung des Vertrages vom 4. November zu verdanken, da er das Dokument gleich nach seiner Unterzeichnung an den Markgrafen von Rötteln übersandte.

Ursprïnglich als Mitglied der Gesandtschaft vorgesehen, die unter der Führung Guy de Brimeus von Trier aus den Papst aufsuchen sollte ${ }^{161}$, begleitete er

157 HR, 6, Nr. 221, S. 191.

158 Brief Hanerons an Hagenbach und Instruktion gedruckt bei STEIN, Haneron, S. 337-339, falsch datiert auf 1473 .

159 Dies gegen BRAUER-GramM, Hagenbach, S. 218-220. Nach dem Schreiben vom 5.10.1470 in STEIN, Antoine Haneron, S. 337, hatte Karl Haneron versprochen, »tenir la main pour moy [Haneron]火. Zudem hätte Haneron ohne die Zustimmung Karls keine Aussicht auf das Bistum gehabt.

${ }^{160}$ STEIN, Haneron, S. 296f. m. Anm. 4: Druck von Lille ADN B 2097/67 280.

161 PAQUET, Une ébauche de la nonciature, S. 127. 
Karl dann von Trier ins Elsaß, wo er sich im Dezember 1473 und Januar 1474 vor allem mit der Frage der Mülhausener Schulden auseinandersetzte. In enger Zusammenarbeit mit Hagenbach und in regem Schriftverkehr mit der Stadt Mülhausen betrieb er das Ziel der herzoglichen Politik, Mülhausen ungeachtet ihres Status als Reichsstadt durch Erwerb des Schultheißenamtes in die Pfandlande einzugliedern. Diese Bemühungen scheiterten jedoch und am 7. Januar 1474 wurden in Anwesenheit Hanerons in Ensisheim Rudolf von BadenHachberg und Hagenbach zur Entscheidung über die nach der vorläufig gefundenen Regelung verbliebenen Streitfragen eingesetzt ${ }^{162}$. Damit enden die Nachrichten über diplomatische Aktivitäten Hanerons, der wohl nicht zuletzt aufgrund seines Alters seit dieser Zeit auf weitere Reisen verzichtete ${ }^{163}$.

\subsection{Bürgerliche}

a) Legisten und Räte

Der Anteil der nicht-adligen und nicht-geistlichen Legisten ${ }^{164}$ und Räte an den im Reich tätigen Gesandten des Herzogs war klein. Neben Zufällen wird hierfür der hohe juristische Ausbildungsstand aller geistlichen und einiger der adligen Gesandten verantwortlich gewesen sein, der die Teilnahme bürgerlicher Legisten nicht zwingend erforderlich machte. Die klassische Aufgabenteilung zwischen dem repräsentierenden Adel und den für die technischen Aspekte zuständigen bürgerlichen Laien-Juristen ${ }^{165}$ war in den Gesandtschaften Karls in das Reich nicht der Regelfall.

Neben Léonard de Potots und Gérard Vurry ist nur Volpart van Amerongen zu nennen, Rat und Maître des requêtes, der sich mit Reichsangelegenheiten innerhalb der burgundischen Verwaltung befaßte, ohne selbst an Gesandtschaftsreisen teilzunehmen. Nach Verhandlungen mit dem Bischof von Lüttich 1468 ist seine Beteiligung am Entscheid des Großen Rates im Schoßprozeß zwischen Köln und dem Deutschen Kaufmann zu Brügge 1472 belegt ${ }^{166}$. Außerdem berief sich der Herzog auf die Anwesenheit Amerongens als Zeuge

162 Cartulaire de Mulhouse, 4, Nr. 1714, S. 137; Nr. 1715, S. 137f. und Nr. 1723, S. 145f.; Nr. 1728, S. 149-151.

163 STEIN, Haneron, S. 299.

164 Zur Geschichte der Legisten in Flandern BORCHGRAVE, Diplomaten, S. $136 f$.

165 BORCHGRAVE, Diplomaten, S. 138f., 141, 143.

$166 \mathrm{Ob}$ der Titel eines »maître« auf ein Studium hinweist oder nur als Hinweis auf das Amt des Maître de requêtes gebraucht wurde, ist unklar. Lüttich: PARAVICINI, Brimeu, S. 173 Anm. 304, S. 256 Anm. 37b. Schoßprozeß: HR, 6, Nr. 510, S. 473 Anm. 1. 
bei den Gesprächen mit Herzog Adolf von Geldern in Arras Anfang 1471, um die Unnachgiebigkeit Adolfs zu beweisen ${ }^{167}$.

\section{Léonard de Potots}

Der Rat Léonard de Potots aus Besançon, wahrscheinlich Absolvent einer Universität ${ }^{168}$, Maître des requêtes an den Parlamenten von Dôle und Mecheln, nahm zwei Mal an größeren Gesandtschaften teil. Von Januar bis März 1467 begleitete er Antoine de Montjeu nach Basel zu Gesprächen mit kaiserlichen Gesandten. Im Juli 1472 besuchte er im Gefolge von Hagenbach und Bernhard von Ramstein in Bregenz einen Tag mit Gesandten Herzog Sigmunds ${ }^{169}$. Potots wird in diesen Gesandtschaften für die technischen Aspekte der Verhandlungen und eventuell auch ihre schriftliche Niederlegung zuständig gewesen sein. Er bietet außerdem ein Beispiel für das Kriterium der geographischen Nähe bei der Auswahl der Gesandten: Der Einsatz de Potots von Dôle aus nach Basel und Bregenz war effizienter als derjenige eines Rates aus den Niederlanden.

\section{Gérard Vurry}

Noch als Graf von Charolais hatte sich Karl 1461 der Dienste des aus der Freigrafschaft stammenden Gérard Vurry versichert. Der Doktor beider Rechte gehörte seit 1448 als Rat dem Parlament von Beaune an, versah 1449 eine Gesandtschaftsreise nach Italien und fungierte von 1451 bis 1455 als Rat des Parlaments von Dôle und maître des requêtes. Im Namen Karls trug er vor Herzog Philipp die Anklagen gegen die Croÿ vor. Du Clercq sprach von ihm als )tres notable et grand clercq et bien emparlé «170.

Nach seinem Regierungsantritt ernannte Karl Vurry zum Präsidenten des Rates von Luxemburg. In dieser Funktion bemühte er sich gemeinsam mit dem Gouverneur, Markgraf Rudolf von Baden-Hachberg, die Auseinandersetzungen zwischen dem Pfalzgrafen und Herzog Ludwig von Veldenz zu schlichten. Im März 1471 unternahm er einen ersten Versuch, die Kontrahenten zu versöhnen, doch zeigte man sich bei Hof über die Erfolgsaussichten

167 Karl an Guillaume Fillastre, Mai 1471, HStA Düsseldorf, Beziehungen zu Geldern 33, ACO Dijon, Papiers Henri STEIN, Briefwechsel Nr. 1851.

168 BARTIER, Légistes et gens de finances, S. 45 m. Anm. 4; Paravicini, Brimeu, S. 167 Anm. 280.

169 Basel: Lille ADN B 2064 f.84v, 87v-88r. Bregenz: Beglaubigung Karls für Hagenbach, Ramstein und Potots vor 9.7.1472, Innsbruck TLA Urkunden I Nr. 8216, nach GRÜNEISEN RTA-Material, Briefwechsel Nr. 2108.

${ }^{170}$ BARTIER, Légistes et gens de finances, S. 416f. Zitat nach BONENFANT, STENGERS, Le rôle de Charles le Téméraire, S. 128f. m. Anm. 1. Ein Auszug aus einer Rechnung Vurrys als Receveur général von Burgund in: Paris BNF Coll. Bourgogne $65 \mathrm{f} .174 \mathrm{v}$ weist auf diese Tätigkeit Vurrys hin. Sie wird in der Kurzbiographie von BARTIER, ebd., nicht erwähnt. Seine Tochter heiratete Guy de Rochefort, den Bruder Guillaumes, ebd., S. 419. 
wenig optimistisch. Ferry de Clugny formulierte zweifelnd, Vurry breche auf "pour apaiser le conte palatin et le duc Louis, en Baviere, de part monseigneur, se faire se peut. «171. Nach den fruchtlosen Bemühungen Vurrys schaltete sich im Mai 1471 Markgraf Rudolf selbst in die Verhandlungen ein. Aber auch gemeinsam konnten Hachberg und Vurry auf einem weiteren Tag im Dezember kein Ergebnis erzielen ${ }^{172}$.

Im Januar 1473 gehörte Vurry zusammen mit Jean de Crö̈-Chimay, Guy de Brimeu, Ferry de Clugny und Montjeu der Delegtion an, die zu Friedensverhandlungen mit Ludwig XI. bevollmächtigt wurde ${ }^{173}$. Im Frühjahr 1474 verteidigte er vor der Stadt Köln die Interessen Burgunds und des Erzbischofs ${ }^{174}$. Wenige Monate darauf wurde er angewiesen, zusammen mit van der Noot und van der Ee Herzog Karl bei der Hochzeit des Matthias Corvinus mit Beatrix von Aragon zu vertreten. Am 15. August erhielt er dafür den ansehnlichen Vorschuß von $858 \mathrm{lb}$ und weitere $72 \mathrm{lb}$, um sich ein Gewand aus schwarzem Samt anfertigen zu lassen ${ }^{175}$. Während sich aber die Eheschließung des ungarischen Königs immer weiter hinauszögerte, erkrankte Vurry schwer und starb am 8. Dezember 1475. Der Herzog befahl daraufhin van der Noot und van der Ee, die Reise ohne einen Ersatz für Vurry anzutreten ${ }^{176}$.

b) Sekretäre und Schreiber

Die Sekretäre des Herzogs, die diplomatische Aufgaben in den Beziehungen zum Reich übernahmen, waren durchweg bürgerlicher Abkunft und hatten mehrheitlich ein Universitätsstudium absolviert ${ }^{177}$. Auch zur Zeit Karls des Kühnen galt noch, daß die Sekretäre durch ihre persönliche Nähe zum Herzog und ihre durch die Niederschrift der Dokumente erworbene genaue Kenntnis der Materien besonders für schwierige Verhandlungen geeignet waren. Ihr sozialer Status machte außerdem ein großes Gefolge überflüssig, so daß sie ohne besonderen materiellen Aufwand und verhältnismäßig diskret reisen konnten ${ }^{178}$. Für die Zeit Johanns Ohnefurcht konnten Schreiber nicht in diplomati-

171 Ferry de Clugny an Präsident und Rat von Dijon, 18.3.1471 Brüssel, Comines, ed. DuPONT, 3, S. 275-277.

172 Lille ADN B 2088/66 600.

173 PARAVICINI, Brimeu, S. 265 Anm. 66.

174 BARTIER, Légistes et gens de finances, S. 418.

175 Panigarola an Galeazzo Maria, 27.8.1475 Namur, SESTAN, Carteggi, 2, Nr. 342, S. 3640, und Lille ADN B 2105/67 594.

${ }^{176}$ Lille ADN B 17717, o. Fol.

177 Zur Diskussion um die Ausbildung der herzoglichen Sekretäre siehe COCKSHAW, Le personnel, S. 88f. m. Anm. 612; BARTIER, Légistes et gens de finances, S. 69; BORCHGRAVE, Diplomaten, S. 145f. COCKSHAW und BARTIER bezweifeln, daß fast alle Sekretäre studiert hatten, da nicht sicher ist, ob der Titel »maître« nur ein Ehrentitel war oder tatsächlich den Magister bezeichnete.

178 BORCHGRAVE, Diplomaten, S. 146-148. 
schen Funktionen nachgewiesen werden. Karl ernannte den Schreiber Lamberts van der Ee, Jean de Loo, als Entlohnung für die in Gesandtschaften geleisteten Dienste 1471 zum huissier von Brabant ${ }^{179}$.

\section{Thibault Barradot}

Thibault Barradot befand sich seit 1465 im Dienst des Grafen von Charolais ${ }^{180}$. Als einer der acht Sekretäre des Großen Rates, die jeweils zu viert halbjährlich ihren Dienst versahen, wurde er mit dem Titel des »maistre« belegt, ohne daß klar ist, ob es sich dabei um einen universitären Grad handelte. Seit 1474 war er Archivar (Garde des chartes) des Artois. 1482 ernannte ihn Maria zu einem der Meister der Rechenkammer ${ }^{181}$. Barradot begleitete Karl während des Neusser Feldzuges und wurde von ihm im Mai 1475 an den Herzog von Kleve gesandt, um die Herausgabe dringend benötigter burgundischer Pferde zu erreichen, die von klevischen Wirten bis zur Bezahlung des Unterhalts festgehalten wurden ${ }^{182}$. Herzogin Maria sandte Thibault im Januar 1477 zusammen mit Jacques de Dinteville zu Ludwig XI. ${ }^{183}$. Auf diese beiden Missionen scheint sich seine gesandtschaftliche Tätigkeit beschränkt zu haben. Sie zeigen deutlich den immer noch bestehenden ad-hoc Charakter des Gesandtenwesens und die umfassende Einsatzmöglichkeiten derjenigen, die täglich an den $\mathrm{Ge}-$ schäften in der unmittelbaren Umgebung des Herzogs beteiligt waren.

\section{Lambert van der Ee}

Der Sekretär Lambert van der Ee stammte wahrscheinlich aus Flandern oder Brabant ${ }^{184}$. Über seine Ausbildung ist bislang nichts bekannt. 1450 ist er als Sekretär der Kanzlei von Brabant belegt, seit 1451 als Audiencier von Brabant, eine Funktion, zu der er bereits 1449 in Nachfolge seines Bruders Adrien

179 Emennung am 17.9.1471 Abbeville, Brüssel AGR Chartes de l'Audience Nr. 1673, STEIN, Catalogue des Actes, Nr. 1214; BorCHGRAVE, Diplomaten, S. 150f.

180 COCKSHAW, Prosopographie des secrétaries, S. 3f.; BARTIER, Légistes et gens de finances, S. 53 Anm. 9. BonENFANT, STENGERS, Le rôle de Charles le Téméraire, S. $131 \mathrm{~m}$. Anm. 2. Er heiratete eine Brügger Partizierin und ließ sich in dieser Stadt nieder. Der Sohn Thibaults, Jean, war ebenfalls herzoglicher Sekretär und Sekretär Guy de Brimeus, ParavicINI, Brimeu, S. 430 Anm. 143. Vgl. auch SteIN, Catalogue des Actes, Index s.v. "Barradot, Jean« u. "Barradot, Thibault« zur Tätigkeit von Vater und Sohn als herzogliche Sekretäre.

181 CockSHAw, Le personnel, S. 192, 203. BonENFANT, STENGERS, Le rôle de Charles le Téméraire, S. $131 \mathrm{~m}$. Anm. 2.

$182 \mathrm{Karl}$ an Barradot, 11.5.1475 Lager vor Neuss, HStA Duisseldorf, Kleve-Mark, Beziehungen zu Geldern 31, ACO Dijon, Papiers Henri STEIN, Briefwechsel Nr. 3085.

183 PARAVICINI, Brimeu, S. 453.

184 Siehe den Abschnitt zu Lamberts Bruder Adriaan van der Ee in DAMEN, De staat van dienst, S. 456. 
van der Ee ernannt worden war ${ }^{185}$. Seit 1464 ist Lambert als Sekretär des herzoglichen Rates Woutre van der Noot bezeugt ${ }^{186}$. Am 24. Oktober 1467 ernannte der Herzog Lambert zu seinem Sekretär und zur gleichen Zeit van der Noot zu seinem Rat ${ }^{187}$. Im Juni 1474 bestellte er Lambert zum Sekretär des Parlaments von Mecheln ${ }^{188}$. Gemeinsam mit van der Noot nahm er von 1464 bis 1467 an den Verhandlungen mit dem Grafen von Katzenelnbogen in Köln unter der Vermittlung des Pfalzgrafen teil, die Ansprüche des Grafen auf alte burgundische Verbindlichkeiten aus Erbansprüchen auf das Herzogtum Luxemburg klären sollten. Fünf Reisen Lamberts, der sich in der Materie erhebliches Spezialwissen erwarb, sind in diesen Jahren nach Köln und zum Pfalzgrafen belegt. Zum letzten Mal wurde er im Juni 1472 mit einer Botschaft an den Pfalzgrafen gesandt ${ }^{189}$.

Von Juli bis Oktober 1473 führte er gemeinsam mit Halewin und Assendelft in Utrecht die Gespräche mit Vertretern der Hanse über Fragen des Handelsverkehrs und der Aussöhnung mit England. Unter anderem trug er die Entschädigungsansprüche burgundischer Untertanen gegen die Stadt Danzig vor, die sich aus der Kaperung der großen Karawelle Tommaso Portinaris ergaben ${ }^{190}$. Gemeinsam mit Woutre van der Noot wurde er im August 1475 mit der Begleitung Gérard Vurrys zu den Hochzeitsfeierlichkeiten des Königs von Ungarn beauftragt. Als Vurry im Dezember 1475 unerwartet verstarb, befahl Karl Woutre und Lambert, allein zu Matthias Corvinus zu reisen. Ob sie bei der schließlich im Dezember 1476 stattfindenden Hochzeit tatsächlich anwesend waren, ist allerdings nicht gesichert ${ }^{191}$.

\section{Charles Soillot}

Charles Soillot, geboren 1434, erhielt von seinem herzoglichen Taufpaten den Namen des Grafen von Charolais. Nachdem er seine Studien vollendet und die niederen Weihen empfangen hatte, wurde er 1459 herzoglicher Sekretär »si-

185 PARAVICINI, Brimeu, S. 326 Anm. 329. CoCKSHAW, Le personnel, S. 65 Anm. 452; Paul RENOZ, La Chancellerie de Brabant sous Philippe le Bon (1430-1467). Histoire et Organisation. Rédaction et Expédition des Actes, Brüssel 1955, S. 85.

186 Lille ADN B 2054 f.147r-v.

187 Tienen, 24.10.1467, Brüssel AGR Registre des chartes de la Chambre des Comptes de Brabant 134, f.60r; STEIN, Catalogue des Actes, Nr. 139.

${ }^{188}$ Brüssel, 27.6.1474, Brüssel AGR CC Brabant 134, f.154v, STEIN, Catalogue des Actes, Nr. 1897.

1891464 nach Köln: Lille ADN B 2054 f.147r-v. 13.6.-14.8.1465 zum Pfalzgrafen und Herzog Ludwig von Bayern: Lille ADN B 2061 f.179v, vgl. COCKSHAw, Le personnel, S. 178. Im Juni und Oktober 1466 zum Pfalzgrafen: Lille ADN B 2061 f.132r-v. Im September 1467 zum Pfalzgrafen: Lille ADN B 2064 f.284r. Juni 1472 an den Pfalzgrafen: Lille ADN B 2093/66 922 .

190 HR, 7, Nr. 34, S. 10; Lille ADN B 2064 f.284r.

191 Panigarola an Galeazzo Maria, 27.8.1475 Namur, SESTAN, Carteggi, 2, Nr. 342, S. 40; Lille ADN B 2105/67 594; Lille ADN B 17717, o. Fol. 
gnant en finances«. Möglicherweise war er Doktor des weltlichen Rechts. Neben dem Dekanat von Sankt Peter in Middelburg akkumulierte er weitere Pfründen mit einer päpstlichen Erlaubnis, die er während einer Gesandtschaftsreise nach Rom 1472 erwirkte. Er war einer der acht Sekretäre des GroBen Rates, die jeweils zu viert halbjährlich ihren Dienst versahen. Von August 1471 bis November 1488 amtierte er als Contrôleur des audiences und wurde 1491 Nachfolger Steenberghs als Schreiber des Ordens vom Goldenen Vlies. Seine Übersetzungen antiker Stoffe widmete er unter anderen auch Herzog Karl ${ }^{192}$.

1460 war Soillot als Mitglied einer Gesandtschaft an Karl VII. zum ersten Mal diplomatisch tätig. 1467 beauftragte ihn Karl mit Missionen zur Beilegung der Konflikte in Lüttich und zur Eintreibung der von den Lüttichern zu zahlenden Geldstrafen ${ }^{193}$. Im Frühjahr 1470 reiste er im Gefolge des Markgrafen von Baden-Hachberg und Guillaume de Rocheforts zu Herzog Sigmund, um im Namen Karls auf die Vorschläge des Herzogs von Tirol zu einer burgundischen Standeserhöhung zu antworten ${ }^{194}$.

\section{Martin Steenbergh}

Trotz seiner illegitimen Geburt gelang es Martin Steenbergh nach dem Studium in Löwen, eine Laufbahn als Stadtschreiber und öffentlicher Notar zu beginnen und bald darauf in den Dienst von Adolf von Kleve-Ravenstein zu wechseln. Er empfing die niederen Weihen und erhielt unter Herzog Philipp neben einer beachtlichen Anzahl weiterer Pfründen das Dekanat von SainteGudule in Brüssel ${ }^{195}$. In den herzoglichen Dienst trat er 1445 als stellvertretender Sekretär (Secrétaire remplaçant) und wurde 1454 als einer der Kanzleisekretäre während der Regentschaft des Grafen von Charolais geführt. Von 1445 bis 1467 bekleidete er außerdem das Amt des Sekretärs der Kanzlei von Brabant. Die nächsten Stufen der Karriereleiter waren die Ernennungen zum Sekretär signant en finances im Oktober 1462 und wenig später zu einem der

192 Albert COUNSON, "Soillot, Charles«, in: Biographie Nationale de Belgique, 23, 19211923, Sp. 111-114 ; COCKSHAW, Le personnel, S. 71-73, 185, 192, 196 ; DERS., Prosopographie des secrétaires, S. 52f. Zu den Pfründen s. JONGKEES, Staat en Kerk, S. 284f.; COCKSHAW, Le personnel, S. 146.

193 Cockshaw, Le personnel, S. 178. ParaviCINI, Brimeu, S. 128 Anm. 117, S. 167 m. Anm. 279. In der Angelegenheit der Geldstrafen reiste er im Dezember 1467 mit Potots und Jehan du Bois.

194 Instruktion in Comines, ed. LeNGLET, 3, Nr. 199, S. 238f.; Lille ADN B 338/16 240; Brüssel AGR CC 1925 f.263v-264r und GRÜNEISEN, Reichsstände, S. 55.

195 Steenbergh immatrikulierte sich 1443, Matricule de l'Université de Louvain, 153, 29. Cockshaw, Le personnel, S. 87 Anm. 602, S. 89 Anm. 615, S. 91, 146. PARAVICINI, Brimeu, S. 431 m. Anm. 144. JoNGKeES, Staat en Kerk, S. 283f.; COCKSHAW, Prosopographie des secrétaires, S. $53 f$. 
acht Sekretäre des Großen Rates. Von 1461/63 bis zum seinem Tod 1491 amtierte er als Schreiber des Ordens vom Goldenen Vlies ${ }^{196 .}$

Erste Erfahrungen im Gesandtschaftswesen konnte Steenbergh bereits ein Jahr nach seinem Eintritt in die herzogliche Kanzlei sammeln, als ihn Philipp der Gute 1446 mit der Teilnahme an einer Gesandtschaft an die englische Regierung der besetzten französischen Gebiete beauftragte. 1462 und 1463 hielt er sich zu Verhandlungen mit den Engländern in Calais auf und reiste in diesen Jahren auch nach Köln, um die Wünsche seines Herrn bei der Neubesetzung des dortigen Erzstuhls geltend zu machen ${ }^{197}$.

Unter der Herrschaft Herzog Karls legte Steenbergh seinen Schwerpunkt auf die Beziehungen zu den nordöstlichen Nachbarn der Niederlande. Im Frühsommer 1468 begab er sich zu den Herzögen von Kleve und Jülich zur Schlichtung strittiger Ansprüche ${ }^{198}$. Weitere Gesandtschaften in diese Regionen absolvierte er in seiner Eigenschaft als Ordensgreffier. Im September 1469 überbrachte er den Orden vom Goldenen Vlies an Eduard IV., im Mai 1473 zitierte er zusammen mit Simon de Lalaing die Ordensritter Herzog Adolf von Geldern und Herzog Johann von Kleve vor das Gericht des Herzogs von Burgund, der sich die Entscheidung in deren Streit um die Herrschaft in Geldern vorbehielt ${ }^{199}$. In den folgenden Monaten wurden die Angelegenheiten des Herzogtums Geldern zum hauptsächlichen Arbeitsgebiet Steenberghs. Er kollationierte sämtliche Urkunden, die zwischen Karl und Herzog Arnold im Zuge der Verpfändung Gelderns an Karl ausgefertigt wurden, und seine Anwesenheit bei den vorausgegangenen Verhandlungen darf als sicher angenommen werden ${ }^{200}$. Vorgesehen war schließlich seine Teilnahme an der von Trier aus im Oktober 1473 geplanten Gesandtschaft nach Rom unter Guy de Brimeu und Haneron. Am 1. Dezember 1473 erhielt Steenbergh den Reisebefehl, doch wird er sich wohl ebensowenig wie die übrigen vorgesehenen Gesandten auf den Weg über die Alpen gemacht haben ${ }^{201}$. Mit den Feldzügen Karls in Lothringen und Burgund versiegen die Nachrichten über die Teilnahme Steenberghs an Gesandtschaften in das Reich, da er wahrscheinlich zur Wahrnehmung seiner Ämter in den Niederlanden blieb.

\section{Jehan Stoop}

Der aus Brüssel gebürtige Jehan Stoop studierte seit 1429 an der Universität Löwen und trat als Schreiber des Sekretärs Dreux vander Vacquerien in die

196 CoCKSHAW, Le personnel, S. 96f., 115 Anm. 718, 185, 191 f., 196.

197 COCKSHAW, Le personnel, S. 177f., 196.

198 Brüssel AGR CC 1923 f. 89r-89v.

199 Geleitbrief, einschließlich einer Begleitung von 40 Personen vom 28.9.1469; vgl. RYMER, Foedera, 5, 2, S. 171 vom 18.9.1469; VAUGHAN, Charles, S. 60. REIFFENBERG, Histoire de l'Ordre, S. 86f.

${ }^{200}$ NIJHOFF, Gedenkwaardigheden, 4, Nr. 532-540.

201 PAQUET, Une ébauche de la nonciature, S. 127; PARAVICINI, Brimeu, S. 465 Anm. 68. 
Kanzlei von Brabant ein. 1447 stieg er zum Sekretär, 1463 zum Schreiber des herzoglichen Rates auf. Nach 1473 fungierte er als erster Rat des Rates von Geldern, Lehnstatthalter von Geldern und Zutphen und als Domänenkommissar $^{202}$.

Der Einsatz Stoops als Gesandter des Herzogs beschränkte sich ganz auf den Niederrhein und begann noch unter Philipp dem Guten, der ihn im Oktober 1465 zu Herzog Johann von Kleve sandte. Von Februar bis März 1466 begab er sich zusammen mit Johann von Halewin zu den Herzögen von Kleve und Geldern im Zuge der zahlreichen burgundischen Versuche, den Konflikt zwischen Arnold und Johann zu schlichten. Zu demselben Zweck suchte er wieder im Juni desselben Jahres zusammen mit Simon de Lalaing die Herzöge auf ${ }^{203}$.

\subsection{Fremde}

Zwei Geistliche, die weder aus den Landen des Herzogs gebürtig noch in ihnen bepfründet waren, dienten Karl als Unterhändler mit dem Kaiser vor allem während und nach dem Kölner Stiftskrieg. $\mathrm{Zu}$ ihnen ist für die Zeit nach dem Tode Cappacios Ende November 1475 noch Alexander Numai, Bischof von Forli, zu rechnen. Karl verzichtete während der Kriege in Lothringen und Burgund fast gänzlich auf die eigenen bewährten Gesandten, um die Wiederannäherung an den Kaiser und die Ehe Marias und Maximilians zu verhandeln. $\mathrm{Da} B$ er außerdem einen großen Teil dieser Gespräche in eigener Person führte, ist oben bereits deutlich geworden ${ }^{204}$. Der Einfluß, den in dieser Phase die um den Herzog im Heerlager versammelten Ratgeber auf den Verlauf der Gespräche hatten, ist nicht mehr greifbar. Es deutet jedoch viel darauf hin, daß sich Karl in der Gestaltung der Beziehungen zu Friedrich III. und dem hartnäckigen Festhalten am Traum von der Kaiserkrone zunehmend von seinen altgedienten Räten abschottete, deren Warnungen vor einem Krieg gegen die Eidgenossen er bekanntlich verwarf.

\section{Francesco Bertini, Bischof von Capaccio}

Francesco Bertini, gebürtig aus Lucca, studierte wahrscheinlich in Padua und schloß sich dort humanistischen Kreisen an. Seine gründliche Bildung trug ihm die rühmende Erwähnung in den Vite seines Freundes Vespasiano da Bisticci ein. Nach dem Empfang der Weihen sammelte er 1451 im Gefolge des

202 Matricule de l'Université de Louvain, 1, 81, 36; Archief van Huis Bergh, hg. v. SChILFGAARDE, 2, 1932, Nr. 265, S. 63; PARAVICINI, Guy de Brimeu, S. 125 Anm. 101a, S. 345f. COCKSHAW, Le personnel, S. 181; RENOZ, La Chancellerie, S. 57, 60, 86f. Er erhielt von den geldrischen Städten 1474 ein Geschenk von $80 \mathrm{lb}$, PARAVICINI, Brimeu, S. 350 Anm. 434.

203 1465: Lille ADN B 2058 f.111r. Februar-März 1466: Lille ADN B 2061 f.132v. Juni 1466: Lille ADN B 2061 f.91r-v.

204 Siehe oben S. $206 f$. 
Kardinals Bartolomeo Roverella in England erste diplomatische Erfahrungen. Durch die Protektion König Ferrantes von Neapel, dessen Vertrauter er wurde, gelangte Bertini 1465 auf das Bistum Andria und wurde 1471 zum Bischof von Capaccio geweiht.

Auf der Rückreise von England, wohin ihn Ferrante 1468 entsandt hatte, handelte Bertini ein Bündnis zwischen Burgund und Neapel aus, das am 1. November 1471 in Saint-Omer unterzeichnet wurde. Von nun an hielt sich Bertini beinahe ununterbrochen als Vertreter seines Herm am burgundischen Hof auf und bezeugte beispielsweise das am 8. Juni 1472 mit Venedig geschlossene Bündnis. Nach der Teilnahme am Tag von Trier kehrte er an den Hof von Neapel zurück, wo er von Ferrante den Auftrag empfing, die Ehe zwischen Maria von Burgund und dem Thronfolger Friedrich von NeapelAragon auszuhandeln ${ }^{205}$.

Unter den burgundischen Höflingen erwarb sich Bertini vor allem die Freundschaft Guy de Brimeus, der ihm wiederholt vertrauliche Mitteilungen zu seiner Einschätzung der herzoglichen Politik machte. Die entsprechenden Berichte des Bischofs sind allerdings zerstört und nur noch teilweise aus zweiter Hand zu rekonstruieren ${ }^{206}$. Im Juni 1474 äußerte Brimeu in Luxemburg Bertini gegenüber seine Kritik am Abschluß des einjährigen Waffenstillstands mit Ludwig XI., der die Belagerung von Neuss absichern sollte. Seiner Ansicht nach hätte zunächst der Krieg gegen Frankreich beendet werden müssen, bevor das burgundische Heer im Reich gebunden würde und die Niederlande dem Angriff des Königs schutzlos ausgeliefert wären ${ }^{207}$. Bertini gelang es in der folgenden Zeit, auch das Vertrauen des Herzogs zu gewinnen. Dieser bevollmächtigte den Bischof, der sich während der gesamten Kölner Stiftskrieges im burgundischen Lager aufgehalten hatte, im April 1475 zusammen mit Brimeu zu den Waffenstillstandsverhandlungen mit dem Kaiser. Die engen Verbindungen Bertinis mit Brimeu werden dazu beigetragen haben, daß letzterer auch nach dem Zug des Herzogs in das Elsaß und die Stammlande über die Verhandlungen mit dem Kaiser informiert wurde und sie beratend begleitete ${ }^{208}$. Der Herzog beauftragte Bertini auch mit den Friedensverhandlungen mit dem Kaiser, die in das Abkommen von Nancy vom 17. November 1475 mündeten. Bertini sah sich dabei auf kaiserlicher Seite dem päpstlichen Legaten

205 Ingeborg WALTER, »Bertini, Francesco«, in: Dizionario biografico degli Italiani, 9, Rom 1967, S. 540-542. ParavicINI, Brimeu, S. 91 Anm. 22, 465f. m. Anm. 69. Zu den burgundisch-neapolitanischen Beziehungen 1474-1476 Ernesto PONTIERI, Sulle mancate nozze tra Federico d'Aragona e Maria di Borgogna (1474-1476), in: DERS., Per la storia del Regno di Ferrante I d'Aragona Re di Napoli, Neapel, ${ }^{2} 1969$, S. 161-208.

206 Siehe BITTMANN, Ludwig XI., 1, 1, S. 570-73, S. 575 Anm. 86, S. 584, 2, 1, S. 85 Anm. 104, S. 233-37, 247, 249.

207 BITTMANN, Ludwig XI. 2, 1, S. 233f., in Auszügen und englischer Übersetzung bei Vaughan, Charles, S. 288-290.

${ }^{208}$ PARAVICINI, Brimeu, S. 471-476 m. Anm. 82-90. 
Alexander Numai, Bischof von Forlì, gegenüber ${ }^{209}$. Die Ratifizierung des Vertrages erlebte Bertini nicht mehr, da er am 22. oder 23. November 1475 starb $^{210}$. Zum Abschluß der Verhandlungen mit dem Kaiser ernannte Karl seinerseits am 31. Januar 1476 den Bischof von Forli zu seinem Bevollmächtigten, während Friedrich III. durch Georg Heßler vertreten wurde211.

Agostino de Lignana, Abt von Casanova

Aus Piemont stammend, war Agostino de Lignana, Abt von Casanova und Saint-Claude, den Eidgenossen und vor allem der Stadt Bern eng verbunden. 1471 traten ihre Bürger für die Wahl Casanovas zum Bischof von Lausanne ein. Einig zeigte sich die Familie Lignana mit den Eidgenossen auch in der Feindschaft zum Herzog von Mailand, die mit der Gefangennahme Galeazzo Marias durch die Brüder Lignana 1466 während seiner Rückkehr aus Frankreich nach dem Tod Francesco Sforzas einen Höhepunkt erreichte. Seine Laufbahn als Diplomat begann Agostino im Dienst Herzogs Amadeus VIII. von Savoyen, für dessen Papstwahl auf dem Basler Konzil er sich nachdrücklich einsetzte ${ }^{212}$. Etwa seit dieser Zeit beschränkte sich der Abt nicht mehr auf den Dienst am savoyischen Hof. Er verkörperte nun weniger den Typ des »Mitunternehmers $\&^{213}$ am Fürstenhof als denjenigen eines Dienstleistungsanbieters, der sein diplomatisches Können unter Wahrung der eigenen Interessen denjenigen Fürsten zur Verfügung stellte, die ihm am nützlichsten waren. Charakteristisch war sein Auftreten am Kaiserhof als päpstlicher Gesandter, ohne $\mathrm{da} B$ er eine Vollmacht des Papstes besssen hätte. Der Zwischenfall trug ihm das dauernde Mißtrauen der Kurie ein²14.

Zwei Brüder Agostinos, Antonio und Pietro, standen seit Oktober 1472 als Söldnerführer im Dienst Karls, Antonio außerdem als Rat und Kammerherr. Wahrscheinlich wurde der Herzog im Zuge der Verhandlungen mit Antonio und Pietro über ihr militärisches Dienstverhältnis auf Agostino aufmerksam und erkannte ihn als geeigneten Vertreter burgundischer Interessen vor allem gegenüber den Eidgenossen. Der Abt wurde nun gleichfalls zum Rat er-

209 PARAVICINI, Brimeu, S. 474 Anm. 85f.; CHMEL, Aktenstücke 1, 1, S. 125-130. Zu Numai siehe auch Richard WALSH, Diplomatic Aspects of Charles the Bold's Relations with the Holy See, in: Bijdragen en Mededelingen betreffende de Geschiedenis der Nederlanden 95 (1980) S. 265-278, hier S. 266f.

210 Panigarola an Galeazzo, 24.11.1475 Nancy, SESTAN, Carteggi, 2, Nr. 376, S. 121.

211 CHMEL, Aktenstücke 1, 1, S. 133. In der Friedensurkunde Friedrichs III. vom 31.1.1476 Wiener Neustadt wird Bertini als Unterhändler noch einmal erwähnt, Regesten Friedrichs III., 7, bearb. v. Thomas KRAUS, 1990, Nr. 571, S. 297.

212 SESTAN, Carteggi, 1, Nr. 209, S. 347 Anm. 1.

213 Nach MORAW, Von offener Verfassung, S. 171.

214 Jacobus Trottus an Borso d'Este Herzog von Mantua, 22.9.1469 Rom, Deutsche Reichstagsakten, 22,1, hg. v. Ingeborg MOST-KolBE, S. 63f. Nr. 19 g). Siehe dazu WALSH, Charles the Bold and the crusade, S. 74f. 
nannt215. Gleichzeitig wählte Karl ihn als seinen Unterhändler bei Friedrich III. aus. Am 5. Juni 1472 stellte der Abt eine Quittung über $306 \mathrm{lb}$ aus, die ihm zur Ausrüstung für seine bevorstehende Gesandtschaft zum Kaiser gezahlt wurden. Dabei wird es sich um die gleiche Reise gehandelt haben, die ihn im Auftrag Karls auch zu den Eidgenossen führte und in deren Verlauf er außerdem Herzogin Yolanthe von Savoyen aufsuchte, von deren Hof er Ende Juni oder Anfang Juli an Guillaume de Rochefort brieflich Bericht erstattete216.

Casanova stieß offenbar sofort nach seiner Verpflichtung durch Karl zur Partei um Rochefort und den Kanzler Hugonet, die den Ausgleich mit den Eidgenossen suchte und mit der Entsendung Casanovas an den Kaiserhof im Juni 1472 einen vorläufigen Sieg über die Schweizerfeinde um Hagenbach errang. Ein zweites Mal suchte der Abt im Juni 1473 die Eidgenossen im Auftrag Karls auf, um ihnen eine Allianz mit Burgund vorzuschlagen, die in Ausweitung des Bündnisses von 1467 alle Orte umfassen und sich gegen Mailand wenden sollte ${ }^{217}$. Das Vertrauen der Eidgenossen in Casanova war offenbar trotz seiner Dienste für den Burgunderherzog auch in den 1470er Jahren nicht erschüttert worden. Im November 1473 bat ihn Bern, sich bei Karl für die Stadt Mülhausen zu verwenden und den Empfang einer eidgenössischen Gesandtschaft beim Herzog vorzubereiten. Karl ordnete zu dieser Zeit in Trier eine nochmalige Vermittlungsmission des Abtes zwischen Herzog Sigmund und den Eidgenossen an, um die Kriegsforderungen des Österreichers abzuwehren ${ }^{218}$.

Der zweite Schwerpunkt der gesandtschaftlichen Tätigkeit Casanovas lag in den Beziehungen zu Friedrich III. In der zweiten Novemberhälfte 1472 kehrte der Abt vom Kaiser zu Karl nach Abbeville zurück. Mit weiteren Instruktionen verlie $\beta$ er die Niederlande im Dezember wieder in Richtung Graz ${ }^{219}$. Im Vorfeld des Treffens von Trier wurde er zu zwei aufeinanderfolgenden Gele-

215 RoDT, Die Feldzüge Karls des Kühnen, 1, S. 162f.; Aliprando an Galeazzo Maria, 31.12.1472 Brügge, SESTAN, Carteggi, 1, Nr. 183, S. 305 m. Anm. 10; Panigarola an Galeazzo Maria, 26.1.1476 Besançon, SESTAN, Carteggi, 2, Nr. 395, S. 167. Vaughan, Charles, S. 216. Rat: CHMEL, Aktenstücke 1, 1, S. 16.

216 Quittung: Lille ADN B 2096/67 169; Instruktion an die Eidgenossen: RoDT, Die Feldzüge Karls des Kühnen, 1, S. 161f. Brief vom Hof Yolanthes: Karl an Herzogin Yolanthe, 18.7.1472 Lager bei Beauvais, Briefwechsel Nr. 2112. Vgl. HEIMPEL, Karl der Kühne, S. 12 m. Anm. 18; BITTMANN, Ludwig XI., 2, 1, S. 444.

217 Kredenz Karls für Casanova vom 1.6.1473 Maastricht, Briefwechsel Nr. 2294; VAUGHAN, Charles, S. 275.

218 Bern an Casanova, 27.11.1473, Bern StA Lateinische Missiven A f.222r, nach GRÜNEISEN RTA-Material. Bern an Casanova, 28.12.1473, Bern StA Deutsche Missiven C 167, nach GRÜNEISEN RTA-Material. Wien HHStA Hs weiß $558 \mathrm{f} .121 \mathrm{v}-122 \mathrm{v}$, nach GRÜNEISEN RTA-Material, teilweise gedruckt bei CHMEL, Aktenstücke, 1, 1, S. 45-49. Quittung des Abtes von Casanova vom 21.10.1473 über $26 \mathrm{lb}$ für Kleidung für die Reise zu den Eidgenossen: Lille ADN B 2096/67 170.

${ }^{219}$ Comines, ed. Lenglet, 3, 1747, S. 371; CHMEL, Aktenstücke, 1, 1, S. 16 f. 
genheiten zu Reisen an den Kaiserhof bevollmächtigt. Auch wenn die entsprechenden Instruktionen nicht erhalten sind, kann davon ausgegangen werden, daß die Fragen der Königskrone und der Ehe im Mittelpunkt standen. Dafür spricht auch die Anweisung an Hagenbach von Anfang 1473, seinen Vortrag vor dem Kaiser in Gegenwart Casanovas zu halten ${ }^{220}$.

Im Zusammenhang der italienischen Verbindungen des Herzogs begegnet Casanova im Februar 1476, als ihm Herzog Galeazzo Maria gegen das Versprechen Karls, für das Wohlverhalten der Lignanas einzustehen, einen Geleitbrief und Verzeihung gewährte. Im folgenden Oktober sandte Karl den Abt in "geheimer und sehr wichtiger Angelegenheit" sogar direkt an Galeazzo221. In beiden Fällen wird es sich um die Werbung italienischer Soldkompanien und die Bitte um mailändische Waffenhilfe gehandelt haben; und, parallel zu den Bemühungen Montjeus und Rocheforts, auch um ein Bündnis mit Venedig. Auch wenn Karl mit Rochefort, Montjeu oder den Clugnys über Gesandte verfügte, denen er rückhaltloser vertraute als dem Abt, so kann insgesamt doch dem Urteil Vaughans zugestimmt werden, daß er "one of the duke's most trusted and experienced diplomats « war ${ }^{222}$.

\section{Die Gesandten als Gruppe}

\subsection{Geographische Herkunft}

Die Betrachtung der geographischen Herkunft der Gesandten, die für Herzog Karl das Reich bereisten, bestätigt die Feststellung Bartiers, daß in der Verwaltung der herzoglichen Länder die Burgunder aus der Freigrafschaft und dem Herzogtum dominierten ${ }^{223}$. Von den vierundzwanzig in die Übersicht aufgenommenen Gesandten waren ein Drittel, nämlich Barradot, die Brüder

220 CHMEL, Aktenstiucke 1, 1, S. 34.

221 Galeazzo an Panigarola, 28.2.1476 Pavia, SESTAN, Carteggi, 2, Nr. 435, 436, S. 241f.; Panigarola an Galeazzo, 17.3.1476 Lausanne, ebd., Nr. 470, S. 297f.; Panigarola an Galeazzo, Mailand 19.10.1476, ebd., Nr. 651, S. 677f. Nach Galeazzos Aussagen in einem Schreiben an einen Unbekannten hatte er dem Abt bereits vor 1474 auf dessen dringende Bitten hin Verzeihung gewährt, Vigevano, 24.2.1474, SESTAN Carteggi, 1, Nr. 209, S. 347.

222 VAUGHAN, Charles, S. 216.

${ }^{223}$ BARTIER, Légistes et gens de finances, S. 46-50; CoCKSHAW, Le personnel, S. 17; Werner PARAVICINI, Structure et fonctionnement de la cour bourguignonne au $\mathrm{XV}^{\mathrm{e}}$ siècle, in: Jean-Marie CAUCHIES (Hg.), À la cour de Bourgogne. Le duc, son entourage, son train, Turnhout 1998, S. 1-8, hier S. 6f., zuerst in: Jean-Marie CAUCHIES (Hg.), Milan et les Etats bourguignons: deux ensembles politiques princiers entre Moyen Age et Renaissance, Basel 1988, S. 67-74. Bei BORCHGRAVE, Diplomaten, findet sich keine Analyse der geographischen Herkunft der Gesandten. 
Clugny, Hugonet, Montjeu, Rochefort, Potots und Vurry, aus den burgundischen Stammlanden gebürtig. Halewin, Stoop, van der Noot und wahrscheinlich auch van der Ee stammten aus Flandern, Brimeu, Haneron und wohl auch Miraumont aus dem Artois. Assendelft war in Holland beheimatet, was auch für Steenbergh wahrscheinlich ist.

Vier Gesandte, Johann von Nassau, Espach, Hagenbach und BadenHachberg, waren aus dem Reich oder dem südwestlichen Grenzraum gebürtig. Der Tradition entsprechend wurden sie hauptsächlich in die Gegend ihrer Herkunft gesandt224. Mit einem Sechstel war ihr quantitativer Anteil an der Gestaltung der Beziehungen zum Reich nicht sehr groß. Trotzdem waren sie, vor allem Nassau und Baden-Hachberg, angesichts ihrer Sprachkenntnisse und der Vertrautheit mit den politischen und personellen Gegebenheiten an den Zielorten nicht zu ersetzen. Weder Nassau noch Baden-Hachberg gehörten zum innersten Kreis der herzoglichen Räte, die an der Gestaltung der Beziehungen zum Kaiser maßgeblich mitwirkten, auch wenn sie mit bedeutenden Verhandlungen mit anderen Reichsständen beauftragt wurden. Hagenbach hingegen, dessen soziale und auch persönliche Qualifikationen sich nicht mit denen Baden-Hachbergs und Nassaus messen konnten, wurde von Karl im Vorfeld des Trierer Tages wiederholt zu Gesprächen mit Friedrich III. bevollmächtigt. Die kleine Gruppe der deutschsprachigen Gesandten demonstriert damit eindringlich die Neigung Karls, unbedingte Loyalität über fachliche Eignung zu stellen.

\subsection{Soziale Herkunft}

Wie unter Johann Ohnefurcht stellte auch unter Karl der Adel einen erheblichen Anteil an der Gesamtheit der Gesandten, nämlich elf der hier untersuchten vierundzwanzig. Dabei wurden, wie bereits angedeutet, die juristisch Ausgebildeten, Montjeu und Rochefort, bei weitem am häufigsten beansprucht. Sämtliche adligen Gesandten waren Räte und Kammerherren des Herzogs. Sie vereinigten in sich den erforderlichen sozialen Status und die Kenntnisse des Zeremoniells, beides unverzichtbare Elemente der höfischen Kommunikation $^{225}$.

Die hier untersuchten vier Geistlichen waren sämtlich bürgerlicher Abkunft, ebenso wie erwartungsgemäß die fünf Sekretäre und die Räte Amerongen, Potots und Vurry sowie der Kanzler Hugonet. In ihrer Bedeutung für die herzogliche Diplomatie hielten sich Adel und Bürgerliche also in etwa die Waage. Bezeichnend für den Herrschaftsstil des Herzogs ist, daß elf der Gesandten,

${ }^{224} \mathrm{Zu}$ Ausländern in diplomatischen Diensten eines Herrschers am englischen Beispiel Amd REITEMEIER, Ritter, Königstreue, Diplomaten - Deutsche am englischen Hof, in: ZhF 24 (1997) S. 1-23; BORCHGRAVE, Diplomaten, S. 157.

225 BORCHGRAVE, Diplomaten, S. 45, 94, $119 \mathrm{f}$. 
nämlich Brimeu, Hagenbach, Baden-Hachberg, Montjeu, Rochefort, Hugonet, Ferry de Clugny, Haneron, Potots, Vurry und Barradot, Karl bereits als Graf von Charolais gedient hatten, ihm also seit geraumer Zeit vertraut waren und ihre Loyalität bewiesen hatten ${ }^{226}$. Rechnet man die nicht ursprünglich in den Umkreis des Hofes gehörigen Bertini und Lignana ab, so stellten die alten Diener des Herzogs sogar einen Anteil von 50\%.

\subsection{Ausbildung}

Der Bildungsstand der herzoglichen Gesandten war hoch. Von den vierundzwanzig Männern hatten siebzehn, also gut zwei Drittel, nachweislich eine Universität besucht. Von diesen hatte ein Drittel weltliches oder geistliches Recht oder beide studiert, und aus dieser Gruppe wiederum führten sechs den Titel eines Doktors in einem oder beiden Rechten. Von den fünf hier in Betracht kommenden Sekretären hatten vier die Universität besucht. Alle diplomatisch tätigen Geistlichen hatten geistliches oder weltliches Recht studiert und stellten so erwartungsgemäß die Gruppe mit dem höchsten Ausbildungsgrad.

Unter den Adligen war der Anteil der Studierten erheblich niedriger, von elf adligen Gesandten hatten nur vier ein Studium absolviert. Montjeu und Rochefort als Doktoren der Rechte allerdings nahmen im Gesandtschaftswesen des Herzogs herausragende Positionen ein. Alle diejenigen, die eine traditionell höfische Erziehung genossen hatten, beherrschten mindestens zwei Sprachen, Brimeu Französisch und Latein, Hagenbach, Baden-Hachberg und Johann von Nassau Französisch und Deutsch.

Über die Sprachkenntnisse der übrigen Gesandten lassen sich keine gesichterten Aussagen treffen. Im Verkehr mit dem Reich ist in der Regel davon auszugehen, daß sich die Gesandten aus dem romanischen Sprachraum, ebenso wie die Engländer, des Lateinischen bedienten, wenn sie nicht Deutsch sprachen $^{227}$. Es gab jedoch auch Gelegenheiten, zu denen man den offiziellen Charakter lateinisch geführter Gespräche vermeiden wollte. Als Karl noch als Graf von Charolais 1466 durch die Vermittlung Graf Ludwigs von Helfenstein mit Kurfürst Friedrich von Brandenburg in Verhandlungen über eine Ehe mit dessen Tochter eintrat, bat der Graf um die Entsendung von Deutsch sprechenden Gesandten. Karl antwortete, daß er lediglich zwei des Deutschen mächtige Herolde zur Verfügung habe, nämlich Rupelmonde und Charolais,

${ }^{226} \mathrm{Vgl}$. Holger KRUSE, Hof, Amt und Gagen. Die täglichen Gagenlisten des burgundischen Hofes (1430-1467) und der erste Hofstaat Karls des Kühnen (1456), Bonn 1996, Index der auf den Gagenlisten des Grafen von Charolais erscheinenden Personen, S. 313-326.

227 Joyceline G. RUSSELL, Diplomats at Work. Three Renaissance Studies, Gloucester 1992, S. 3, 21 . 
die beide abwesend seien. Peter von Hagenbach werde bei der Belagerung Dinants gebraucht. Er bat Helfenstein deshalb, selbst einen Gesandten zu schikken $^{228}$. Die Kapazitäten an deutschsprachigem Personal, die dem burgundischen Thronfolger zur Verfügung standen, waren also sehr begrenzt. Sie erweiterten sich in der Herzogszeit Karls jedoch beispielsweise durch den Herold Namur, der den Pfalzgrafen während seines Besuchs 1467 begleitete ${ }^{229}$.

\subsection{Die Häufigkeit der Einsätze}

Die Anzahl der Einsätze zu Gesandtschaften schwankte zwischen einer einzigen Mission und etwa zehn selbständigen Reisen, wobei die Aufträge an Montjeu und Rochefort nach Savoyen, zu den Eidgenossen und nach Italien teilweise nicht eindeutig einer einzelnen Mission und einem einzigen Zielort zuzuordnen sind. Die Genannten weisen zusammen mit Rudolf von BadenHachberg, Haneron und Hagenbach mit jeweils acht bis zehn Einsätzen die höchste Anzahl von Gesandtschaften in das Reichsgebiet auf. Auf sie folgt ein Mittelfeld aus Lignana, van der Ee, Espach, van der Noot und Vurry mit vier bis sieben Reisen und die große Gruppe derjenigen, die nur zu einer bis drei Gelegenheiten in gesandtschaftlichen Kontakt mit dem Reich kamen, nämlich Johann von Nassau, Miraumont, Barradot, Assendelft, Halewin, Potots, Soillot, Bertini, Steenbergh und Stoop. Im Vergleich zur Regierungszeit Johanns Ohnefurcht sank der Anteil derjenigen, die nur eine bis drei Gesandtschaften ausführten, von etwa $70 \%$ auf unter $50 \%$, die personelle Kontinuität war also dementsprechend größer ${ }^{230}$. Die Gruppe der führenden Diplomaten blieb aber weiterhin klein, der Großteil der Reichsgesandtschaften unter Herzog Karl wurden von etwa fünf Männern getragen.

Diese Beobachtungen dürfen allerdings nicht zu der Annahme verleiten, da $B$ mit Montjeu, Rochefort, Hagenbach und Haneron die Entscheidungsträger in den jeweils anstehenden reichspolitischen Fragen vorzustellen sind oder auch, $\mathrm{daB}$ nur diese Männer mit Verhandlungen von Bedeutung betraut wurden. Zum einen wurde bereits in den Abschnitten zu Guy de Brimeu und Ferry de Clugny angedeutet, $\mathrm{da} B$ die engsten Berater des Herzogs in die Reichspolitik eingebunden waren, ohne selbst als Gesandte tätig zu sein. Andererseits beauftragte Karl auch solche mit entscheidenden Verhandlungen, die bis dahin nur wenig Erfahrung in der burgundischen Reichspolitik gesammelt hatten, wie Francesco Bertini. Die Entscheidungsstrukturen am burgundischen Hof und die Zufälle der jeweiligen Verfügbarkeit einzelner Gesandter und der Vorlie-

$228 \mathrm{Karl}$ an Ludwig von Helfenstein, 7.7.1466 St. Quentin, RIEDEL, Codex Diplomaticus Brandenburgensis, 3, 1, Nr. 271, S. 393; Briefwechsel Nr. 417.

229 Siehe oben S. 105 f.

${ }^{230}$ BORCHGRAVE, Diplomaten, S. $92 \mathrm{f}$. 
ben des Herzogs brachten es mit sich, daß sich personelle Kontinuitäten für bestimmte Aufgaben und Zielregionen der burgundischen Diplomatie zwar entwickeln konnten, aber bei weitem nicht immer bewußt aufgebaut oder aufrechterhalten wurden.

\subsection{Die Auswahl der Gesandten} und die Zusammensetzung der Gesandtschaften

Die Spezialisierung eines Gesandten auf ein oder mehrere Zielländer war ein im mittelalterlichen Gesandtschaftswesen und auch unter den Vorgängern Karls seit langem verbreitetes Phänomen ${ }^{231}$. Durch die Anhäufung von Wissen über das Zielland, die Gepflogenheiten des dortigen Hofes und seines Fürsten konnten diese Gesandten das Fehlen eines Archivs und anderer geregelter Informationsquellen teilweise kompensieren, ohne da $B$ jedoch ihre Kenntnisse der Kanzlei oder anderen Gesandten systematisch nutzbar gemacht worden wären. So wurde beispielsweise Hagenbach 1473 angewiesen, wegen seiner Unkenntnis des Kaiserhofes seinen Vortrag vor Friedrich III. zunächst mit dem Abt von Casanova zu besprechen und ihn dann in dessen Anwesenheit zu halten, da dieser mit den dortigen Verhältnissen vertraut war. Guillaume de Rochefort unterrichtete Anfang 1475 Panigarola über den burgundischen Hof und sicherte sich so die Dankbarkeit des Mailänders ${ }^{232}$.

In den Reichsbeziehungen unter Herzog Karl sind für eine Anzahl der Gesandten Spezialisierungen zu beobachten. In enger Verbindung mit ihrer Heimatprovinz oder den dort von ihnen bekleideten Ämtern engagierten sich Assendelft und Halewin in den Verhandlungen der holländischen Provinzen und des Herzogs mit den Hansestädten und dem Hansekontor zu Brügge. Ebenso waren Steenbergh und Stoop auf Einsätze im Gebiet des Niederrheins beschränkt. Eine beachtliche regionale und personelle Kontinuität entwickelte sich für einige Jahre in den Beziehungen der Herzöge Philipp und Karl zum Pfalzgrafen, die von van der Noot, van der Ee, Vurry und zeitweilig von Baden-Hachberg getragen wurden. Die Erklärung hierfür liegt für die frühe Zeit in den stark finanztechnisch bestimmten Verhandlungen um die Entschädigung für den Grafen von Katzenelnbogen, die den Einsatz nicht eingearbeiteter Personen unpraktikabel machten.

Von der Konzentration einzelner Gesandter auf eine Zielregion kann in gröBerem Umfang bei Baden-Hachberg, Montjeu, Rochefort, Hagenbach und Ca-

231 REITEMEIER, Außenpolitik im Spätmittelalter, S. 367-370; BORCHGRAVE, Diplomaten, S. 101.

232 Hagenbach: CHMEL, Aktenstücke 1,1, S. 34. Rochefort: Panigarola an Galeazzo, 23.2.1475 Rochefort bei Dôle, SESTAN, Carteggi, 1, Nr. 250, S. 412. Panigarola an Galeazzo, 9.2.1475 Turin, ebd., Nr. 246, S. $405 f$. 
sanova gesprochen werden. Baden-Hachberg und Hagenbach befaßten sich jeweils aufgrund der eigenen Herkunft beziehungsweise ihres Amtes intensiv mit den Beziehungen zu den Eidgenossen und Herzog Sigmund. Die Kontakte zu den italienischen Herrschern wurden in der Hauptsache von Rochefort und Montjeu getragen, wobei Rochefort, wie Casanova, maßgeblich das Verhältnis zu den Eidgenossen und Savoyen pflegte. Montjeu schließlich wurde beinahe zu allen Reichsständen entsandt, mit denen der Herzog Beziehungen pflegte. Es fällt auf, daß in den Verhandlungen mit Friedrich III., deren Ergebnisse für Karl langfristig von der größten Tragweite waren, keine signifikante personelle Kontinuität zu erkennen ist. Auf den Reichstagen von 1472 und 1474 durch Montjeu und Baden-Hachberg vertreten, beauftragte der Burgunder zu den direkten Gesprächen mit dem Kaiser Haneron, Johann von Nassau, Casanova, Hagenbach, Espach und schließlich Bertini und den Bischof von Forlì. Von diesen waren wiederum nur Haneron und Hagenbach bei den Trierer Verhandlungen Teil des engen herzoglichen Beraterkreises.

Sieht man außerdem von den in Trier von Karl aufgewandten ungeheuren Kosten ab, ging der gesandtschaftliche Kontakt mit den Reichsständen ohne nennenswerten repräsentativen Aufwand vonstatten. Im Vergleich zu den Delegationen, die Karl zu den Königen von England und Frankreich entsandte, waren diejenigen an die Reichsstände eher klein. Die Reichstage wurden lediglich mit jeweils zwei Doktoren, Baden-Hachberg und Montjeu, beschickt. Bündnisverhandlungen mit dem Pfalzgrafen, dem Herzog von Bayern oder dem Erzbischof von Mainz wurden von zwei oder drei Gesandten geführt, die auch mit ihrem Gefolge kein außergewöhnlich repräsentatives Bild abgegeben haben können. Gleiches gilt für die Gesandtschaften zum Kaiser.

Baden-Hachberg und Johann von Nassau waren als Reichsgrafen die höchstrangigen Gesandten, die für Karl im Reich Verhandlungen führten. Derart aufwendige Reisen wie die Bastard Antons nach England 1467 oder nach Italien 1475 aber gab es in das Reich nicht, und keiner der Angehörigen des führenden romanischen Hofadels oder der burgundischen Bischöfe war an den Verhandlungen über das römische Königtum und die Ehe vor und nach dem Tag von Trier beteiligt. Betrachtet man dagegen die Delegationen, die der Herzog zu Ludwig XI. und Eduard IV. sandte, ist der Unterschied merklich: Mit dem französischen König verhandelten regelmäßig der Kanzler Hugonet, Guy de Brimeu, Philippe de Crèvecoeur, Philippe de Croÿ-Chimay und der Bischof von Tournai, Ferry de Clugny. Damit sind nur die bedeutendsten Teilnehmer dieser Delegationen genannt, die sich vor allem um den Abschluß von Waffenstillständen und Friedensabkommen mit Ludwig XI. bemühten ${ }^{233}$.

${ }^{233}$ Im folgenden seien wichtige burgundische Delegationen nach Frankreich genannt. 1465: Thibault de Neufchâtel, Pierre de Bauffremont Graf von Charny, Jean de Neufchâtel Herr von Montagu, Johann IV. Herr von Crécquy, Johann Bastard von Luxemburg Herr von Haudbourdin, Louis le Jeune Herr von Contay, Guillaume Bische, Gérard Vurry, Guillaume 
Die burgundisch-englischen Beziehungen gestalteten sich mit den Vorbereitung zur Heirat Karls und Margaretes, der Flucht Eduards IV. in die Niederlande 1470/71, den anschließenden Allianzen gegen Ludwig XI. und der Brüskierung Karls durch Eduard in Picquigny wechselhafter als die stetige Wiederkehr von Krieg und Diplomatie im Verhältnis zu Ludwig XI. Von 1465 bis 1469 wurde unter beiderseitigem hohem personellen Aufwand sowohl in England wie in den Niederlanden verhandelt. Karl beauftragte an führender Stelle Ludwig von Brügge Herm von Gruuthuse, Johann von Halewin, Ferry de Clugny, Pierre de Miraumont und nicht zuletzt seine Mutter, Herzogin Isabella. Die Höhepunkte dieser Periode bildeten der mit größtem Pomp gestaltete Besuch Bastards Anton in England im Frühjahr 1467, die Überbringung des Ordens vom Goldenen Vlies an Eduard im September 1469 und die Hochzeit mit Margarete im Juni 1468234. Die an die Rückkehr Eduards nach England anschließenden Geheimverhandlungen um die antifranzösische Allianz wurden zunächst auf der Ebene der Sekretäre und Räte geführt, bis sie wieder von Bastard Anton im Juli 1474 abgeschlossen wurden ${ }^{235}$. Um im August 1475

Hugonet, Jean Carondelet: Comines, ed. LENGLET, 2, Nr. 66b, S. 507-509. Januar 1466: Philippe de Crèvecoeur, Guyot d'Usie, Hugonet: Paris BNF Ms fr 5041 f.43r. November 1466 bis Februar 1467: Ferry de Clugny, Thibault de Neufchâtel, Jean Carondelet, Guyot d'Usie: Lille ADN B 2064 f.61r-v. Anfang 1470: der Johann IV. Herr von Crécquy, Jean Carondelet, Jean Meurin: PlanCHER, Histoire, 4, S. 263-267. 1471: Ferry de Clugny: PlancheR, Histoire, 4, S. 308-311. Oktober 1472: Johann Graf von Marle-Luxembourg, Philippe de Croÿ-Chimay, Guy de Brimeu, Antoine Rolin Herr von Aymeries: BARANTEGACHARD, Histoire des ducs de Bourgogne, 2, 1838, S. 727. März 1473: Hugonet, Brimeu, Bische: Paris BNF Ms fr 5041 f.164r-171v. Februar/Mai 1473: Ferry de Clugny, Philippe de Croÿ-Chimay, Arthur de Bourbon: PLANCHER, Histoire, 4, S. 321f. Ende 1473/Anfang 1474: Hugonet, Ferry de Clugny: Paris BNF Ms fr 6980 f.253r-v. März 1474: Philippe de Crö̈Chimay, Ferry de Clugny: Lille ADN B 2105/67 598. Juni 1474: Hugonet, Brimeu, Arthur de Bourbon, Charles Soillot: PLANCHER, Histoire, 4, S. 335f. Sommer 1476: Ferry de Clugny, Philippe Pot Herr von la Roche, Jehan Gros: PLANCHER, Histoire, 4, S. 364f.; Lille ADN B 2111/67994.

234 Die Verhandlungen von 1465-1467 wurden teilweise in Saint-Omer und Calais sowie in England geführt von Bastard Anton, Ludwig von Brügge Herr von Gruuthuse, Simon de Chasteller, Josse de Halewin, Pierre de Miraumont, Alart de Rabodenghes, André Colin, Louis du Chesne und George Bul: Brüssel AGR CC 1924 f.374v-375r, RYMER, Foedera, 5, 1741, S. 142; Brüssel AGR CC 1923 f.112r-v. Reise Bastard Antons im Frühjahr 1467: siehe z.B. Lille ADN B 2064 f.121r-124r, 140v-141r. Oktober-Dezember 1467: Simon de le Kerrest: Brüssel AGR CC 1923 f.279r. Oktober 1467: Olivier de la Marche: STEIN, Olivier de la Marche, S. 169. November 1467 und Mai 1468: Ferry de Clugny: Lille ADN B 2064 f.394r-v, Brüssel AGR CC 1923 f.114r-v. September 1469: Guillaume Fillastre und Pierre Vasque mit einem Gefolge von 50 Personen; Jean de Crécquy und Martin Steenbergh mit einem Gefolge von 40 Personen: RYMER, Foedera, 5, 1741, S. 171 f.

235 Sommer 1471: Simon de le Kerrest: Lille ADN B 2086/66 322. Ende 1472: Lupo da Garda, Nicolas Bouesseau: Lille ADN B 2093/66 862. Dezember 1472-Mai 1473: Volpart von Amerongen, George Baert: Lille ADN B 2105/67 597. Frühjahr 1473: Lupo da Guarda: Lille ADN B 2097/67 294. Juli 1474: Bastard Anton, Pierre de Miraumont, Antoine Gérard: Lille ADN B 2105/67 594, VAUGHAN, Charles, S. 340. 
schließlich seinen Verbündeten davon abzuhalten, kampflos französischen Boden zu verlassen, entsandte Karl in dessen Lager seine führenden Räte Ferry de Clugny, Philippe de Croÿ-Chimay und Philippe de Crèvecoeur ${ }^{236 .}$

Dieser kurze Überblick macht deutlich, daß der romanische Hofadel unter Karl dem Kühnen für die Pflege der Beziehungen zu den Reichsständen dem Herzog wenig geeignet schien und sich auch selbst in dieser Richtung kaum engagierte. Seine traditionelle politische und kulturelle Ausrichtung band ihn an Frankreich. Diese überkommene Orientierung spiegeit sich in der Zusammensetzung der Gesandtschaften, die in das Reich wesentlich inhomogener waren als an die großen westlichen Höfe. Nach Frankreich und England reisten häufig Delegationen aus drei oder mehr hohen Adligen und Bischöfen, während die typische Gesandtschaft in das Reich nur aus ein bis zwei, bürgerlichen oder adligen, Räten oder Sekretären bestand. Mit Ausnahme Simon de Lalaings, der einige Male an den Herzog von Kleve gesandt wurde, also an einen Fürsten, der eigentlich schon zum burgundischen Hof gerechnet werden konnte, wurde in der gesamten Regierungszeit Karls kein einziger Ritter des Goldenen Vlieses mit einer Gesandtschaft in das Reich beauftragt. Die Zersplitterung des Reiches in viele mehr oder weniger mächtige Herrschaftsträger und ihr im Vergleich zu den westlichen Nachbarn wenig glanzvolles höfisches Leben regte nicht zu besonderen repräsentativen Anstrengungen an.

Erschwerend kam in den letzten drei Regierungsjahren Karls seine permanente Abwesenheit von den nördlichen Ländern und damit von den Sitzen der wichtigsten stationären Verwaltungsorgane hinzu. Einerseits stand ihm während der Feldzüge in Burgund und Lothringen das gewöhnlich vorhandene Reservoir an Sekretären und Räten aus praktischen Gründen nicht mehr im vollen Umfang zur Verfügung, andererseits war ein nicht unerheblicher Teil dieser Personen in der Verwaltung der zurückgelassenen Lande gebunden. Als Beispiel ist hier nur der faktisch bestehende Regentschaftsrat der Niederlande unter der Herzogin, Bastard Anton und Guy de Brimeu zu nennen. Hier mag ein zusätzlicher Grund für die Verwendung der Bischöfe von Capaccio und Forlì gelegen haben, die den finanzpolitisch und militärisch vollauf beschäftigten Räten Karls eine willkommene Entlastung gewesen sein könnte. Schließlich führte Karl, wie bereits angedeutet, einen großen Teil der Verhandlungen mit dem kaiserlichen Gesandten Heßler in den Heerlagern in Lothringen und Burgund 1475 und 1476 allein. Den Abschluß des Ehevertrages mit dem Kaiser wollte der mißtrauische Herzog wohl keinem seiner Räte mehr anvertrauen. 


\subsection{Entscheidungsfindung}

Zwei Problemkreise der burgundischen Außenbeziehungen lassen die Hofparteien erkennen, die auf die Entscheidungen in der Reichspolitik Einfluß zu nehmen suchten. Der Schoßstreit zwischen dem Hansekontor zu Brügge und der Stadt Köln einerseits und das Verhältnis zu Österreich und den Eidgenossen andererseits polarisierten den burgundischen Hof auffallend gleichartig. Über die Parteinahmen im Schoßstreit sind wir durch die Berichte des Kölner Vertreters Johann Zeuwelgin unterrichtet, der sehr bald Guillaume Bisches, den Kanzler Pierre de Goux und Johann von Luxemburg für die Sache Kölns gewinnen konnte ${ }^{237}$. Zwischen 1468 und 1470 rechnete man in Köln auch Bastard Anton, Montjeu, Rochefort, Fillastre und Hugonet zu den Freunden der Stadt238. Im März 1472 bedankte diese sich bei Hugonet und Fillastre für den Entscheid des Großen Rates zugunsten Kölns ${ }^{239}$. Unter den Gegnern Kölns sind neben Pierre Bladelin und Jan van Schoonhoven ${ }^{240}$ vor allem Antoine Haneron und Peter von Hagenbach von Interesse, die sich bereits 1468 auf die Seite des Erzbischofs gegen die unbotmäßige Stadt stellten ${ }^{241}$.

Diese Parteiungen finden sich beinahe identisch in der Frage des Verhältnisses zu Savoyen, Italien, Herzog Sigmund von Tirol und den Eidgenossen wieder. Die Bemühungen Hagenbachs vom Herbst 1472, den Herzog durch Gilgenberg von der Notwendigkeit des Krieges gegen die Eidgenossen zu überzeugen, scheiterten an der Obstruktion der Partei um den Kanzler Hugonet und Guillaume de Rochefort. Unbelastet von dem traditionellen $\mathrm{HaB}$ auf die Eidgenossen, den Hagenbach mit dem sundgauischen Adel und Herzog Sigmund teilte, waren die allesamt dem romanischen Adel angehörigen Mitglieder dieser Partei der Ansicht, daß ein Krieg gegen die Eidgenossen unbedingt vermieden werden mußte, um den burgundischen Einfluß auf Savoyen nicht zu gefährden. Dominanz in Savoyen wiederum war die Voraussetzung für die Lösung Mailands aus der französischen Allianz ${ }^{242}$. Die Haltung Hanerons in dieser Frage ist nicht belegt, aber angesichts seiner engen Kooperation mit

237 HUB, 9, Nr. 376, S. 237f. Zu Goux außerdem ebd. Nr. 390, S. 251 ; Nr. 393, S. 252f.; zu Bische ebd. S. 251 Anm. 3. Goux und Bische erhielten von Zeuwelgin als Geschenk Silberkannen, ebd. Nr. 399, S. 259; Nr. 401, S. 262; Nr. 405, S. 265. Johann von Luxemburg: ebd. Nr. 423, S. 278.

${ }^{238}$ HUB, 9, Nr. 425, S. 281; Nr. 613, S. 513, 515; Nr. 784, S. 690.

239 HR, 2, 6, Nr. 510, S. 473f.

${ }^{240}$ HUB, 9, Nr. 376, S. 237f.; Nr. 613, S. 510; zu Schoonhoven DAMEN, De staat van dienst, S. 490; zu Bladelin Jean-Marie CAUCHIES, Deux grands commis bâtisseurs de villes dans les Pays-Bas bourguignons: Jean de Lannoy et Pierre Bladelin (vers 1450/60), in: De Jacques Cour à Renault. Gestionnaires et organisations, Toulouse 1995, S. 45-59.

241 HUB, 9, Nr. 425, S. 281.

242 BITTMANN, Ludwig XI., 2, 1, S. 443f. Der Ansicht BRAUER-GRAMMs, Hagenbach, S. 202, daß Gilgenberg Rochefort für die Sache Sigmunds zu vinteressieren« vermochte, kann ich nicht folgen. 
Hagenbach in der Frage des Basler Bistums und in dem Bemühen, Mülhausen unter burgundische Herrschaft zu zwingen, liegt die Vermutung sehr nahe, daß er nicht gegen die Absichten des Landvogtes bei Karl arbeitete.

Der Vorsto $ß$ Hagenbachs und Gilgenbergs bei Karl folgte nicht lange nach der ersten Bevollmächtigung des Abtes von Casanova im Juni 1472 als Gesandter des Herzogs an den Kaiser, Herzogin Yolanthe von Savoyen und die Eidgenossen. Ende Juni oder Anfang Juli erstattete der Abt Rochefort schriftlich Bericht über den Fortgang seiner Verhandlungen, so daß es naheliegt, hinter der Ernennung Casanovas Rochefort und Hugonet zu vermuten ${ }^{243}$. Casanova als Savoyarde mußte ihnen als idealer Vertreter ihrer Interessen erscheinen und seine Entsendung durch Karl als Sieg über Hagenbach. Der Einfluß Hagenbachs gewann allerdings in Folge der Vorstellungen Gilgenbergs bei Karl wieder an Boden und wurde in der Ernennung Hagenbachs zum Gesandten an den Kaiser zu Beginn des Jahres 1473 offenkundig ${ }^{244}$. Der Herzog wollte sich nicht auf eine der beiden vertretenen Strategien vollständig einlassen und begünstigte sie im Wechsel.

Nimmt man zu diesen Beobachtungen die Aussagen Brimeus gegenüber Bertini bezüglich seiner Ablehnung des Engagements im Reich und des Waffenstillstands mit Frankreich, so wird deutlich, da $B$ sich schon sehr bald nach dem Herrschaftsantritt Karls zwei Lager von recht unterschiedlichem numerischen Gewicht gebildet hatten. Die romanische Partei unter der Führung Hugonets, Rocheforts und Brimeus wandte sich dem traditionellen Konflikt mit dem französischen König zu und verfolgte die Annäherung an Mailand. Ihr gehörte ein großer Teil des einflußreichen Hofadels an, unter anderem auch Bastard Anton, und sie setzte die von Philipp dem Guten überkommene Politik der Frankreichorientierung, wenn auch mit den von Karl vorgegebenen feindlichen Vorzeichen, in den Grundzügen fort. Die Gegenpartei, als deren Exponent vor allem Hagenbach deutlich greifbar wird, kam im Gefolge Karls an den Hof und stützte dessen Ambitionen auf Expansion im Reich und Annäherung an das Haus Habsburg. Hagenbach erreichte sein langgehegtes Ziel, Karl zum Krieg gegen die Eidgenossen zu bewegen, jedoch paradoxerweise erst nach und in gewisser Weise in Folge seiner Hinrichtung. Da Karl in Übereinstimmung mit den Wünschen der Hugonet-Rochefort Fraktion von einem Engagement zugunsten Herzog Sigmunds absah, wandte sich der Habsburger der antiburgundischen Allianz zu und durchkreuzte so letztlich die Planungen beider Parteien.

${ }^{243}$ Quittung: Lille ADN B 2096/67 169; Instruktion an die Eidgenossen: RoDT, Die Feldzïge Karls des Kühnen, 1, S. 161f. Brief vom Hof Yolanthes: Karl an Herzogin Yolanthe, 18.7.1472 Lager bei Beauvais, Briefwechsel Nr. 2112. Vgl. HeIMPEL, Karl der Kühne, S. 12 m. Anm. 18; BITTMANN, Ludwig XI., 2, 1, S. 444.

244 Comines, ed. LENGLET, 3, 1747, S. 371; CHMEL, Aktenstücke, 1, 1, S. 16 f. 
Trotz der quantitativen Überlegenheit der romanischen Partei um den Kanzler, die diejenige Hagenbachs auch sozial-qualitativ dominierte, kann nicht von einer beherrschenden Stellung dieser Gruppe in den Fragen der Außenbeziehungen gesprochen werden. Die Entscheidungsfindung in diesem Bereich war nach wie vor dem Herzog und dem ihm beratend zur Seite stehenden Kanzler und Großen Rat vorbehalten ${ }^{245}$. In den Beziehungen zu Kaiser und Reich trat außerdem die Neigung Karls zur Selbstregierung besonders deutlich hervor, und seine Entscheidungen deuten darauf hin, daB er sie weitgehend unabhängig von den Parteiinteressen seines Hofes traf. Diese Beobachtungen bestätigen die Nachricht Wielants, Karl habe sich stets die Meinungen seiner Ratgeber angehört, seine Entscheidungen dann aber nach seinem eigenen Gutdünken, und meist konträr zu den Ansichten seiner Räte, gefälltt246. Die Gesandten selbst waren an die meist sehr ausführlich gehaltenen Instruktionen gebunden, über deren Erfüllung sie nach ihrer Rückkehr dem Herzog persönlich Bericht erstatteten. Die Eigenschaft als Gesandter berechtigte zu keinerlei Einfluß auf die Gestaltung der Verhandlungen. Es konnte auch vorkommen, $\mathrm{da}$ der Große Rat oder einer der Provinzräte einem Gesandten Instruktionen ausstellten, allerdings ist dann von ausführlichen Anweisungen des Herzogs an das betreffende Gremium auszugehen. So werden vor allem praktische Erwägungen eine Rolle gespielt haben, als 1474 der herzogliche Rat in Dijon die Instruktion an Montjeu für dessen Verhandlungen mit der Herzogin von Savoyen verfaßte ${ }^{247}$. Da der Inhalt der Instruktionen von der Genehmigung des Herzogs abhängig war, lag es an der jeweiligen Position der Hofpartei, der sich der Gesandte zurechnete, inwieweit die Anweisungen in seinem Sinne ausfielen ${ }^{248}$.

Wenn sich also über den eigentlichen Proze $B$ der Entscheidungsfindung keine sicheren Aussagen machen lassen, und die Indizien darauf hindeuten, daß der Herzog die Richtlinien der Reichspolitik weitgehend allein bestimmte ${ }^{249}$, so sind doch die Wege erkennbar, die man beschreiten mußte, um auf Karl und seine nächste Umgebung Einfluß zu nehmen. Wie üblich an einem Fürstenhof war die Nähe zum Herrscher oder wenigstens die Nähe zu denen, die Zutritt zu ihm hatten oder ihn kontrollierten, von größter Wichtigkeit. Einhergehend mit der steigenden Bedeutung des Zeremoniells im 15. Jahrhundert

245 Zur außenpolitischen Entscheidungsfindung in England unter Heinrich IV. siehe REITEMEIER, Außenpolitik im Spätmittelalter, S. 128-142, bes. S. 137f. Auch Heinrich IV. ließ sich in außenpolitischen Fragen nicht von den Meinungen seiner Räte bestimmen, sondern entschied nach ihrer Anhörung eigenständig.

246 BARTIER, Légistes et gens de finances, S. 35f.; BORCHGRAVE, Diplomaten, S. 5 If; VAUGHAN, Charles, S. 167.

${ }^{247}$ Paris BNF Ms fr 18983 f.29r-v; BoRCHGRAVE, Diplomaten, S. 98-100.

$248 \mathrm{Vgl}$. oben die Sendung Casanovas an den Kaiser oder die von Haneron veranlaßte Instruktion für Hagenbach bezüglich des Basler Bistums.

249 PARAVICINI, Karl der Kühne, S. 39. 
wurden Distanz und Nähe zum Fürsten zu Mitteln der Hierarchisierung 250 . Machtausübung war damit an den Zutritt zu Räumen gebunden, und unter diesen war die Privatkammer des Herzogs der entscheidende. Die Hofordonannzen Karls lassen bereits Versuche erkennen, eine Hierarchisierung der Räume in Form einer Zimmerflucht vorzunehmen, um die Nähe zum Herrscher zu reglementieren. Die Kontrolle des Zugangs zum Herzog war deshalb eine lukrative Einnahmequelle.

Ein Unzufriedener beklagte 1468, daß eine Audienz bei Karl nur über seinen Günstling, den »mignone de camera«, zu erlangen war ${ }^{251}$. Panigarola verwandte einen ansehnlichen Anteil seiner Zeit und Ressourcen darauf, Kontakte mit der unmittelbaren Umgebung des Herzogs zu knüpfen und zu pflegen. Eine Krise trat für den Mailänder mit dem Tod seines bisherigen Vertrauten ein, des italienischen Arztes Matteo di Troya. Nun galt es, sich das Wohlwollen der potentiellen Nachfolger zu sichern. Panigarola wählte mit geübtem Blick vier Männer von unterschiedlicher Herkunft und Funktion aus, die ihm bei jeweils verschiedenen Anliegen behilflich sein konnten. Es waren der portugiesische Arzt Lupo, der Sekretär Jean Coulon (»Colombo«), der Herr von Contay Louis le Jeune und der Türhüter Heinrich von Antwerpen. Ein ganz ähnliches Vorgehen schilderte auch Johann Zeuwelgin an seine Auftraggeber nach Köln ${ }^{252}$. Umgekehrt gewährte der Herzog die Nähe zu seiner Person als einen besonderen Gunstbeweis. Zeuwelgin wurde beispielsweise mit der Zulassung zum levée im »heymlichen gemach« und zur Morgenmesse im herzoglichen Oratorium ausgezeichnet ${ }^{253}$.

Auch auf dem Gebiet der Außenbeziehungen deutet damit viel auf einen autokratischen Regierungsstil des Herzogs hin, der dem Rat seiner Umgebung wenig Beachtung schenkte. Zum Ende seiner Regierungszeit scheint Karl die Verhandlungen mit den Gesandten Friedrichs III. weitgehend allein geführt zu haben. Ebenso wie diese Beobachtungen sprechen auch die Ergebnisse der vorangegangenen Kapitel dafür, daß sich der Herzog damit letztlich überforderte und den Anforderungen einer umsichtigen und den Realitäten angepaßten Reichspolitik nicht gerecht werden konnte.

250 PARAVICINI, Einleitung, in: DERS. (Hg.), Zeremoniell und Raum, S. 12, 23.

${ }^{251}$ Die Klage kam von einem Diener des Grafen von Saint-Pol. Bei dem Günstling handelte es sich wahrscheinlich um Guillaume Bische. Panigarola an Galeazzo Maria, 16.6.1468 Schloß Braie Comte Robert bei Paris, Paris BNF Ms it 1649 f.182r. Vgl. PARAVICINI, Ordre et règle, S. 333-335.

252 Panigarola an Galeazzo Maria, 15.3.1476, Lausanne, und ders. an dens., 28.7.1476 La Rivière, SESTAN, Carteggi, 2, Nr. 468, S. 292; ebd., Nr. 644, S. 659f. Zeuwelgin: HUB, 9, Nr. 423.

253 HUB, 9, Nr. 399, 423. Zum herzoglichen Oratorium s. PARAVICINI, Einleitung, in: DERS. (Hg.), Zeremoniell und Raum, S. 24. 


\section{Die Geschenke}

Das Geben und Empfangen von Geschenken war integraler Bestandteil des diplomatischen Verkehrs, eingebettet in das »europaweit geltende Empfangssystem des 15 . Jahrhunderts ${ }^{254}$. Öffentliche und private Audienz, die je nach politischer und privater Wertschätzung gewährt wurden, die folgenden Verhandlungen mit dem Fürsten und/oder seinem Rat und schließlich die Abschiedsaudienz bildeten den Rahmen für den Austausch von Gaben ${ }^{255}$, die im gesandtschaftlichen Kontext ihre spezifische Bedeutung erhielten. Bot die Empfangsaudienz den Gesandten die Möglichkeit, mitgebrachte Gaben dem Adressaten zu überreichen, war in der Regel die Verabschiedung der Diplomaten der Zeitpunkt, zu dem die Geschenke an ihren Auftraggeber und sie selbst übergeben wurden 256 .

Gabe und Gegengabe gehören zu den Kommunikationsmitteln, deren sich der gesandtschaftliche Verkehr seit jeher mit Vorliebe bedient hat. In Anleh-

254 Werner PaRAVICINI, Einleitung, in: DeRs. (Hg.), Alltag bei Hofe, 3. Symposium der Residenzen-Kommission der Akademie der Wissenschaften in Göttingen, Sigmaringen 1995, S. 16; REITEMEIER, Außenpolitik, S. 435-447, bes. S. 446f.; MENZEL, Gesandtschaftswesen, S. 147-150.

255 Der Terminus »Geschenk“ ist erst mit dem Entstehen der bürgerlichen Geschenkkultur des 18. Jahrhunderts in der heutigen Verwendung belegt, für die vorangegangene Zeit ist "Gabe« der adäquate Terminus, Helmuth BERKING, Schenken. Zur Anthropologie des Gebens, Frankfurt a.M., New York 1996, S. 17; Jürgen HANNIG, Ars donandi. Zur Ökonomie des Schenkens im früheren Mittelalter, in: GWU 37 (1986) S. 150. Siehe zur Geschenkpraxis des Spätmittelalters Carol M. CHATTAWAY, Looking a medieval gift horse in the mouth. The role of giving of gift objects in the definition and maintenance of the power networks of Philip the Bold, in: Bijdragen en Mededelingen 114 (1999) S. 1-15. Jan HIRSCHBIEGEL, Gabentausch als soziales System? Einige theoretische Überlegungen, in: EWERT, SEL.ZER (Hg.), Ordnungsformen des Hofes, S. 44-55. Unter Heranziehung statistischer Methoden: Ulf Christian EWERT, Jan HIRSCHBIEGEL, Gabe und Gegengabe. Das Erscheinungsbild einer Sonderform höfischer Repräsentation am Beispiel des französisch/burgundischen Gabentausches zum neuen Jahr um 1400, in: VSWG 87 (2000), S. 5-37. Jan HIRSCHBIEGEL, Étrennes. Untersuchungen zum höfischen Geschenkverkehr im spätmittelalterlichen Frankreich zur Zeit König Karls VI. (1380-1422) am Beispiel der Neujahrsgeschenke, Diss. phil. Ms., Kiel 1997, demnächst Pariser Historische Studien 60, voraussichtlich 2002.

Im Folgenden werden beide Begriffe, Geschenk und Gabe, gebraucht. Vage im Sinne der angesprochenen Definitionen ist die Terminologie der burgundischen Quellen, insbesondere der Rechnungslegung. In ihr werden Sach- und Geldzuwendungen fast jeder Art, seien es Kompensationen für ausgefallene Gagen oder Pensionen, über die hier untersuchten Geschenke an Gesandte bis hin zu Tauf- oder Hochzeitsgeschenken, als don bezeichnet.

256 BUMKE, Höfische Kultur, S. 314f.; Werner PARAVICINI, Von der Heidenfahrt zur Kavalierstour. Über Motive und Formen adligen Reisens im späten Mittelalter, in: Horst BRUNNER, Richard WOLF (Hg.), Wissensliteratur im Mittelalter und in der frühen Neuzeit, Wiesbaden 1993, S. 91-130, hier S. 106f. Vgl. die Verweigerung der Übergabe des Silbergeschirrs bei der Verabschiedung der burgundischen Gesandten an Charles de France, unten S. 279. 
nung an Soziologie und Rechtsethnologie kann der mittelalterliche Geschenkverkehr mit Althoff ${ }^{257}$ als eine Form der rituellen Kommunikation betrachtet werden, die in vorstaatlichen Vergesellschaftungsstufen eine ebenso erhebliche Rolle spielten wie im Zusammenleben der sog. "modernen« Gesellschaften. Gregor von Tours sah im Gabentausch eine Standesqualität des Adels, deren Regeln der demonstrativen Verschwendung es zu beherrschen galt. Giselbert von Mons berichtete, Friedrich Barbarossa habe auf dem Mainzer Hoffest 1184 Geschenke "pro suis proprii nominis fama dilatanda" verteilt ${ }^{258}$. Schon diese Nachrichten aus dem frühen und hohen Mittelalter zeigen, daß es sich beim Gabentausch um eine Form der öffentlichen Inszenierung handelte, die Geber und Nehmer auf das durch die Gabe definierte Verhältnis öffentlich verpflichtete. Die Gabe fungierte als Zeichen, das eine stabilisierte (oder veränderte) Ordnung anzeigte. Diese grundlegende Funktion des Kommunikationsmittels behielt das Geschenk auch im späten Mittelalter ${ }^{259}$.

Die Gabe als Indikator sozialer und politischer Beziehungen war ein Ausdrucksmittel der Ehre. Daher besa B derjenige, der in der Lage war, Ehre derart zu verteilen oder vorzuenthalten, in aller Regel ökonomische und politische Macht - er war der Fürst. Oder wie es der Songe du Vergier formulierte: »Les Roys et les Impereurs sont donataires, et par conséquent ils sont seigneurs. $\ll^{260}$. Der Fürst, der Gebende, schrieb nach dem Grundsatz, daß Geben stets ehrenvoller (»seliger «) denn Nehmen sei261, die bestehende Hierarchie fort oder veränderte sie, so weit möglich, nach seinen Vorstellungen, indem er sich die

257 Gerd ALTHOFF, Einleitung, in: DERS., Spielregeln der Politik im Mittelalter, Kommunikation in Friede und Fehde, Darmstadt 1997, S.9, nach dem sich Untersuchungen der Rechtsethnologie sog. primitiver Gesellschaften »über weite Strecken wie eine Beschreibung mittelalterlicher Verhältnisse auf diesem Gebiet火 lesen.

258 Gregor von Tours, Historia Francorum, 2, 20 u. 4, 29, nach HANNIG, Ars donandi, S. 150. Giselbert von Mons, Chronicon Hanoniense, La chronique de Gislebert de Mons, hg. v. Léon VANDERKINDERE, Brüssel 1904, S. 155-157.

259 ALTHOFF, Einleitung, in: Spielregeln der Politik im Mittelalter, S. 11. Ebd. auch zur Diskussion um die mittelalterliche Öffentlichkeit. Speziell zu den Stadtgesellschaften des Spätmittelalters Valentin GROEBNER, Angebote, die man nicht ablehnen kann. Institution, Verwaltung und die Definition von Korruption am Ende des Mittelalters, in: R. BLÄNKNER, B. JUSSEN (Hg.), Institution und Ereignis. Über historische Praktiken und Vorstellungen gesellschaftlichen Ordnens, Göttingen 1998, S. 163-184; Valentin GROEBNER, Flüssige Gaben und die Hände der Stadt. Städtische Geschenke, städtische Korruption und politische Sprache am Vorabend der Reformation, in: Klaus SCHREINER, Gabriela SIGNORI (Hg.), Bilder, Texte, Rituale. Wirklichkeitsbezug und Wirklichkeitskonstruktion politisch-rechtlicher Kommunikation in Stadt- und Adelsgesellschaften des späten Mittelalters, Berlin 2000 S. 17-34, bes. S. 18 .

${ }^{260}$ Marion SchNerb-Lievre (Hg.), Le Songe du Vergier, 1-2, Paris 1982, hier: 2, S. 123; vgl. Alain GUERY, Le roi dépensier. Le don, la contrainte, et l'origine du système financier de la monarchie française d'Ancien Régime, in: Annales 39 (1984) S. 1241-1269, hier S. 1243.

261 In Anlehnung an eine Formulierung Werner Paravicinis, Paris, anläßlich der Tagung »Négocier le Don - Negotiating the Gift« am DHI Paris, 11.-13. Dezember 1998. 
Empfänger immer weiter verpflichtete. Gabe und Gegengabe, die sich nicht rational gegeneinander aufrechnen ließen, waren also "Inbegriff aristokratischen Wirtschaftens, subtiles Mittel der Hierarchisierung«262. Sie waren das "zentrale, die Binnenstruktur des Adels als Gruppe charakterisierende Medium $«$, das »Beziehungszeichen par excellence ${ }^{263}$. Auch die aufkommende Bürokratie des späten Mittelalters vermochte seinen Einsatz nicht einzuschränken, obwohl es durch seine hohen Kosten den Fürsten immer wieder in emste finanzielle Bedrängnis brachte ${ }^{264}$.

Hiermit werden die herrschaftserhaltenden Mechanismen des Gabentausches im allgemeinen, d. h. im wesentlichen im innerhöfischen Kontext angesprochen, doch interessiert im folgenden der Bereich der zwischenhöfischen Kontakte. Untersucht wird, inwieweit sich Herzog Karl und seine Zeitgenossen im zwischenfürstlichen Geschenkverkehr von den Grundsätzen der Reziprozität leiten ließen, und in welchem Verhältnis Repräsentation, Tradition und der Versuch der Hierarchisierung bei den Geschenken des Fürsten an die Gesandten standen. Auch der Gabentausch zwischen den Fürsten fungierte als Stabilisator bestehender Verhältnisse und damit als Mittel der Konfliktregulierung ${ }^{265}$, was in verkleinertem Maßstab auch für die Behandlung der jeweiligen Gesandten am fremden Hof galt. Es ist also davon auszugehen, da $B$ der Faktor der Ehre im diplomatischen Geschenkverkehr eine mindestens ebenso große, wenn nicht noch größere Rolle spielte als im innerhöfischen, da der Fürst sich hier in seiner »Gesamtheit« nach außen repräsentierte, daß aber gleichzeitig der unmittelbare Nutzen der Gabe für die Macht des Fürsten geringer war. In den zwischenhöfischen Beziehungen mußten Teile des Beziehungsgeflechtes eines fremden Hofes, die Gesandten oder der Fürst selbst, erreicht und beeinflußt werden. Das Ergebnis dieser Bemühungen wiederum wurde erst in den Entscheidungen der dortigen höfischen Elite, nämlich des Fürsten und seines Rates, sichtbar.

Wird im Folgenden die Dichte des Gabentausches zwischen den Höfen als Indikator der gegenseitigen Wertschätzung und des Stellenwertes der zwischenhöfischen Kontakte gewertet, so muß die lückenhafte Quellenlage stets im Blick behalten werden. Das Fehlen der Rechnungen des Argentiers seit 1471 ist gerade auf dem Gebiet der Geschenke schmerzlich. Als Ersatz wur-

262 PARAVICINI, Einleitung, in: Alltag bei Hofe, S. 18.

263 BERKING, Schenken, S. 189.

264 PARAVICINI, Einleitung, in. Alltag bei Hofe, S. 19f. Zur hierarchisierenden Funktion des Gabentausches zwischen Fürsten vor allem im früheren Mittelalter ALTHOFF, Demonstration und Inszenierung, S. 244f. Zu den (vergeblichen) Versuchen der Republik Venedig, die Kosten für Empfang fremder Gesandter durch Limitierung der an sie gestatteten Geschenke zu kontrollieren siehe Donald E. QUELLER, Early Venetian Legislation on Ambassadors, Genf 1966, S. 54.

${ }^{265}$ GUERY, Le roi dépensier, S. $1242 f$. 
den die erhaltenen pièces comptables herangezogen ${ }^{266}$. Zusammengenommen erlaubt diese Quellengrundlage jedoch einen Vergleich des burgundischen Geschenkwesens, wie es jeweils gegen das Reich, Italien, Frankreich und England praktiziert wurde.

\subsection{Freier Wille oder Zwang?}

Die Theorie sieht das Charakteristikum der Gabe im Gegensatz zur Bezahlung in der Offenheit der durch sie initiierten Beziehung, deren Endpunkt ebensowenig kalkulierbar sei wie die Erwiderung auf die aktuelle Gabe ${ }^{267}$. Diese Beobachtung trifft den hier untersuchten historischen Kontext nur teilweise, besaß doch auch im ausgehenden 15. Jahrhundert das »Gesetz der erwiderten Gabe ${ }^{268}$ weiter seine volle Gültigkeit. Das Wirken des Gesandten und der dafür zu erwartende Lohn durch den aufgesuchten Fürsten hatten nur noch wenig von der Offenheit einer durch Gabentausch eingeleiteten Beziehung. Der verhältnismäßig hohe Grad an Stereotypierung der Geschenke an Gesandte wird im folgenden deutlich. Trotzdem mußte, um die Fiktion des ehrenhaften, weil freiwilligen Gebens aufrecht zu erhalten, die Realität von Gabe und Gegengabe, Erwartung und Verpflichtung, ignoriert werden ${ }^{269}$. Dieser Zwang wurde besonders in den Beziehungen zwischen den Fürsten empfunden, da hier die Sensibilität hinsichtlich der Demonstration von Rang und Macht, die die Gabe leicht zu einem »aggressiven Akt $^{270}$ machen konnte, ungleich größer war als zwischen Fürst und Gesandtem.

So sah sich Francesco Sforza veranlaßt, seine Geschenke an Ludwig XI., edle Pferde und eine Rüstung, durch seinen Gesandten dezidiert nicht als Gaben und Geschenke ("presente e dono«), sondern als Zeichen der Liebe (»uno signo de amore «) beschreiben zu lassen ${ }^{271}$. Durch den Wechsel der semantischen Ebene vom Geben hin zur Liebe wurden in Verwendung des Bescheidenheitstopos die Gaben an den König einerseits als unwürdig dargestellt, an-

266 Siehe oben S. 20.

267 BERKING, Schenken, S. 24.

268 Werner PARAVICINI, Die Preußenreisen des europäischen Adels, 2, Sigmaringen 1995, S. 126. Zur Praxis des besonders von den Städten erzwungenen Geschenks anläßlich der Hochzeiten des burgundischen Adels und der hohen Amtsträger siehe Werner PARAVICINI, Invitations au mariage. Pratique sociale, abus de pouvoir, intérêt de l'état à la cour des ducs de Bourgogne au $\mathrm{XV}^{e}$ siècle, in: Académie des Inscriptions et Belles-Lettres. Comptes rendus des séances (1995) S. 687-711, sowie mit Quellenedition als: Invitations au mariage. Pratique sociale, abus de pouvoir, intérêt de l'état à la cour des ducs de Bourgogne, 13971478. Documents introduits, édités et commentés, Stuttgart 2001 (Instrumenta, 6).

${ }^{269}$ BERKING, Schenken, S. 191-195, am Beispiel des »Welschen Gast« des Thomasin von Zirklaere.

270 Vgl. zum Schenken als aggressivem Akt BERKING, Schenken, S. 22.

271 Francesco Sforza an Panigarola, 9.8.1465, MANDROT, Dépêches, 3, S. 343f. Anm. 2. 
dererseits die besondere Beziehung der beiden Fürsten hervorgehoben, die dem Kreislauf der Reziprozität bereits enthoben sei. Wenige Jahre später sprach der Sohn Francescos in einem Schreiben an seine Gesandten bei Herzog Karl, in einem für den hofinternen Gebrauch bestimmten Schriftstück also, im einzelnen die Regeln der Gegenseitigkeit an, die im Geschenkverkehr zwischen den Fürsten gewahrt werden mußten: Sollte Karl den Gesandten anbieten, Galeazzo Maria Falken zu senden, so müßten sie die Bedingungen herausfinden und anschließend sofort einen reitenden Boten nach Mailand schikken, damit Galeazzo die Falken mit der gebotenen Ehrerbietung empfangen könne. Weiterhin erteilte Galeazzo Maria den Gesandten ausdrücklich die Erlaubnis, Geschenke des Burgunders anzunehmen ${ }^{272}$. Zwar werden Gesandte selten den Befehl erhalten haben, Geschenke nicht anzunehmen, doch spiegelt die Anweisung des Mailänders der Wunsch wieder, genau zu kontrollieren, wem sich seine Vertreter in seinem Namen durch die Annahme von Gaben verpflichteten. Auch Ludwig XI. legte durch das tiefe Mißtrauen, das er gegen seine früheren Vertrauten Poncet de Rivière und Antoine de Castelnau hegte, weil diese dem Herzog von Bretagne während des Krieges des Bien Public ein Pferd geschenkt hatten, Zeugnis ab von dem verpflichtenden Charakter, den die Gabe allen gegenteiligen Beteuerungen zum Trotz für die Zeitgenossen besa ${ }^{273}$.

Daneben aber besaßen nicht nur die Eidgenossen keinerlei Scheu, die durch Geschenke eingegangene Beziehung beim Namen zu nennen und die erwarteten Gegenleistungen einzufordern. Sie beklagten unter genauer Aufzählung der Geschenke, die sie Hagenbach im Verlauf seiner Amtszeit als Landvogt im Elsaß gemacht hatten, dessen groben Undank und sein diesen Gaben in keiner Weise entsprechendes Verhalten ${ }^{274}$. Auch Pierre de Goux, Kanzler Burgunds, stand nicht an, den Kölner Vertreter Johann Zeuwelgin durch seinen Sekretär daran zu erinnern, daß eine Anerkennung für den Einsatz Goux' zu Gunsten der Stadt erwartet werde. Der Sekretär ließ Zeuwelgin eine sheymliche warnung" zukommen, »ob ych nyt danckber syn en wille syner gnaden« für die Dienste, die der Kanzler dem Rat zu Köln bereits geleistet hatte. Sehr ähnlich äußerte sich Charles de Melun, Bailli von Sens, gegenüber Panigarola am französischen Hof, da er aus Mailand immer noch keine Gegenleistung, kein "present« für seine Dienste erhalten habe ${ }^{275}$.

272 Instruktion Galeazzo Marias an seine Gesandten, 5.2.1476 Pavia, SESTAN, Carteggi, 2, Nr. 403, S. 185; Galeazzo Maria an seine Gesandten, 7.5.1469 Abbiategrasso, SESTAN, Carteggi, 1, Nr. 159, S. 249f.; ebd., Nr. 166, S. 264 f.

${ }^{273}$ Panigarola an Francesco Sforza, 1.12.1465 Orléans, MANDROT, Dépêches, 4, S. 143.

274 Basler Chroniken, 3, S. 373-380.

275 Goux: HUB, 9, Nr. 401, S. 262; Nr. 405, S. 265. Zeuwelgin schenkte dem Kanzler und Bische Silberkannen, die er für 120 Gulden vergolden ließ. Die Kölner Stadtrechnungen vermerken für den 8.2.1472 rund 642 Mark, die für Weingeschenke am burgundischen Hof 


\subsection{Typologie der Gaben}

a) Gaben zwischen Fürsten

Das Exotische erlaubte es dem Fürsten in besonders greifbarer Weise, seine Macht auch über das Nicht-Alltägliche und Fremde zu demonstrieren 276. Dromedare und Kamele waren bereits kein ungewöhnlicher Anblick mehr in den herzoglichen Parks von Brüssel, Hesdin oder Quesnoy. Man erinnerte sich noch in Trier, daß der Vater des osmanischen Prinzen, der sich im Gefolge des Kaisers befand, Karl einst Kamele übersandt hatte 277 . Auch Jean de Rubempré, Herr von Bièvres, schenkte Karl ein Dromedar, das im Park von Quesnoy von dem herzoglichen Hüter der Kamele und Dromedare Floris de Bellemarin zusammen mit seinen Artgenossen versorgt wurde. 1472 allerdings waren 5 der ehemals dort lebenden 6 Tiere bereits tot, da ihnen das rauhe Klima wohl wenig zusagte 278 . Sowohl Philipp der Gute als auch sein Sohn besaßen Löwen. Ein Venezianer schenkte Philipp einen Löwen, wohl um sich geschäftliche Vorteile zu verschaffen. Karl ließ während des Gastmahls für den Kaiser in Trier seine Löwin, eventuell das Tier, das sein Vater erhalten hatte, vor der Tafel auf- und abführen ${ }^{279}$.

Zeichen militärischer Erfolge und nicht nur symbolischer Herrschaft waren hingegen die drei Tambourin spielenden Türken, die Matthias Corvinus im

in der Schoßsache aufgewendet wurden, HUB, 10, S. 89 Anm. 3. Melun: Panigarola an Francesco Sforza, 14.10.1465 Paris, MANDROT, Dépêches, 4, S. 4.

276 In Anlehnung an die von Hartmut BOOCKMANN sogenannte "gnädig honorierte Unvollkommenheit«, über die der Fürst herrschte wie über alle anderen Untertanen: Hartmut BOOCKMANN, Spielleute und Gaukler in den Rechnungen des Deutschordens-Hochmeisters, in: Detlef ALTENBURG, Jörg JARNUT, Hans-Hugo STEINHOFF (Hg.), Feste und Feiern im Mittelalter, Sigmaringen 1991, S. 217-227, hier S. 219. Zu Früh- und Hochmittelaler Percy Ernst SCHRAMM, Florentine MÜTHERICH, Denkmale der deutschen Könige und Kaiser. Ein Beitrag zur Herrschergeschichte von Karl dem Großen bis Friedrich II. 768-1250, München 1962, S. 72, 77-80; François Louis GANSHOF, Merowingisches Gesandtschaftswesen, in: Aus Geschichte und Länderkunde, Festschrift für Franz Steinbach, Bonn 1960, S. 178-181.

277 Kamele des osmanischen Herrschers: Paris BNF Ms fr 11590 f.117v. Zum Tierpark mit möglichst exotischen Bewohnern als fürstlichem Prestigeobjekt siehe Werner PARAVICINI, Die Residenzen der Herzöge von Burgund, 1363-477, in: Hans PATZE, Werner PARAVICINI (Hg.), Fürstliche Residenzen im spätmittelalterlichen Europa, Sigmaringen 1991, S. 207263, hier S. 228, 243f. m. Anm. 277; DERS., Des animaux pour un roi mourant: Louis XI et les Hanséats de 1479 à 1483, in: Philippe CONTAMINE, Thierry DUTOUR, Bertrand SCHNERB (Hg.), Commerce, Finances et Société (XI ${ }^{e}-\mathrm{XVI}^{e}$ siècles), Paris 1993, S. 101-121, hier S. 116; BOOCKMANN, Spielleute, S. 218 m. Anm. 9.

278 LABORDE, Les ducs de Bourgogne, 1, S. 229. Verendete Kamele: Lille ADN B 2087/66 401.

279 Geschenk an Philipp: LABORDE, Les ducs de Bourgogne, 1, S. 477. Löwin Karls in Trier:

Paris BNF Ms fr 11590 f.127r. 
Frühjahr 1474 an Karl übersandte. Sie wurden im April in Maastricht getauft, ein weiterer Akt der Herrschaft, wobei der freie Wille der Betroffenen wahrscheinlich nur eine untergeordnet Rolle spielte ${ }^{280}$. In dieselbe Kategorie gehören auch die afrikanischen Speere und die Holzstatuette, die man Karl 1470 aus Portugal übersandte, und die das Ausgreifen dieses Königreiches auf bislang nicht zur christlichen Welt gehörende Gebiete repräsentierten ${ }^{281}$.

Für den Bereich des aristokratischen Zeitvertreibs par excellence, des Kämpfens und Jagens, wurde es als Zeichen der besonderen Verbundenheit empfunden, wenn ein befreundeter Fürst um Jagdhunde, Pferde, Falken oder Waffen von besonderer Qualität oder eigentümlicher Machart gebeten wur$\mathrm{de}^{282}$. Besonders dicht ist dieser Austausch von Aufmerksamkeiten zwischen Karl und Galeazzo Maria von Mailand belegt.

Der Mailänder ließ 1469 durch seine Gesandten eigens bei Karl anfragen, welche Art Geschenk ihm am liebsten sei. In jedem Fall natürlich müsse es sich um »qualche cosa honorevole « handeln, er selbst habe an eine Rüstung oder ein Pferd gedacht ${ }^{283}$. Karl selbst empfand keine Hemmungen, italienischen Herrschern gegenüber seine Wünsche nach Pferden oder Kriegsausrüstung zu äußern. Dem italienischen Vorbild nachzueifern, war mit seinem Stolz durchaus vereinbar, und so bat er Galeazzo Maria wiederholt um Streitrösser und um einen Pavillion, nachdem er bereits mehrere Pferde von König Ferrante von Neapel erhalten hatte 284 . Noch im Juni 1476 wünschte Karl die Entsendung des Waffenschmiedes Galeazzos nach Burgund, um sich eine neue Rüstung anzupassen, da ihm die alte durch Gewichtsverlust im Krieg zu groß geworden sei285. Im Gegenzug bemühte sich Karl, dem Mailänder spezielle Produkte der nordalpinen Waffentechnik bekannt zu machen. Im April 1475 bat er den Herzog von Kleve um zwei »cranequins« (Armbrüste), eine nach ober- und eine nach niederdeutscher Art gefertigt, um sie dem Herzog von Mailand zu senden, der darum gebeten hatte. Jagdhunde und Falken fehl-

280 Lille ADN B 2105/67 598 o.Fol.

281 Jacques Paviot (Hg.), Portugal et Bourgogne au XV siècle, Lissabon, Paris 1995 , Nr. 408, S. 436.

282 PARAVICINI, Einleitung, in: Zeremoniell und Raum, S. 18f.; Dieter HECKMANN, Preußische Jagdfalken als Gradmesser für die Außenbeziehungen europäischer Höfe des 15. und 16. Jahrhunderts, in: Preußenland 37 (1999) S. 39-62.

${ }^{283}$ Instruktion Galeazzo Marias an seine Gesandten, 7.5.1469 Abbiategrasso, SESTAN, Carteggi, 1, Nr. 158, S. 245.

284 Lille ADN B 2105/67 597 o.Fol. Panigarola an Galeazzo Maria, 4.6.1475 Neuss, SESTAN, Carteggi, 1, Nr. 306, S. 529; ders. an dens., 22.10 .1475 Vaudemont, SESTAN, Carteggi, 2, Nr. 360, S. 86f. Zu Karls Vorliebe für alles Italienische siehe PARAVICINI, Karl der Kühne, S. 42 und WALSH, Charles the Bold and Italy, passim.

285 Panigarola an Galeazzo Maria, 20.-21.6.1476 Morat, SESTAN, Carteggi, 2, Nr. 609, S. 582. 
ten ebensowenig im Austausch zwischen den Herzögen ${ }^{286}$. Auch Fürstinnen schenkten Kriegsgerät, wenn sie selbst die Regierungsgeschäfte führten. Herzogin Yolanthe von Savoyen ließ Karl im April 1476 einen mit Leder gedeckten Wagen überreichen, der als Schlafgelegenheit im Feld dienen sollte287.

Auch anläßlich zweier (halb-)italienischer Hochzeiten ließ Karl durch seine Gesandten reiche Gaben überbringen. Die Markgräfin von Ferrara erhielt im Sommer 1473 zwei weiße Zelter mit langem Schweif und kostbaren Sätteln und Zaumzeugen. Die Sättel waren mit vergoldeten Knäufen und dem Wappen der Braut ausgestattet, die Zaumzeuge mit rotem Samt umkleidet. Für die gesamte Reise nach Ferrara und die anderen dort überreichten Geschenke wurden dem Ritter, Rat und Kammerherr Louis de Nesle in der Endabrechnung $1100 \mathrm{lb}$ erstattet ${ }^{288}$. Für Beatrix von Aragon, Braut des Matthias Corvinus, ordnete Karl den Kauf von Juwelen an. Die Finanzkommissare von Dijon beauftragten einen Goldschmied in Brügge, etwas Angemessenes zu besorgen, und schlugen dem Herzog schließlich ein günstig zu erwerbendes Schmuckstück in Form einer Lilie mit Diamanten und Rubinen vor ${ }^{289}$.

Es kann also kein Zweifel daran bestehen, daß sich Karl in den Belangen fürstlicher Repräsentation weitgehend am italienischen Vorbild orientierte. Ergänzt wird dieses Bild durch das fast völlige Fehlen vergleichbarer Indizien für das Reich. Einzig mit dem Pfalzgrafen trat der Herzog in einen ähnlich intensiven Austausch, um die gegenseitige Wertschätzung zu bezeugen. Die ersten Kontakte datieren aus dem Jahr 1466, als sich die Fürsten im Rahmen ihrer politischen Annäherung gegenseitig um Jagdhunde baten. Auch hier erscheint der Begriff der Ehre wieder an zentraler Stelle, da Karl ausdrücklich schöne Tiere verlangte, »dont pourrons avoir honneur ainsi que le desirons $\ll^{290}$. Fortgeführt wurde dieser freundschaftliche Austausch während des Besuches des Pfalzgrafen in den Niederlanden im Januar und Februar 1467. Karl schenkte seinem Gast mehrere kostbare Jagdvögel und stattete ihn mit reicher Kleidung, vergoldetem Sattelzeug und bestickten Satteldecken aus, die er teilweise in derselben Ausführung auch für sich anfertigen ließ291. Diese Geste

${ }^{286}$ Karl an Johann von Kleve, 7.4.1475 Lager vor Neuss, Düsseldorf HStA, Kleve-Mark, Beziehungen zu Geldern 30, 20, ACO Dijon, Papiers Henri STEIN, Briefwechsel Nr. 3012. Jagdhunde: Panigarola an Galeazzo Maria, 20.12.1475 Nancy, SESTAN, Carteggi, 2, Nr. 386, S. 147; Falke: Karl an Galeazzo Maria, 21.1.1476 (Brüssel), ZAMBARBIERI, Milano et Borgogna, 2, S. 13, Briefwechsel Nr. 3321.

287 Panigarola an Galeazzo Maria, 7.4.1476 Lausanne, SESTAN, Carteggi, 2, Nr. 502, S. 360.

288 Lille ADN B 2096/67 215: 250 lb für die Pferde; Lille ADN B 2096/67 239: 361 lb 10s für die Herstellung der Satteldecken. Lille ADN B 2096/67 238: 16 lb 16s für die Herstellung der Sättel und der Zaumzeuge. Lille ADN B 2096/67 162: Endabrechnung.

289 Lille ADN B 17717, o.Fol., vom Dezember 1475, nicht in Briefwechsel.

$290 \mathrm{Karl}$ an Josse Blondel Herm von Pamele, 12.3.1466 Brügge, in: L. van LERBERGHE, J. ROUSSE, Audenardsche Mengelingen 2 (1846), S. 42, Briefwechsel Nr. 386.

291 Kleidung: Lille ADN B 2064 f.72r-v; 73v-74r, 74r-75r. Sattelzeug: ebd., f.69v, 130v. Jagdvögel: ebd., f.75v. 
weist auf den symbolischen Charakter der Gaben hin, die vor allem als Indikator für den Stand der Beziehungen dienten. Die äußere Gleichartigkeit in der Kleidung stand als pars pro toto für die identischen politischen Zielsetzungen, die man zu verfolgen wenigstens vorgab.

Nachrichten über Austausch von Gaben mit dem Pfalzgrafen nach seinem Besuch bei Karl sind nicht bekannt, und ebenso schweigsam sind die Quellen hinsichtlich einschlägiger Kontakte Karls zu anderen Reichsfürsten. Noch zum Ende der Regierung Philipps des Guten wurden zur Taufe des Sohnes Jungherzog Adolfs von Geldern 12 Silbertassen und zwei Schalen in Sonnenform, beide reich mit Email und Edelsteinen verziert, für $493 \mathrm{lb}$ ls $9 \mathrm{~d}$ angefertigt. Georg von Baden, Bischof von Metz, erhielt anläßlich seines Besuchs bei Karl in Gent im Januar 1467 ein graues Pferd. Im Oktober desselben Jahres übersandte der Erzbischof von Trier, der Bruder des Metzers, Karl ebenfalls einen grauen Hengst mitsamt einer vergoldeten Rüstung292. Wenn auch durch ungünstige Überlieferung die eine oder andere Gabe unbekannt geblieben sein wird, so wirken doch die Bemühungen Karls, durch repräsentatives Schenken das Wohlwollen oder gar die Freundschaft der Reichsfürsten zu gewinnen, besonders im Vergleich zu Italien sehr zurückhaltend.

$\mathrm{Daß}$ um die Herzöge von Kleve und Geldern nicht mehr eigens mit den üblichen Aufmerksamkeiten geworben wurde, sieht man von den Geschenken anläßlich von Familienereignissen wie der Taufe einmal ab, überrascht angesichts ihrer Pensionen nicht. Darüber hinaus sind aber weder an den Kaiser noch an die übrigen Kurfürsten und andere bedeutende Reichsfürsten Geschenke von irgendeiner Bedeutung bekannt. Man wird kaum davon ausgehen können, daß dem Herzog einzig an dem Bündnis mit dem Pfalzgrafen gelegen war und er deswegen die anderen Fürsten, voran den Kaiser, ignorierte. Gerade im Vorfeld und im Verlauf des Trierer Tages sowie während der Wiederannäherung an den Kaiser in den Jahren 1475 und 1476 wären günstig plazierte Gaben sicherlich für den Verhandlungsgang von Nutzen gewesen. Karls auffallende Zurückhaltung in dieser Hinsicht während des Treffens in Trier wurde bereits angesprochen und könnte mit dem abrupten Abbruch der Verhandlungen begründet werden.

So viel Wert er auf den Prunk seiner eigenen Ausstattung und der seines Gefolges legte, so wenig war ihm an fürstlicher largesse gelegen. Es ist nicht erkennbar, $\mathrm{daB}$ er die Verhältnisse am Kaiserhof, wo die Annahme von Geld durch die Höflinge von Friedrich III. aus Mangel an eigenen Ressourcen gerne 
geduldet wurde ${ }^{293}$, systematisch für die eigenen Ziele genutzt hätte. Das Angebot an den Grafen von Sulz, burgundisches Geld in der kaiserlichen Umgebung zu verteilen, schlug sich in den burgundischen Rechnungen nicht nieder, so daß zweifelhaft ist, ob es je umgesetzt wurde. Um die Kurfursten scheint man sich am burgundischen Hof erst gar keine Gedanken gemacht zu haben, obwohl man sich ihrer Bedeutung als Königswähler spätestens seit dem Trierer Tag, eigentlich aber schon seit 1470/71 bewußt sein mußte.

\section{b) Gaben des Fürsten an Gesandte}

Im Alltag des Gesandtschaftsverkehrs stand allerdings nicht das Geschenk von Fürst zu Fürst, sondern die Entlohnung der Gesandten in Form einer Gabe im Vordergrund. Auf diesem Gebiet des Zeremoniells existierte im Einflußbereich der französischen Krone der weitgehend akzeptierte Standard, daß einer abreisenden Gesandtschaft Silbergeschirr oder kostbarer Stoff zu überreichen sei $^{294}$. Als Geschenkobjekt für viele Gelegenheiten war das Geschirr auch am burgundischen Hof sehr beliebt, meist in Form von Trinkgefäßen, "qui se fabriquaient, se vendaient et se donnaient par douzaine ${ }^{295}$. Die Form des Trinkgefäßes ging auf die seit der geschichtlichen Frühzeit bestehende Sitte zurück, dem fremden Gast das Trinkgefäß zu schenken, das er während seines Aufenthalts benutzt hatte ${ }^{296}$. Es verbanden sich dabei rituelle Elemente mit dem sehr praktischen Zweck, durch die rasch in Bargeld umzusetzenden Silbergefäße den oft schlecht ausgestatteten Gesandten einen standesgemäßen Lebensunterhalt oder wenigstens die Heimreise zu ermöglichen ${ }^{297}$. Dies wird auch deutlich in den Rechnungen, die stets das Gewicht des in Gefäßform verschenkten Silbers nennen, das für seinen Wert entscheidend war, während die künstlerische Gestaltung zwar erwähnt wird, aber als reine Handwerksarbeit auf den Preis der Objekte so gut wie keine Auswirkung hatte. Das Bedürfnis nach Repräsentation drückte sich auf dieser Ebene also bereits in einer vergleichsweise versachlichten Form aus. Extravagante Ausgaben zur repräsentativen Beschenkung fremder Gesandter wurden unter Karl nur in seltenen Fällen getätigt, denn in der Hauptsache wurden die finanziellen Ressourcen zur Inszenierung der eigenen Person und zur Kriegführung benötigt.

293 Visconti an Galeazzo Maria, 9.11.1473 Trier, CUSIN, Impero, Borgogna, 2, S. 40-43; ders. an dens, 18.11.1473 Trier, ebd., S. 43f.

$294 \mathrm{Vgl}$. für die burgundischerseits auf der Konferenz von Arras gemachten Geschenke JOLIVET, Se vêtir, S. 27-30, 33.

${ }^{295}$ LABORDE, Les ducs de Bourgogne, 1, S. xi.

296 BERKING, Schenken, S. 175.

297 Vgl. mit ähnlicher Funktion die seit dem 16. Jahrhundert in Gebrauch kommenden Goldketten, R.A. de MAULDE-LA-Clavière, La diplomatie au temps de Machiavel, 3, Paris, 1892-1893 (ND Genf 1970), S. 370f. 
Ein Brief königlicher Räte an Ludwig XI. aus dem Jahr 1469 illustriert, daß die Verweigerung des stereotypierten Abschiedsgeschenks einen pointiert unfreundlichen, wenn nicht beleidigenden Akt bedeutete ${ }^{298}$ : Karl von Frankreich, Bruder Ludwigs XI., fragte dessen Räte, ob er den Gesandten Karls, die ihn zu einer Allianz gegen den König gewinnen wollten, das gewohnte Silber überreichen sollte. In seiner Umgebung habe man ihm dazu geraten, «...pour ce que c'est une chose accoutumée de faire aux ambassadeurs, soit d'amis ou ennemis, et qu'on avoit ja trouvé ladite vaiselle..... Die königlichen Räte aber befanden, daß man den Burgundern die neue Treue Karls zu seinem Bruder verdeutlichen sollte, indem man sie mit der Verweigerung des zeremoniellen Geschenks brüskierte ${ }^{299}$.

Ähnlich beliebt wie Silbergeschirr waren Stoffe als Gaben sowohl an Gesandte wie an Angehörige eines Hofes überhaupt. Der Kölner Johann Zeuwelgin verlieh 1467 seinem Erstaunen darüber Ausdruck, mit welcher Häufigkeit pelzverbrämte Mäntel am burgundischen Hof verschenkt wurden ${ }^{300}$. Gleichermaßen bediente sich der Herzog von Mailand wertvoller Stoffe als Anerkennung für geleistete Dienste oder als ehrenvolle Gabe an einflußreiche Persönlichkeiten. Guillaume de Rochefort erhielt für seinen Anteil am Zustandekommen des Vertrages von Moncalieri aus Mailand Samt, und Guy de Brimeu sollte ebenfalls mit schwarzem Samt den mailändischen Anliegen, vor allem hinsichtlich des Kaisers, geneigt gemacht werden ${ }^{301}$. Auch Ämter und Titel konnten sich eignen, erbrachte oder noch erhoffte Dienste zu honorieren: Edward IV. erhob Ludwig von Brügge, Herrn von Gruuthuse, zum Grafen von Winchester, Galeazzo Maria versprach, sich um ein Bistum für Humbercourts Bruder Philippe zu bemühen ${ }^{302}$.

Geben und Nehmen von Geld war ebenfalls mit den Konzepten von Macht und Ehre verknüpft ${ }^{303}$, ohne daB heutige Kategorien von Bestechlichkeit und Korruption darauf angewendet werden könnten. Der Austausch von Geld, Naturalien oder Ehrungen war ein fester Bestandteil des spätmittelalterlichen Verwaltungsalltags, der bis weit in die Neuzeit hineinreichte. Die Forderung nach dem unbestechlichen Beamten entstand erst im Zuge der Trennung von

298 QUELLER, The Office of Ambassador, S. 203 m. Anm. 157.

299 PLANCHER, Histoire, 4, S. cclx-cclxi.

300 HUB, 9, Nr. 405, S. 265.

301 Rochefort: Panigarola an Galeazzo Maria, 9.2.1475 Turin, SESTAN, Carteggi, 1, Nr. 246, S. 405f. Brimeu: Panigarola an Galeazzo Maria, 19.3.1475 Neuss, ebd., Nr. 262, S. 433f.; ders. an dens., 31.5.-4.6.1475 Neuss, ebd., Nr. 304, S. 516f.; Galeazzo Maria an Panigarola, 12.4.1475 Villanova, ebd., Nr. 278, S. 463f.

302 Gruuthuse: RYMER, Feodera, 5, 3, 1741, S. 25. Philippe de Brimeu: Panigarola an Galeazzo Maria, 18.3.1475 Neuss, SESTAN, Carteggi, 1, Nr. 258, S. 425f.; ders. an dens., 31.5.4.6.1475 Neuss, ebd., Nr. 304, S. 516f.; Galeazzo Maria an Panigarola, 12.4.1475 Villanova, ebd., Nr. 278, S. 463f.

${ }^{303}$ GUERY, Le roi dépensier, S. 1245. 
Amt und Person, wie sie im 15. Jahrhundert noch so gut wie nicht existierte. Vorwürfe der persönlichen Bereicherung, die durchaus bereits geläufiges Argumentationsmaterial darstellten, wurden stets nur dann erhoben, wenn der Beschuldigte aus anderweitigen Gründen unliebsam geworden war ${ }^{304}$. Wie erwähnt, war es am Kaiserhof eine allgemeine und auch von Friedrich III. akzeptierte Praxis, daß seine Räte Geld fremder Fürsten annahmen, da sie den notorisch zahlungsunfähigen Herrscher von der Notwendigkeit enthob, seine Diener selbst versorgen zu müssen ${ }^{305}$.

Grundsätzlich galt zwar am burgundischen Hof, »dat erlicher were, cleynoyt dan gelt zu geven «, wie Johann Zeuwelgin im September 1467 erfuhr $^{306}$, doch scheuten sich auch Personen hohen Standes keineswegs, größere Beträge anzunehmen, die zur öffentlichen Übergabe vielleicht in ein Ziergefäß gefüllt wurden ${ }^{307}$. Der Bischof von Salisbury erhielt von Karl nach Abschluß der Hochzeitsfeierlichkeiten mit Margarete von York $1200 \mathrm{lb}$ als Aufwandsentschädigung, und zum selben Anlaß wurde der Bruder der englischen Königin, John Woodville, mit $630 \mathrm{lb}$ bedacht. Thomas Vaughan und William Hatcliffe, enge Vertraute Eduards IV., hatten schon 1467 im Zuge der Eheverhandlungen Silbergeschirr im Wert von $229 \mathrm{lb}$ und $202 \mathrm{lb}$ bekommen, nach der Hochzeit schenkte Karl Vaughan noch einmal 375 lb $^{308}$. Als Panigarola im September vom Hof Karls abberufen wurde, stellte der eigentlich unter akuter Geldnot leidende Herzog noch einmal ostentativ seine fürstliche Großzügigkeit unter Beweis und beeindruckte den Gesandten mit einem Abschiedsgeschenk von 400 Goldflorenen. $220 \mathrm{lb}$ wurden dem neapolitanischen Ritter zugedacht, der im Namen König Ferrantes im Sommer 1474 drei Streitrösser an Karl überbrachte ${ }^{309}$.

Neben derartigen individuellen Geschenken an Gesandte und Vertraute des Fürsten waren auch Versuche, den gesamten Hof oder bedeutende Parteien zu gewinnen, keine Seltenheit: In Mailand entrüstete man sich im Dezember

304 Alain DERviLle, Pots-de-vin, cadeaux, racket, patronage. Essai sur les mécanismes de décisions dans l'état bourguignon, in: Revue du Nord 56 (1974) S. 341-364; Marc BoONE, Dons et pots-de-vin, aspects de la sociabilité urbaine au bas Moyen Age. Le cas gantois pendant la période bourguignonne, in: Revue du Nord 70 (1988) S. 471-487; Wim BlockMANS, Patronage, Brokerage and Corruption as Symptoms of incipient State Formation in the Burgundian-Habsburg Netherlands, in: Antoni MACZAK (Hg.), Klientelsysteme im Europa der frühen Neuzeit, München 1988, S. 117-126; Holger KRUSE, Les malversations commises par le receveur général Martin Cornille à la cour de Philippe le Bon d'après l'enquête de 1448/49, in: Revue du Nord 77 (1995) S. 283-312.

305 Visconti an Galeazzo Maria, 18.11.1473 Trier, Cusn, Impero, Borgogna, 2, 1936, S. $43 \mathrm{f}$. 306 HUB, 9, Nr. 401, S. 262.

${ }^{307}$ QUELLER, Office of Ambassador, S. $203 f$.

308 Salisbury und Woodville: Brüssel AGR CC 1923 f.148v. Vaughan und Hatcliff 1467: Lille ADN B 2064 f.143v. Vaughan 1468: Brüssel AGR CC 1923 f.281r.

309 Panigarola: Panigarola an Galeazzo Maria, 5.9.1476 Aux, SESTAN, Carteggi, 2, Nr. 650 , S. 676f. Neapolitanischer Ritter: Lille ADN B 2105/67 597 o.Fol. 
1472 über die venezianische Praxis, jedes Jahr mindestens 20000 Dukaten an die Räte und Heerführer am burgundischen Hof zu verteilen. Anstoß genommen wurde dabei weniger an der Summe an sich als an der Heimlichkeit der Zahlung. Derartige "tributi secreti« wurden von den venedigfeindlichen Mailändern als unehrenhaft konstruiert ${ }^{310}$. Aus Anlaß des Schoßprozesses vor dem Großen Rat war es für den Rat der Stadt Köln selbstverständlich, durch Geschenke in Form von Silberkannen die ihr ohnehin gewogenen Ratsmitglieder noch günstiger zu stimmen; ein Vorgehen, das von den betreffenden burgundischen Räten erwartet wurde ${ }^{311}$.

Vor diesem Hintergrund ist die Praxis Herzog Karls bei der Vergabe von Geschenken an Gesandte zu beurteilen. Dabei ist der Vergleich zwischen englischen und italienischen Gesandten und solchen aus dem Reich besonders instruktiv. In Fragen der militärischen Repräsentation scheute der Herzog keine Kosten und ließ den lothringischen Herold, der ihm am 9. Mai 1475 die Kriegserklärung Renés von Lothringen überbrachte, wertvoll beschenken und prächtig bewirten ${ }^{312}$. Während eines dreitägigen Waffenstillstands im Juni 1475 erhielten alle Deutschen, die das burgundische Lager vor Neuss besuchten, ein Geschenk ${ }^{313}$. Vor allem der venezianischen Gesandtschaft, die ihn im Frühjahr und Sommer 1475 vor Neuss aufsuchte, empfahl sich Karl durch Gaben und Aufmerksamkeiten aller Art als machtvoller Fürst und Bündnispartner. Bei ihrer Ankunft im März 1475 überreichte der Burgunder den Venezianern ein Bild, das die Belagerung von Neuss mit der burgundischen Zeltstadt in allen Einzelheiten darstellte und die eigene militärische Stärke beschwor. Im Juli desselben Jahres schlug er einige der Gesandten in Maastricht zu Rittern. $\mathrm{Zu}$ ihrer Verabschiedung im August schließlich ordnete Karl an, ihnen Geschirr im Wert von 5000 Mark Silber zu schenken ${ }^{314}$.

Die großzügige Belohnung der englischen Unterhändler während der Verhandlungen um die Eheschließung Karls und Margaretes wurde bereits angesprochen. Als weitere Beispiele für eine angemessene Entschädigung fremder Gesandter sind das Silbergeschirr im Wert von $133 \mathrm{lb}$ 12s 9d zu nennen, das Peter de Borges, Kammerherr des Königs von Portugal, im März 1468 überreicht wurde, sowie dasjenige für $320 \mathrm{lb}$, das Georg von Stein als Gesandter des Matthias Corvinus im Frühsommer 1475 erhielt $^{315}$.

310 Aliprandi an Galeazzo Maria, 31.12.1472 Brügge, SESTAN, Carteggi, 1, Nr. 183, S. 306. $\mathrm{Zu}$ Öffentlichkeit und Heimlichkeit s. HaNNIG, Ars donandi, S. 158.

${ }^{311}$ HUB, 9, Nr. 405, S. 265.

312 Paris BNF Ms fr 6981 f.115r-116r, wahrscheinlich Auszug aus einer Chronik.

313 Panigarola an Galeazzo Maria, 4.6.1475 Neuss, SESTAN, Carteggi, 1, Nr. 306, S. 527f.

314 Bild: Basler Chroniken, 2, S. 144. Ritterschlag: Panigarola an Galeazzo Maria, 11.7.1475 Gent, SESTAN, Carteggi, 1, Nr. 327, S. 572. Silbergeschirr: Lille ADN B 2105/67 594, o.Fol. 315 Stein: Lille ADN B 2105/67 594, o.Fol. Vgl. Rudolf KNESCHKE, Georg von Stein. Versuch einer Biographie, Weida i.Th. 1913, S. 45-47. De Borges: Brüssel AGR CC 1923 f.45v. 
Wieder aber ergibt sich der Befund, daß Karl weder den Gesandten der Reichsfürsten noch denjenigen des Kaisers Geschenke machte, die über das notwendige, von der Tradition diktierte Minimum hinausgingen. Der kaiserliche Bote Hans Rosenkranz ritt 1468 mit $3 \mathrm{lb}$ 10s nach Hause zurück, der Herold Romreich verließ den Hof mit $30 \mathrm{lb}$. Der Herold Stockholm des Königs von Dänemark dagegen reiste aus Brügge im April 1467 mit immerhin $80 \mathrm{lb}$ $a^{316}$. Im Fall des kaiserlichen Sängers und Kaplans Matthias Vogel wurde gar die Grenze zur Mildtätigkeit erreicht, als es im April $1468 \mathrm{zu}$ den $16 \mathrm{lb}$, die ihm gegeben wurden, hieß, "pour Dieu et en amoisne et pour soy ayder a vivre « ${ }^{317}$. Zwar lassen sich durch die sehr lückenhafte Überlieferung der Rechnungen des Argentier nach 1470 keine endgültigen Schlüsse zur Geschenkpraxis Karls den kaiserlichen Gesandten gegenüber ziehen. Da aber auch in den burgundischen Quittungen und Zahlungsanweisungen und den Quellen aus dem Reich keine einschlägigen Hinweise erhalten sind, deutet alles auf einen äußerst geringen zeremoniellen Aufwand im alltäglichen Gesandtschaftsverkehr zwischen Kaiser, Reichsfürsten und Burgund hin.

\section{3. "...non essendo molto largo nel spendere di sua natura"}

Mit diesen Worten beschrieb Rodolfo Gonzaga 1470 Karl in einem Brief an seine Mutter, Markgräfin Barbara von Mantua. Die Italiener am burgundischen Hof jedenfalls vermißten die echte Großzügigkeit in den Gaben des Herzogs ${ }^{318}$. Auf dem Gebiet des Gabentausches spielte neben politischen und traditionellen Vorgaben die Persönlichkeit des Fürsten eine wichtige Rolle. Bei Karl verbanden sich das Streben nach einer effizienten Verwaltung mit der Überzeugung, Gehorsam und Gefolgschaft seien Pflicht jedes Adligen auch ohne den Anreiz fürstlicher Gaben mit der Absicht, die ihm zur Verfügung stehenden Ressourcen auf die Kriegführung zu konzentrieren. Sein Hang zur Stereotypierung der Gaben auch an die Angehörigen des eigenen Hofes auch als Mittel zur Bekämpfung der von Karl in den Hofordnungen selbst so genannten corruption, ist erst unlängst von Paravicini festgestellt worden ${ }^{319}$. Andererseits glaubte Commynes, da $B$ ihm kein Fürst in dem Wunsch gleichgekommen sei, die Großen an seinen Hof zu ziehen und dort zu halten. Auch Gesandte und andere Fremde habe er stets auf das Beste empfangen und ihnen die größte Ehre erwiesen. Doch räumt auch der Chronist ein, daß die herzogli-

316 Rosenkranz: Brüssel AGR CC 1923 f.30v; Romreich: Lille ADN B 2061 f.137v. Stockholm: Lille ADN B 2064 f. $125 v$.

317 Brüssel AGR CC 1923 f.70r.

318 Zitiert nach Richard WALSH, Charles the Bold and Italy, S. 407, Meinung der Italiener ebd., S. 407f.

319 PARAVICINI, Ordre et règle, S. 332, 341. 
chen Wohltaten nie besonders groß gewesen, da er sie auf eine möglichst groBe Zahl zu verteilen wünschte 320 .

Karl befand sich also in dem Dilemma, als einer der reichsten Fürsten des Abendlandes auch durch seine Geschenke angemessen repräsentieren zu müssen, andererseits aber seine schließlich doch begrenzten finanziellen Reserven in erster Linie in seine Armee investieren zu wollen. Diese Verhältnisse führten ihn zu einer rigorosen Scheidung zwischen den auswärtigen Beziehungen, die seiner Ansicht nach einen hohen zeremoniellen Aufwand rechtfertigen, wie mit Italien und England, und solchen, die im gewöhnlichen Gesandtenverkehr strikt auf der Ebene des Alltagsgeschäfts gehalten wurden. Hierzu sind, stets mit der Ausnahme des Trierer Tages und der Anfangsphase der Beziehungen zu Pfalzgraf Friedrich, so gut wie alle diplomatischen Kontakte zu Kaiser und Reichsfürsten zu rechnen. Diese Art des ökonomischen Denkens findet sich bereits vorgezeichnet in dem ganz ähnlichen Verhalten, das Philipp der Gute während seines Zuges zum Reichstag von Regensburg 1454 an den Tag legte. Auch der Vater hielt außer Herzog Ludwig dem Reichen von Bayern-Landshut keinen der deutschen Fürsten eines besonderen repräsentativen Aufwands für würdig, sondern suchte seine Finanzen für den erwarteten Türkenzug zu schonen. Das Fernbleiben des Kaisers von Regensburg bestärkte die Burgunder zusätzlich in ihrer Meinung, daß das weltliche Haupt der Christenheit nicht seiner Würde gemäß auftrete und der Verkehr mit ihm deshalb auch keiner besonderen repräsentativen Anstrengungen bedürfe. In die dergestalt wenig zuvorkommende Behandlung der Reichsfürsten mag schließlich auch hineingespielt haben, daß es die Burgunder aus dem Gefühl der Überlegenheit heraus schlicht für unnötig hielten, diesen aufwendige Geschenke wie unter Gleichgestellten zu machen ${ }^{321}$.

$\mathrm{Da}$ diese Geringschätzung von Kaiser und Reich keinesfalls eine zwangsläufige Haltung der Angehörigen des französischen Königshauses war, wird

320 Commynes, Mémoires, ed. CALmetTe, 2, S. 154: "Nul prince ne le passa jamais de désirer nourrir grans gens et les tenir bien reiglez. Ses bienfaicts n'estoient point fort grans, pour ce qu'il vouloit que chacun s'en sentist ... Il portoit fort grand honneur aux ambassadeurs, et gens estrangers. Ils estoyent fort bien festoyés et recueillis chez luy.« Vgl. auch den Bericht Panigarolas über die abschätzigen Bemerkungen eines Dieners des Grafen von Saint-Pol, der Karl im Juni 1468 als habgierig und geizig beschrieb: "...he [Karl] principe molto dato a l'avaritia et cumullare thesorro, spendendo con grandissima fatica, et parendoli quando dona cinquanta scuti che fazi uno grande presente.«, Panigarola an Galeazzo Maria, 16.6.1468, Schloß Braie Comte Robert, Paris BNF Ms it 1649 f.182r.

${ }^{321}$ Zur hierarchisierenden Funktion von Geschenken Ivan HLAVÁČEK, Überlegungen zum Geschenkwesen im Mittelalter, in: Mitteilungen der Residenzen-Kommission bei der Akademie der Wissenschaften zu Göttingen 2 (1992) S. 12-15. Zur Reise Philipps des Guten: Petra EHM, Der reisende Hof und die Gabe. Zur Geschenkpraxis Philipps des Guten auf seiner 1454 in das Reich, in: Ordnungsformen des Hofes, S. 67-76, hier S. 72-74. Vgl. zu dieser Reise Wemer ParavicINI, Philippe le Bon en Allemagne (1454), in: Revue Belge de Philologie et d'Histoire 75 (1997) S. 967-1018. 
bei Betrachtung der entsprechenden Praxis Ludwigs XI. gegenüber den Gesandten des Kaisers und der Reichsfürsten deutlich. Die Aussage Commynes', Ludwig sei ein Meister darin gewesen, wichtige Männer durch Geld oder Würden und seine große Freigebigkeit zu gewinnen, findet sich hier bestätigt $^{322}$. Auch Ludwig gab fast ausschließlich Silbergeschirr, schenkte aber den jeweiligen Gesandten in der Regel wesentlich großzügiger ${ }^{323}$. Als Gesandter deutscher Fürsten erhielt Graf Johann von Montgriffon (Greifenberg) 1469

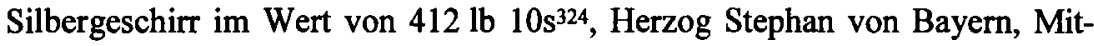
glied des Kölner Domkapitels und Führer der Opposition gegen Erzbischof Ruprecht und Karl, wurde im Mai 1474 Silbergeschirr für $605 \mathrm{lb}$ geschenkt, als er bei Ludwig um Hilfe gegen die burgundischen Belagerer von Neuss bat ${ }^{325}$. Zwei nicht namentlich genannte Gesandte aus dem Reich wurden 1476/77 mit Geschirr aus 400 Mark Silber für $1175 \mathrm{lb}$ geehrt ${ }^{326}$. Auch Ludwig aber unterschied nach dem Rang der Gesandten, so daß sich Johann Keller, kaiserlicher Fiskalprokurator, mit 6 silbernen emaillierten Kannen im Wert von $199 \mathrm{lb}$ zufriedengeben mußte ${ }^{327}$.

Das Geschenk übte im diplomatischen Kontext keinen entscheidenden Einfluß auf den Gang der Verhandlungen aus, war aber als Bestandteil des Zeremoniells ein feiner Indikator für Ehrbezeugung und Wertschätzung. Gesandtengeschenke boten in der Regel aufgrund ihrer Einbindung in das Abschiedszeremoniell die dem Vorgang typische hohe »Verhaltens- und Erwartungssicherheit ${ }^{328}$. Sie waren weitgehend stereotypiert und bestanden in ihrer überwältigenden Mehrheit aus Silbergeschirr und Stoffen. Weitaus stärker war die Gabe unter den fürstlichen Standesgenossen am Bedürfnis nach Ehre orientiert, wobei der zugemessene Wert meist in umgekehrtem Verhältnis zum praktischen Nutzen stand. An höchster Stelle rangierte das Fremde: exotische Gegenstände wie Einhörner oder Walroßzähne, denen magische Eigenschaften zugeschrieben wurden, oder Heiden und Mohren. Stets angemessen war außerdem die Ausrüstung für den standesgemäßen Zeitvertreib von Jagd und Kampf, und schließlich wurden auch reine Wertgegenstände nicht verschmäht.

Karl wurde nur selten wegen seiner Freigebigkeit gerühmt. Die Untersuchung seiner Gaben an Reichsfürsten und an Gesandte aus dem Reich bestä-

322 Commynes, Mémoires, ed. CALMETTE, 1, S. 67.

323 Dies trifft auch bei Berücksichtigung des geringeren Wertes des Pfund tournois zu 32-36 Flämischen Groschen gegen das in den burgundischen Rechnungen teilweise noch verwendete Pfund zu 40 Groschen zu. Vgl. Vaughan, Phillip, S. xvii.

324 BNF Ms fr 20685 S. 447.

325 BNF Ms fr 20685 S. 615.

326 BNF Ms fr 23264 f.3r.

327 BNF Ms fr 20685 S. 682.

328 PARAVICINI, Einleitung, in: Zeremoniell und Raum, S. 14. 
tigt, daß er den Kaiser und die vergleichsweise armen Reichsfürsten, die sich mit einem König von Frankreich oder einem Herzog von Burgund nicht vergleichen konnten, auch zeremoniell kaum als ebenbürtig betrachtete. Die Behandlung der englischen, mailändischen und neapolitanischen Herrscher und Gesandten hebt sich hiervon deutlich ab. Diese Beobachtungen weisen ebenso wie die Ergebnisse der Untersuchung der Gesandten auf eine Geringschätzung des Reiches, die es dem Herzog erschwerte, seine Ziele mit den eigentlich angemessenen und zur Verfügung stehenden Mitteln zu verfolgen.

\section{Die Bezahlung der Gesandten}

Die Entlohnung der Gesandten ${ }^{329}$ war nach dem in der Finanzordonnanz von 1468 ausgedrückten Willen des Herzogs fest in das System der Finanzverwaltung des gesamten Hofes eingebunden. Zuständig für die Bezahlung der Gesandten war der Argentier, der für jede Summe über 40s, die er an einen Boten oder Gesandten zahlte, eine Anweisung des Herzogs selbst, zusätzlich von einem der Finanzkommissare unterzeichnet, vorweisen mußte. Im Gegenzug war der Gesandte verpflichtet, dem Argentier eine Quittung auszustellen ${ }^{330}$. Für jede Gesandtschaft in das Reich, nach England oder Frankreich mußte daher eine solche Anweisung vorliegen. Weiterhin hatten die Finanzbeamten bei der Rechnungsprüfung darauf zu achten, ob ein Gesandter während seiner Abwesenheit vom Hof weiter auf den Gagenlisten, den écroes, geführt worden war, um eine doppelte Bezahlung zu verhindern. Der festgestellte Sachverhalt

329 Borchgrave, Diplomaten, behandelt diesen Aspekt nicht. Für die Praxis in England zu Beginn des 15. Jahrhunderts siehe REITEMEIER, Außenpolitik, S. 75-80; John M. CURRIN, "Pro Expensis Ambassatorum«: Diplomacy and Financial Administration in the Reign of Henry VII, in: English Historical Review (1993) S. 589-609. Zur Entlohnung der im hôtel des Herzogs dauerhaft Beschäftigten siehe Monique SOMME, Que représente un gage journalier de 3 sous pour l'officier d'un hôtel ducal à la cour de Bourgogne au $x^{e}$ siècle?, in: JeanPierre SOSSON, Claude THIRY, Sandrine THONON, Tania VAN HEMERLYCK (Hg.), Les niveaux de vie au moyen âge. Mesures, perceptions et représentations. Actes du colloque international de Spa, 21-25 octobre 1998, Bruylant 1999, S. 297-315. Im allgemeinen wurde unter Karl bei der Abrechnung der Gagen das Pfund zu $32 \mathrm{~s}$ zugrundegelegt, jedoch gab es noch immer Ausnahmen, vgl. VAugHAN, Philip the Good, S. xvii und Peter SPUFFORD, Handbook of Medieval Exchange, London 1986, S. 400ff.

330 Text der Ordonnanz in STEIN, Haneron, S. 324-332, hier S. 328. Vgl. Christian ALBRECHT, Die Monatsrolle des burgundischen Argentiers Nicolas de Gondeval, S. 88 Anm. 50; und DERS., Eine reformierte Zentralfinanz: Die Finanzverwaltung während der Herrschaft Karls des Kühnen untersucht anhand der Rechnungsüberlieferung des burgundischen Argentiers, in: Marc BOONE, Walter PREVENIER (Hg.), Finances publiques et finances privées au bas moyen âge, Löwen, Apeldoorn, 1996, S. 219-237. 
wurde in einigen Fällen eigens auf den Zahlungsanweisungen vermerkt, um die Höhe der Auszahlung zu begründen ${ }^{331}$.

Dies war die im Normalfall angewandte Prozedur, doch ergaben sich immer wieder Abweichungen, sei es aufgrund von Zeitnot oder der geographischen Entfernung der Akteure voneinander. Solche Unregelmäßigkeiten gaben der burgundischen Verwaltung AnlaB zu interessanten Sonderegelungen: So befahl der Herzog im November 1474 den Finanzkommissaren, sie möchten die sofortige Auszahlung von $720 \mathrm{lb}$ an Antoine de Montjeu in Dijon veranlassen, der soeben von einer Reise aus Italien zurückgekehrt war und umgehend wieder dorthin aufbrechen sollte. Da der Argentier sich bei Karl in Neuss aufhielt, schrieben die Kommissare an Gérard Vurry, Generaleinnehmer des Herzogtums Burgund in Dijon und wiesen ihn an, an Montjeu die genannte Summe zu zahlen. Dieser sollte bei Empfang aber eine Quittung zugunsten des Argentier ausstellen, für die ein Muster mitgesandt wurde. Ein ähnliches Problem ergab sich für George Baert, der ebenfalls 1474 nur für kurze Zeit zwischen zwei Englandreisen in den Niederlanden weilte und durch den Generaleinnehmer Pierre Lanchals mit neuen Geldmitteln ausgestattet werden sollte ${ }^{332}$.

Die Tagesgagen der Hofangehörigen spiegelten ihren sozialen Rang, und nicht anders war es bei der Entlohnung der Gesandten. Zwischen etwa 12s und 36s am Tag bewegte sich die Gage für die höheren Hofämter, wobei je zu versorgendem Lebewesen, sei es Diener oder Pferd des betreffenden Stelleninhabers, 3s veranschlagt wurden ${ }^{333}$. Im Rahmen der Gesandtschaft wurde der Tagessatz jeweils entsprechend den zusätzlichen Aufwendungen für Unterkunft, Kleidung und die für nötig erachtete Begleitung erhöht. Außerdem wurde zur eigentlichen Reise die Zeit hinzugerechnet, die der Gesandte vor und nach Abschluß seiner Mission am herzoglichen Hof verweilte, um Instruktionen zu empfangen und Bericht zu erstatten. Unmittelbar vor ihrer Abreise erhielten die Gesandten in der Regel einen Vorschuß - prest - der ebenfalls durch den Herzog oder die Finanzkommissare angeordnet worden sein mußte. Er wurde nach der Rückkehr mit den zu erstattenden Tagesgagen und eventuell weiteren angefallenen Ausgaben verrechnet. Hatte ein Diplomat keinen Vorschuß erhalten, konnte er sich zur Aufnahme von Krediten im Ausland genötigt sehen, wie der Rat Juste de Boldin während seiner Reise auf die iberische Halbinsel in der ersten Hälfte des Jahres 1474, als er sich bei venezianischen Kaufleuten

331 Siehe z. B. die Anweisung für die Gesandtschaften des Protonotars Arthur de Bourbon 1474 nach Frankreich, Lille ADN B 2110/67 904; oder diejenige für Olivier de la Marche nach seiner Reise in die Bretagne vom Dezember 1468 bis zum Mai 1469, STEIN, Etude sur Olivier de la Marche, Nr. XXVI, S. 172.

332 Beide Schreiben Lille ADN B 17713 o. Fol.; Schreiben an Lanchals o.D. 1474; Schreiben an Vurry vom 24.11.1474 mit beiliegendem Entwurf für die Quittung.

333 Werner PARAvicINI, Soziale Schichtung und Soziale Mobilität am Hof der Herzöge von Burgund, in: Francia 5 (1977) S. 127-182, hier S. $130 f$. 
Geld borgen mußte ${ }^{34}$. Die Niederlassungen der Medici-Bank wurden von Karl aufgrund seiner engen Verbindungen zu Tommaso Portinari als reguläre Geldquelle zur Versorgung der Gesandten genutzt, die das Geld an dem jeweiligen Ort im Ausland in Empfang nahmen, das an Portinari in Brügge zurückgezahlt wurde 335 .

Für die Teilnahme an Verhandlungen mit fremden Gesandten innerhalb der herzoglichen Länder galt ein geringerer Tagessatz als für Einsätze außerhalb der Territorien Karls. Sie entsprachen im allgemeinen den auch bei Anwesenheit am Hof gezahlten Gagen. So bekam Woutre van der Noot $146632 \mathrm{~s}$ am Tag für Verhandlungen mit Gesandten des Grafen von Katzenelnbogen in Maastricht ${ }^{336}$.

An einigen Beispielen sollen die sozialen Abstufungen in der Gesandtenentlohnung gemäß der höfischen Hierarchie verdeutlicht werden: Ein häufiger Tagessatz für Räte waren 54s am Tag, wie sie Antoine de Montjeu 1467 für seine Reise nach Lothringen erhielt ${ }^{337}$. 1465 reisten der Sekretär Lambert van der Ee und der Rat und Kammerherr Woutre van der Noot nach Köln. Lambert wurde mit $2 \mathrm{lb}$, Woutre mit $3 \mathrm{lb}$ am Tag vergütet. ${ }^{338}$ Auf den gleichen Satz kam Woutre im selben Jahr bei seiner Reise zu Herzog Ludwig dem Reichen, wobei sich dieses Mal die Bezahlung aus einem Vorschuß von $100 \mathrm{lb}$, einem Tagessatz von $1 \mathrm{lb}$ und schließlich einer Nachzahlung für zusätzliche Aufwendungen für Unterkunft, Verpflegung, Führer und Geleite von $42 \mathrm{lb}$ zusammensetzte ${ }^{339}$. Auch Antoine Haneron kam trotz seiner Position als enger Vertrauter Karls ebenfalls nicht über $3 \mathrm{lb}$ je Tag hinaus, als er für die 77 Tage, die er von Juli bis Oktober 1473 im Auftrag des Herzogs zwischen dem kaiserlichen und dem herzoglichen Hof pendelte, $218 \mathrm{lb} 8 \mathrm{~s}$ zugewiesen erhielt ${ }^{340}$. $\mathrm{Da} B$ Hanerons anderweitige Verdienstmöglichkeiten beträchtlich waren, ist hier nicht von Belang. Aufschlußreich ist allein, daß er als nichtadliger Rat keinen Anspruch auf ein höheres Tagegeld als andere Räte auch besaß. Ähnliches gilt für Peter von Hagenbach, der sich im Winter 1466/67, als er den Pfalzgrafen von Lothringen aus zu Karl nach Brüssel geleitete, noch mit einer Gage von $1 \mathrm{lb} 12 \mathrm{~s}$ am Tag zufriedengeben mußte ${ }^{341}$ und auch für seine Bemü-

${ }^{334}$ Z. B. erhielt der Abt von Casanova im Juni $1473360 \mathrm{lb}$ Vorschuß für seine Reise zum Kaiser, unter Einrechnung von Diensten, die er dem Herzog zuvor geleistet hatte, Lille ADN B 2096/67 169. Boldin: Lille ADN B 17713 o.Fol., Schreiben Karls an die Finanzkommissare vom 8.8.1474, nicht in Briefwechsel.

335 Siehe z.B. die entsprechende Transaktion über $110 \mathrm{lb}$ während des Aufenthalts des Ritters und Kammerherrn Jehan de Coppons in London zum Jahreswechsel 1466/67, Lille ADN B 2064 f.64r-v.

336 Lille ADN B 2058 f. 166v-167r.

${ }^{337}$ Brüssel AGR CC 1923 f.68r.

338 Lille ADN B $2054 \mathrm{f} .147 \mathrm{r}-\mathrm{v}$.

${ }^{339}$ Lille ADN B $2061 \mathrm{f} .122 \mathrm{r}, 179 \mathrm{v}$; Lille ADN B $2054 \mathrm{f} .140 \mathrm{v}$.

${ }^{340}$ Lille ADN B 2097/67 280.

${ }^{341}$ Lille ADN B 2064 f.60v. 
hungen im Frühjahr und Sommer 1473 vor dem Trierer Tag nur mit den vergleichsweise geringen Summen von $74 \mathrm{lb}$ und $105 \mathrm{lb}$ entschädigt wurde ${ }^{342}$. Sein Begleiter Johann Espach wurde zu diesen Reisen an den Oberrhein und nach Baden ebenfalls mit den üblichen $3 \mathrm{lb}$ am Tag versehen ${ }^{343}$.

Betrachtet man nun die Summen, die Graf Johann von Nassau zur standesgemäßen Reise nach Mainz und zum Kaiser 1462 und 1469/70 zugestanden wurden, wird das Konzept der hierarchischen Gagengliederung offensichtlich. Graf Johann verbrachte 1462 insgesamt 53 Tage zur Vermittlung im Mainzer Bistumsstreit in Mainz und am burgundischen Hof zur Berichterstattung, wofür ihm $918 \mathrm{lb}$ ls $8 \mathrm{~d}$ zugestanden wurden, also $17 \mathrm{lb}$ am Tag. Denselben Tagessatz erhielt er wieder zwischen Dezember 1469 und Juli 1470, als er zusammen mit Erzbischof Adolf von Mainz zu Friedrich III. reiste, um wegen Ehe und römischem Königtum vorzufühlen. Unter Einrechnung der Tage, die er anschließend in Hesdin verbrachte, um Karl vom Verlauf der Gespräche zu unterrichten, belief sich die Gesamtsumme auf $1920 \mathrm{lb}^{344}$. Noch üppiger wurde Anton von Burgund, der Halbbruder Karls, anläBlich seiner Reisen 1467 nach England und 1474 nach Italien ausgestattet. Hier galt es, durch ein Familienmitglied Ehre und Reichtum des Herzogshauses zu repräsentieren ${ }^{345}$.

Das häufigste Problem, das sich bei der Vergütung der Gesandten ergab, war das der zeitlichen Verzögerung und läßt sich ebenfalls am Beispiel Graf Johanns illustrieren. Die oben angeführten $918 \mathrm{lb}$ für die Vermittlung in Mainz 1462 wurden dem Grafen 1471 erstattet - er hatte also neun Jahre und einen Herrschaftswechsel lang auf eine Entschädigung warten müssen ${ }^{346}$. Ähnlich erging es Antoine Haneron, der zu Beginn der 1460er Jahre während eines Aufenthalts am Kaiserhof unerwartete Ausgaben tätigen mußte und außerdem fünf Pferde verlor. Vom Kaiser gebeten, die Niederkunft der Kaiserin abzuwarten und das Kind aus der Taufe zu heben, beliefen sich seine Auslagen für die dabei anfallenden Geschenke an den Kaiser, das Kind, die Kammerfräulein und die Ammen zusammen mit dem Verlust der Pferde auf insgesamt $277 \mathrm{lb}$, die ihm schließlich 1469 angewiesen wurden ${ }^{347}$. Konnten Johann und Haneron es noch finanziell verkraften, derart lange auf ihre Bezahlung zu warten, so war es anderen, die nicht über den direkten Zugang zu den Patronage- und Geldquellen des Hofes verfügten, unmöglich, ohne einen Vorschuß und prompte Zahlungen eine Gesandtschaft anzutreten. Der Abt von Cîteaux sah sich im Juli 1474 oder 1475 genötigt, eine geplante Gesandtschaft an den Papst nicht anzutreten, da seine vom Hof kommenden Begleiter ihm den an-

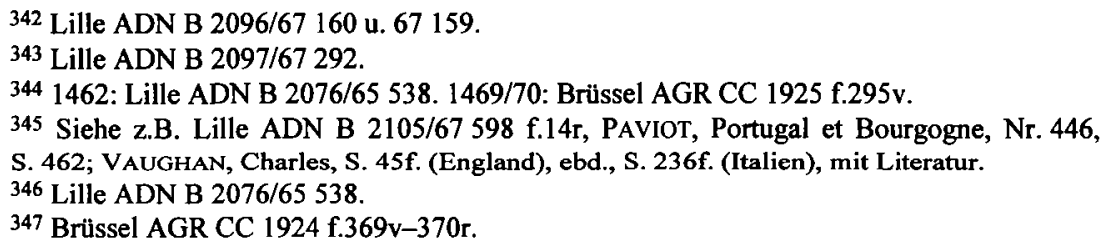


gekündigten Vorschuß nicht überbracht hatten. Da sie auch kein ihn befriedigendes Mandat Karls über eine ausreichende Bezahlung nach der Rückkehr von der Reise vorweisen konnten, weigerte sich der Abt aufzubrechen und entschuldigte sich deswegen beim Herzog ${ }^{348}$.

Insgesamt erwies sich das System zur Finanzierung der herzoglichen Gesandtschaften als verhältnismäßig effizient. Die aufgeführten Beispiele für Verzögerungen und ungenügende Ausstattung bereits im Vorfeld bilden wohl Ausnahmen eines im allgemeinen gut eingespielten Vorgangs. Reichtümer allerdings ließen sich mit der Tätigkeit als Gesandter nicht gewinnen, ebensowenig wie mit den ansonsten im Dienst des Herzogs gezahlten Gagen. Auch hier handelte es sich nur um die Voraussetzung dafür, sich aus günstiger Position heraus lukrative Einnahmequellen in der Verwaltung von Land und Kirche zu verschaffen ${ }^{349}$.

348 Der Abt von Cîteaux an Karl, 25.7.1474 oder 1475, Dijon ACO B 11934, Briefwechsel Nr. 2643, nach Grüneisen, RTA-Material. Ein Jahr später, im April 1475, reiste der Abt dann doch noch nach Rom, diesmal offenbar besser ausgestattet, Auszug aus der 2. Rechnung Gérard Vurrys 1474/75, Paris BNF Coll. de Bourgogne 65, f.174v.

349 Vgl. ParaviCINI, Einleitung, in: Alltag bei Hofe, S. 12. 
